\title{
Overwintering abundance and distribution of striped bass (Morone saxtilis) in the Hudson River estuary using hydroacoustic techniques
}

\author{
Brian William Nagy \\ West Virginia University
}

Follow this and additional works at: https://researchrepository.wvu.edu/etd

\section{Recommended Citation \\ Nagy, Brian William, "Overwintering abundance and distribution of striped bass (Morone saxtilis) in the Hudson River estuary using hydroacoustic techniques" (2002). Graduate Theses, Dissertations, and Problem Reports. 1567.}

https://researchrepository.wvu.edu/etd/1567

This Thesis is protected by copyright and/or related rights. It has been brought to you by the The Research Repository @WVU with permission from the rights-holder(s). You are free to use this Thesis in any way that is permitted by the copyright and related rights legislation that applies to your use. For other uses you must obtain permission from the rights-holder(s) directly, unless additional rights are indicated by a Creative Commons license in the record and/ or on the work itself. This Thesis has been accepted for inclusion in WVU Graduate Theses, Dissertations, and Problem Reports collection by an authorized administrator of The Research Repository @ WVU. For more information, please contact researchrepository@mail.wvu.edu. 
Overwintering Abundance and Distribution of Striped Bass (Morone saxtilis) in the Hudson River Estuary Using Hydroacoustic Techniques

By

\title{
Brian W. Nagy
}

\author{
A Thesis \\ Submitted to \\ The College of Agriculture, Forestry and Consumer Sciences \\ at \\ West Virginia University \\ in partial fulfillment of the requirements \\ for the degree of \\ Masters of Science \\ In \\ Wildlife and Fisheries Resources
}

Kyle J. Hartman, Ph.D., Chair

Doran M. Mason, Ph.D.

Patricia M. Mazik, Ph.D.

Wildlife and Fisheries Program of the Division of Forestry

Morgantown, West Virginia

2002

Keywords: striped bass, hydroacoustics, target strength, bioenergetics

Copyright 2002 Brian W. Nagy 


\begin{abstract}
Overwintering Abundance and Distribution of Striped Bass (Morone saxtilis) in the Hudson River Estuary Using Hydroacoustic Techniques
\end{abstract}

By

\title{
Brian W. Nagy
}

Using a modification of standard techniques, a target strength to length relationship was developed for white perch (Morone americana) and striped bass (Morone saxtilis). This target strength to length relationship was compared to two standard relationships (Love and Foote). The calculated relationship was not found to be significantly different from Love's equation, but was different from Foote's equation. This calculated relationship was applied to hydroacoustic data collected on the Hudson River in December of 1995 and 1997. The goal of the hydroacoustic data collection was to assess the abundance and distribution of overwintering Hudson River striped bass. Results from this study showed that striped bass primarily occupied the lower 38 river miles of the Hudson River. Also, the resulting 1995 abundance estimate was compared to a tagging study and found to show good agreement, with the hydroacoustic estimate being within $2 \%$ of the tagging estimate. Data on the 1995 and 1997 abundance of striped bass was then entered into a bioenergetics model for the purposes of examining the effect of striped bass populations on the various Alosa populations in the Hudson River. Of primary interest was the affect of increasing striped bass numbers on already dwindling American shad (Alsoa sapidissima) populations. Results from this modeling exercise showed that striped bass have the potential to consume virtually all American shad leaving the Hudson River. 


\section{Acknowledgements}

I would like to thank the members of my graduate committee, Dr. Kyle Hartman, Dr.

Doran Mason and Dr. Patricia Mazik for their guidance throughout the completion of this research. I extend special thanks to Clif Tipton for moral and computational support, as well as field assistance. I wish to thank Dr. Mike Jech and Dr. Jiangang Luo for their work on DEVIS and all the technical support during the analysis phase of my research. I would especially like to thank Roger and Joyce Nagy, as well as my other family, friends and loved ones, for all their emotional support and encouragement during my research. This research was funded by the Hudson River Foundation and support was provided by the Division of Forestry in the College of Agriculture, Forestry and Consumer Sciences at West Virginia University. 
Table of Contents:

$\begin{array}{lr}\text { Introduction } & 1\end{array}$

Chapter 1: A Target Strength and Length Relationship for Striped Bass and 3 White Perch: Implications for Hydroacoustic Abundance Estimates

$\begin{array}{lr}\text { Abstract } & 3 \\ \text { Introduction } & 4 \\ \text { Methods } & 7 \\ \text { Results } & 10 \\ \text { Discussion } & 12 \\ \text { Literature Cited } & 17\end{array}$

Tables:

Table 1. Mean density of fish (as estimated by the combined, Love's and Foote's equation and divided into four size classes) from an across river transect of data from near the Tappan Zee bridge on the Hudson River from December, 1995.

\title{
Figures:
}

Figure 1. A visual representation of the collection and subsequent analysis of acoustic data for determination of target strength of a given fish.

Figure 2. Maximum dorsal aspect target strength in decibels plotted against the log base 10 of total length $(\mathrm{cm})$ for striped bass, white perch, and striped bass and white perch combined.

Figure 3. Predicted maximum dorsal aspect target strength plotted against actual length for all fish measured as estimated by Love's equation, Foote's equation, and the combined striped bass/white perch equation.

Chapter 2: Overwintering Abundance and Distribution of Striped Bass in the Hudson River Estuary Using Hydroacoustic Techniques

\author{
Abstract \\ Introduction
}


Methods

$\begin{array}{ll}\text { Results } & 34\end{array}$

$\begin{array}{ll}\text { Discussion } & 42\end{array}$

$\begin{array}{ll}\text { Literature Cited } & 49\end{array}$

Tables:

Table 1. Volume of water per region as used in the conversion of fish density to fish abundance. Volumes represent strata $>5 \mathrm{~m}$ in depth by utility-defined river regions (from J. Young, Consolidated Edison Power Company)

Table 2. Number of fish from five species caught in a total of nine gillnet sets in the Hudson River, separated into those caught below and above the $0.5 \mathrm{~m}$ mark of the bottom.

Table 3. Results from an ANOVA comparing fish density at 4 different size classes to temperature $(T)$, salinity $(S)$ and the interaction of salinity and temperature (S:T) across 4 different regions in 1995(A) and 3 regions in 1997(B). All values are $p$-values from the ANOVA, a NS equals a non-significant result at the 0.05 level

Table 4. Total fish density and abundance by size class and river region during December 1995 hydroacoustic surveys with 95\% confidence intervals. Size classes correspond to fish too small to be striped bass $(12-90 \mathrm{~mm})$, age- 0 striped bass $(90-160 \mathrm{~mm})$, age- 1 striped bass $(160-300 \mathrm{~mm})$, and age-2+ striped bass $(300-1000 \mathrm{~mm})$.

Table 5. Striped bass density and abundance by size class and river region during December 1995 hydroacoustic surveys with 95\% confidence intervals. Size classes correspond to fish too small to be striped bass $(12-90 \mathrm{~mm})$, age- 0 striped bass $(90-160 \mathrm{~mm})$, age- 1 striped bass $(160-300 \mathrm{~mm})$, and age-2+ striped bass $(300-1000 \mathrm{~mm})$.

Table 6. Total fish density and abundance by size class and river region during December 1997 hydroacoustic surveys with 95\% confidence intervals. Size classes correspond to fish too small to be striped bass $(12-90 \mathrm{~mm})$, age- 0 striped bass $(90-160 \mathrm{~mm})$, age- 1 striped bass $(160-300 \mathrm{~mm})$, and age-2+ striped bass $(300-1000 \mathrm{~mm})$. 
Table 7. Striped bass density and abundance by size class and river region during December 1997 hydroacoustic surveys with 95\% confidence intervals. Size classes correspond to fish too small to be striped bass $(12-90 \mathrm{~mm})$, age- 0 striped bass $(90-160 \mathrm{~mm})$, age- 1 striped bass $(160-300 \mathrm{~mm})$, and age-2+ striped bass $(300-1000 \mathrm{~mm})$.

Figures:

Figure 1. Map of the Hudson River showing the eight different regions of the study area with their respective names.

Figure 2. Percent composition of fish species collected in trawls during 1995 by size range and by river region.

Figure 3. Percent composition of fish species collected in trawls during 1997 by size range and by river region.

Figure 4. Latitudinal density distribution of all acoustically accessible fish in December of 1995 including four size classes: $12-90 \mathrm{~mm}, 90-$ $160 \mathrm{~mm}, 160-300 \mathrm{~mm}$ and $300-1000 \mathrm{~mm}$, from the Battery to Croton-Haverstraw, where the vertical dashed lines represent the transition between regions.

Figure 5. Latitudinal density distribution of striped bass in December of 1995 including three size classes: $90-160 \mathrm{~mm}, 160-300 \mathrm{~mm}$ and $300-1000 \mathrm{~mm}$, from the Battery to Croton-Haverstraw, where the vertical dashed lines represent the transition between regions.

Figure 6. Latitudinal density distribution of all acoustically accessible fish in December of 1997 including four size classes: $12-90 \mathrm{~mm}, 90-$ $160 \mathrm{~mm}, 160-300 \mathrm{~mm}$ and $300-1000 \mathrm{~mm}$, from the Battery to Croton-Haverstraw, where the vertical dashed lines represent the transition between regions.

Figure 7. Latitudinal density distribution of striped bass in December of 1997 including four size classes: $12-90 \mathrm{~mm}, 90-160 \mathrm{~mm}, 160-$ $300 \mathrm{~mm}$ and $300-1000 \mathrm{~mm}$, from the Battery to Croton-Haverstraw, where the vertical dashed lines represent the transition between regions.

Chapter 3: Potential top-down effects of striped bass on outmigrating alosid populations in the Hudson River estuary using a bioenergetics model. 
$\begin{array}{ll}\text { Abstract } & 73\end{array}$

$\begin{array}{ll}\text { Introduction } & 74\end{array}$

$\begin{array}{ll}\text { Methods } & 75\end{array}$

$\begin{array}{ll}\text { Results } & 78\end{array}$

$\begin{array}{lr}\text { Discussion } & 80\end{array}$

$\begin{array}{ll}\text { Literature Cited } & 84\end{array}$

Figures:

Figure 1. Individual weights in grams of age-1 (dashed line) and age-2 (solid line) striped bass per simulation day for 1995 and 1997.

Figure 2. Temperature data per simulation day as interpolated by the biogenetics model.

Figure 3 . Weight $(\mathrm{kg})$ of alosids consumed by age- 1 and age- 2 striped bass for $10 \%$ and $50 \%$ consumption assumptions in 1995 and 1997 in comparison with estimates of natural production of age-0 American shad in 1991 (source: EA Engineering, Science, and Technology 1991).

\section{Appendix:}

Figures:

Figure 1. Vertical temperature (blue line, ${ }^{\circ} \mathrm{C}$ ) and salinity (red line, ppt) profiles compared to vertical striped bass distributions $\left(\mathrm{fish} / \mathrm{m}^{2}\right)$ for the Battery region in 1995.

Figure 2. Vertical temperature (blue line, ${ }^{\circ} \mathrm{C}$ ) and salinity (red line, ppt) profiles compared to vertical striped bass distributions $\left(\mathrm{fish} / \mathrm{m}^{2}\right)$ for the Yonkers region in 1995.

Figure 3. Vertical temperature (blue line, ${ }^{\circ} \mathrm{C}$ ) and salinity (red line, ppt) profiles compared to vertical striped bass distributions $\left(\mathrm{fish} / \mathrm{m}^{2}\right)$ for the Tappan Zee region in 1995.

Figure 4. Vertical temperature (blue line, ${ }^{\circ} \mathrm{C}$ ) and salinity (red line, ppt) profiles compared to vertical striped bass distributions $\left(\mathrm{fish} / \mathrm{m}^{2}\right)$ for the Croton Haverstraw region in 1995. 
Figure 5. Vertical temperature (blue line, ${ }^{\circ} \mathrm{C}$ ) and salinity (red line, ppt) profiles compared to vertical striped bass distributions $\left(\mathrm{fish} / \mathrm{m}^{2}\right)$ for the Battery region in 1997.

Figure 6. Vertical temperature (blue line, ${ }^{\circ} \mathrm{C}$ ) and salinity (red line, ppt) profiles compared to vertical striped bass distributions (fish $/ \mathrm{m}^{2}$ ) for the Yonkers region in 1997.

Figure 7. Vertical temperature (blue line, ${ }^{\circ} \mathrm{C}$ ) and salinity (red line, ppt) 106 profiles compared to vertical striped bass distributions $\left(\mathrm{fish} / \mathrm{m}^{2}\right)$ for the Tappan Zee region in 1997.

Curriculum Vita: 


\section{Introduction}

From December of 1995 through the December of 1997 work was done to assess the overwintering abundance of Hudson River striped bass (Morone saxtilis) using hydroacoustic techniques. The focus of this work was to determine the abundance and distribution of striped bass in the lower portion of the Hudson River. The goal of this study was to provide valuable data for the future management of a species on the rebound from environmental contamination as well as to provide more in depth understanding of the Hudson River estuary.

In the process of this study it was discovered that there were no appropriate published target strength to length relationships for striped bass. A target strength to length relationship is vital to the correct conversion of hydroacoustic data, for the partitioning of density estimates into size classes and to calculate relative and absolute density within these size classes. Therefore, it was necessary to expand the work to include the creation of a target strength to length relationship for both striped bass and a closely related, sympatric species found in the Hudson River, white perch (Morone americana). Data collection for these target strength to length relationships was done in November of 1997 at the Chesapeake Biological Lab, Solomons Island, MD using methods specifically designed for this project.

In an attempt to provide further understanding of the importance of overwintering striped bass in the Hudson River estuary, a bioenergetics model was used to determine the potential effect of striped bass on Hudson River herring (genus: Alsoa). Of particular interest was the effect of striped bass on American shad (Alsoa sapidissima), another commercially important species in the Hudson. Due to time constraints and the 
difficulty in conducting a large scale survey of striped bass diets and alosid outmigration patterns, a bioenergetics model was used to model predicted the potential effects of striped bass on outmigrating alosids by bounding striped bass consumption at two levels determined appropriate, $10 \%$ and $50 \%$ of total consumption.

Results from all aspects of this study have added to the understanding of striped bass, the Hudson River estuary and their interactions. We have provided a new target strength to length relationship specifically for use with the Morone genus, which is an important genus for both freshwater and marine systems. Our hydroacoustic surveys on the Hudson River have established a rapid previously unused technique for population assessment. By combining the results from our hydroacoustic surveys and bioenergetics modeling we were able to show that striped bass have the potential to consume vast quantities of alosids. Considering that striped bass are not the only species in the Hudson which consume alosids, and that striped bass populations are on the increase, there could be significant decreases in Hudson River alosid populations in the future without changes in the current management plans.

This thesis has been divided into three separate chapters. The first chapter deals with the development of the target strength to length relationship. The second chapter deals with the overwintering abundance and distribution of Hudson River striped bass. The third chapter deals with the development of the bioenergetics model and applications to assess the potential impact of striped bass predation upon outmigrating alosids. 


\title{
Chapter 1:
}

\section{A Target Strength and Length Relationship for Striped Bass and White Perch: Implications for Hydroacoustic Abundance Estimates}

\author{
Abstract \\ The non-marine application of hydroacoustic technology is a relatively new \\ concept for some fisheries managers. The lack of target strength to length relationships \\ for freshwater and estuarine fishes is a major factor for reduced use of hydroacoustic \\ techniques in freshwater and estuarine systems. The difficulty in obtaining quality target \\ strength to length relationships without specialized gear or on non-schooling or shoaling \\ species only adds to the problem. The purpose of this study was to provide a target \\ strength to length relationship for striped bass (Morone saxtilis) and white perch \\ (Morone americana). We also show the potential negative effect of borrowing a target \\ strength to length relationship in hydroacoustic applications. The calculated target \\ strength to length relationship TS $=18.441 \log 10 \mathrm{~L}-61.52(\mathrm{r} 2=0.8353, \mathrm{p}<0.001)$, at \\ $120 \mathrm{kHz}$, shows good agreement with Love's equation, while showing significant \\ differences when compared to Foote's equation. This indicates that in this case Love's \\ equation is appropriate, however without foreknowledge, the borrowing of a target \\ strength to length relationship may have consequences when estimating length and \\ allocating abundance from acoustic data, as was the case when using Foote's equation.
}




\section{Introduction}

The use of hydroacoustics in non-marine fisheries is a relatively new concept for many fisheries managers. There are several reasons for this lack of acoustic use in freshwater and estuarine systems. Large equipment size, equipment cost, and lack of acoustically-related knowledge about inland systems have made it difficult for managers to apply hydroacoustics to their waters. Hydroacoustics manufactures have made significant advances towards reducing both size and cost of acoustic gear, thereby eliminating part of the problem. This leaves it up to fisheries biologists and managers to collect the necessary data for feasible use of acoustics in inland systems.

One of the most important pieces of information needed for inland use of hydroacoustics is target strength information on freshwater and estuarine fish species. The target strength of a fish relates the amount of sound reflected from a fish to the original amount of sound transmitted. Target strength information is vital for identification, classification, sizing, and abundance estimation of fish populations using acoustics (Midttum 1984). The commonly accepted belief is that $90 \%$ or more of the sound reflected from a fish can be attributed to its swimbladder (Foote 1980).

Theoretically, the larger the fish (and its swimbladder), the more sound it reflects and the larger it's target strength although there are considerable differences among species and frequencies (Love 1971). Unfortunately, there is currently no widely accepted method for fully and accurately describing or modeling the acoustic scattering properties of fish. It is therefore necessary to conduct experiments in which target strengths for individual species are estimated (Midttum 1984). 
Due to the lack of target strength information for inland fish species, fisheries biologists typically borrow the target strength relationships from other sources to estimate length distributions and abundance. The most commonly used target strength to length equation is Love's (1971) equation (see Results for actual equation). Love's (1971) equation was derived using data collected from 14 different families (all marine) and using a range of frequencies from 15 to $1000 \mathrm{kHz}$. While Love's equation may be acceptable for larger marine species, the appropriateness of this equation has not been shown for inland systems. Therefore it may be necessary for individuals interested in using hydroacoustics to develop their own target strength to length relationships.

There are three standard methods typically used to directly measure target strength (Midttun 1984) and one modeling method for predicting target strength. The first standard method is to acoustically ensonify fish in their natural environment (in situ) while the other two methods involve measures on captive fish. The in situ method has been used extensively in marine systems and in some inland systems (Fleischer et al. 1997) where large schools of fish can be acoustically sounded and then quickly collected to compare actual lengths to target strength. The in situ method requires that fish be spatially separated enough to allow individual fish targets to be registered. It also requires that the fish of interest be a pelagic schooling species such that the school can be captured in its entirety. Both of these factors make the in situ method difficult to use on a majority of inland systems. The other two standard methods involve using captive fish, one of which involves the construction of a large cage that the fish is placed inside while continually measuring the fish's target strength. When using this method fish are typically left in a cage and ensonified for for long periods of time, making this a 
very time consuming and expensive way of collecting target strength data (Edwards and Armstrong 1984). The second standard method for measuring target strength on captive fish is to immobilize the fish, which is then suspended in the acoustic beam and it's target strength measured repeatedly. Nakken and Olsen (1977) measured target strength on a variety of marine species using this method. A rig was constructed where transducers were dropped to the bottom of a 12-14 m deep inlet and the immobilized fish was suspended upside down above the transducers. These fish were then ensonified at a variety of tilt angles in an attempt to quantify how pitch and yaw affect target strength. A fourth, not widely accepted, method of calculating a target strength to length relationship is this use of a Kirchhoff-ray mode model (Clay and Horne 1994). This model uses two sets of cylinders to represent the fish. One set of fluid filled cylinders are used to represent the body, while a set of gas filled cylinders are used to represent the swimbladder. By $\mathrm{x}$-raying fish and digitizing the shape of the swimbladder, the Kirchhoff-ray mode model can predict a target strength to length relationship for the individual fish being examined from any aspect.

White perch and striped bass are abundant and economically important species in coastal and inland systems (Setzler-Hamilton and Hall 1991a; Setzler-Hamilton and Hall 1991b). Due to these factors, they represent a potentially important genus for the application of hydroacoustics in non-marine systems. The objectives of this study were to discover the target strength to length relationship for white perch and striped bass using a modification of the method developed by Nakken and Olsen (1977). We then compared the measured relationship with that of Love (1971) and Foote (1980) to 
evaluate the potential error in estimated fish abundance by "borrowing" target strength relationships, as is commonly done.

\section{Methods}

A Simrad(r) EY500 echo integration unit equipped with a $120 \mathrm{kHz}$ split-beam transducer with a 60 beam angle was used for all target strength measurements. The acoustic unit was calibrated with a standard copper sphere of known target strength using standard methods (Foote 1990; Brandt 1996). Raw data were collected with a $80 \mathrm{~dB}$ threshold at a rate of three pulses (pings) per second with a 0.3 millisecond pulse width to a notebook computer, and subsequently stored on a magneto optical disk for future processing.

\section{Data Collection}

All target strength data were collected from the research pier at the Chesapeake Biological Laboratory, Solomons Island, MD USA. The acoustic transducer was mounted on a finger pier (located off the main research pier) with the transducer facing horizontally towards the shore. The water depth at the pier during high tide was approximately $1.7 \mathrm{~m}$ and the transducer was fixed at $0.5 \mathrm{~m}$ from the bottom. Vertical transducer placement is critical to ensure that the bottom and surface do not interfere with the signal before it reaches the fish. Fish were positioned in the acoustic beam between $5-10 \mathrm{~m}$ from the transducer. Distance from the transducer was determined by fish size, with larger fish placed further from the transducer to ensure the entire fish was in the acoustic beam. Data were collected on fish held in the acoustic beam from two to ten minutes, which equals 360 to 1800 individual target strength measures per fish. The duration of data collection for an individual fish in the beam was determined by the 
time required to center the fish in the beam. We sought to collect dorsal aspect data on fish centered in the beam for a minimum of two minutes (360 pings). Centering of the fish in the beam was ensured through the use of the transducer map included with the EY500 data collection software. If any variation from center was noted during the collection minor corrections in fish position could be made.

Fish were held in the acoustic beam by tethering within a frame. The frame used to hold the fish was constructed of $19 \mathrm{~mm}$ diameter PVC and was $1.5 \mathrm{~m}$ square. Small holes were drilled in the corners of the PVC elbows allowing monofilament line to be attached and permitting the frame to fill with water. Four and a half kilogram monofilament line was used in conjunction with small dual fishhooks to tether fish. Fish were hooked into the frame at four locations on the body: two in either side of the mouth and two in the dorsal side of the caudal peduncle. When placing the fish in the frame care was taken to ensure the dorsal mid-section of the fish would line-up with the center of the transducer. This was done visually.

Acoustic data were also collected on the line and hooks used in the study to determine if there was any significant echo return that could unduly influence the target strength measurement from the fish. No significant echo return $(<-80 \mathrm{~dB})$ was recorded for just the line and hooks allowing the use of the measured target strengths from the fish without correction.

Fish were collected from the Patuxent River, MD two days prior to the experiment. Fish were collected using both a bottom trawl and hook and line sampling. Fish were held in flow-through tanks with ambient Patuxent River water. Prior to being hooked into the frame each fish was anesthetized in tricaine methanesulfonate (MS222) 
until the fish ceased ventilating (approximately five minutes). After acoustically measuring each fish, length and weight was taken for later comparison with target strength measurements. When finished with the experiment all fish were released.

\section{Acoustic Processing}

The resulting acoustical data set was processed using Digital Echo Visualization and Information System (DEVIS) (Jech and Luo, 2000). The raw acoustic data from the Simrad EY500 was converted by DEVIS from a three-dimensional acoustic data set to a two dimensional array. The cells of the array were equivalent to $1 \mathrm{~m}$ vertically and one ping horizontally resulting in arrays that were 10 cells deep (vertically) and between 360 and 1800 cells wide (horizontally). Only the valid target strength values, as determined by DEVIS, from the appropriate depth range were extracted for analysis (see Figure 1). All target strength values were converted to acoustic cross-section (), which was then averaged and converted back to target strength (). In order to ensure only maximum dorsal aspect values were used, and to ensure consistency among individual fish, only the 100 highest acoustic cross-section values for each fish were used in the regression analysis to relate target strength to length for white perch and striped bass.

\section{Data Analysis}

A regression analysis relating target strength to fish length was completed involving only white perch, only striped bass, and white perch and striped bass (combined). A total of 13 white perch and 23 striped bass were used in the regression analysis. More striped bass than white perch were measured due to the greater range in size of striped bass relative to white perch. Linear regression was used as a least 
squares method gave the best fit. Results of the combined model were compared to Love's (1971) equation and Foote's (1980) equation by comparing the values of their intercepts and slopes to ninety five percent confidence intervals placed around the intercept and slope of the combined model. This was done to determine if any statistical difference might exist between the two models, as the raw data used by Love and Foote were not available to make a more direct statistical comparison.

We also applied Foote's (1980) equation, Love's (1971) equation and the combined model to an acoustic transect of data from near the Tappan Zee bridge on the Hudson River to evaluate the potential impact of target strength "borrowing" upon acoustic results. The data for the acoustic transect were collected with the same instrument as used for the target strength analysis. Data were collected at a rate of three pings per second with a pulse duration of 0.3 milliseconds, and an average ship speed of $3 \mathrm{~m}$ per second. The transect was horizontally binned at 20 pings, equaling approximately $20 \mathrm{~m}$, and vertically binned at $1 \mathrm{~m}$ depth intervals. The data was then processed in DEVIS to break the acoustic signal down into separate size bins using Foote's, Love's and the combined equation. The size bins used were $12-90 \mathrm{~mm}, 90-$ $160 \mathrm{~mm}, 160-300 \mathrm{~mm}$ and $300-1000 \mathrm{~mm}$ to correspond to those size ranges used in chapter 2. The resulting densities were compared to determine the effect of using Foote's equation in comparison to Love's or the combined equation.

\section{Results}

A linear regression of target strength versus log of total length was calculated for striped bass, white perch and striped bass and white perch combined (Figure 2). The resulting linear equation for the striped bass was $T S=17.5 \log 10 \mathrm{~L}-60.1(\mathrm{r} 2=0.778$, 
$p<0.001)$, where TS is target strength $(d B)$ and $L$ is length in centimeters. The linear equation for white perch was TS $=31.5 \log 10 \mathrm{~L}-77.3(\mathrm{r} 2=0.892, \mathrm{p}<0.001)$. All fish were combined to determine a final regression line as both species belong to the same genus and because this equation may be more practically applied in systems where the two species overlap in distribution. The linear equation for striped bass and white perch combined data was TS $=18.4 \log 10 \mathrm{~L}-61.5(\mathrm{r} 2=0.835, \mathrm{p}<0.001)$.

To determine the differences between the calculated regression line, Love's (1971) equation (TS = $19.1 \log 10 \mathrm{~L}-67.9)$, and Foote's (1980) equation (TS = 20.0 $\log 10 \mathrm{~L}$ - 71.9), each equation was used to determine the expected target strength for each fish used in the target strength analysis (Figure 3). Ninety five percent confidence intervals were also calculated on both the slope and intercept of the combined equation in an attempt to recognize any statistical differences between the combined equation and both Love's and Foote's equations. The lower and upper bounds on the slope for the combined model were 15.441 and 21.440. The slope of Love's equation (19.1) and Foote's equation (20.0) fell within these bounds indicating that there is no statistical difference. The lower and upper bounds on the intercept for the combined model were 65.744 and -57.301 . The intercept of Love's equation (-67.87) fell just outside these bound indicating a possible statistical difference in the intercepts, while the intercept of Foote's equation (-71.9) fell completely outside these bounds, indicating a statistical difference in the intercepts.

A comparison of the application of Foote's equation (1980), Love's equation (1971) and the calculated regression, on a transect of acoustic data from near the Tappan Zee bridge on the Hudson River, shows the effect of different target strength to 
length relationships on the same data set (Table 1). An analysis of variance of the density values produced by the calculated regression, Love's equation and Foote's equation across size classes showed there to be significant differences $(p(0.05)$ between each technique for all four size classes. Foote's equation consistently over estimated the number of fish in a size range when compared to Love's equation and the calculated regression. Love's equation estimated a larger number of individuals in all the size classes except the $90-160 \mathrm{~mm}$ size class compared to the calculated regression. In all cases, the difference between the calculated regression and Love's equation was small when compared to the difference between either the calculated regression or Love's equation and Foote's equation.

\section{Discussion}

Through the work done on this project we have been able to produce target strength to length relationships for two previously undocumented species, white perch and striped bass. We were also able to produce a combined target strength to length relationship for both species. The method used to obtain these relationships proved rapid and inexpensive, and may be an effective means of determining target strength to length relationship for species where other methods are unrealistic. Other methods of determining target strength to length relationships, such as comparing acoustic soundings and trawl data, can be difficult to implement in larger species that do not shoal or school or are not easily caught, or where tight species aggregations prevent detection of target strength for an individual species or size. The use of the Kirchhoffray mode model has short comings in that it requires the fish to be dead for x-raying, as well as being a new and relatively unstandardized method. Nevertheless, this method 
has been shown to compare favorably with field measurements of target strength (Clay and Horne 1994; Jech et al. 1995).

It is important to note that the methodology described herein is only valid for a single aspect measurement. In the specific case shown here we used dorsal aspect target strength measurements for our relationship. This relationship is only useful when applied to down-looking acoustic data, where the fish being examined is known to maintain a largely parallel dorsal orientation to the hydroacoustic transducer. The striped bass case shown here is a good example of fish that are likely to maintain parallel dorsal orientation to the transducer. Data on Hudson River striped bass were taken during the day when the fish were unlikely to be making any diel vertical migrations in the water column. However, application of a dorsal aspect relationship to a species that did not maintain a parallel dorsal orientation to the transducer would result in incorrect length estimates from the measured target strengths. This would likely result in an under estimation of length, as the dorsal aspect typically gives the highest target strength measurement for any fish. If a user had the desire to make use of the methodologies shown here for a side-looking acoustic application, this could be easily accomplished by hooking the fish into the frame in a side aspect. The same cautions apply to side-looking applications as in down-looking applications. The fish being measured need to maintain a parallel side aspect to the transducer and not face towards or away from the transducer face. This could be accomplished by applying the side-looking acoustics in situations were fish are swimming past the transducer, such as in a river system with fish outmigrating. 
There are numerous factors that should be considered before deciding to borrow a target strength to length equation or create one. Of primary importance is biological knowledge of the species being investigated. Fish size and behavior are critical to the formulation of target strength to length model. If the species of interest is small, it may prove difficult to use the methods of this study to determine the target strength to length relationship. However, for larger species this method is more plausible, or Love's (1971) equation may be used. Fleishcer et al. (1997) showed that for smaller fish in Lake Michigan, such as rainbow smelt (Osmerus mordax), bloater (Coregonus hoyi) and alewife (Alosa pseudoharengus), Love's equation underestimates size at low target strengths and overestimates it for larger target strengths. Fish behavior is also important as it can affect the ease with which different methods of determining target strength to length relationships can be employed. If the species of interest is a schooling species that is targetable with a trawl, then acoustic data can be linked to trawl size data to produce a target strength to length relationship. When examining non-schooling species or species which are not easily caught in trawls, length data are more difficult to obtain for relation to target strength. This leads the researcher to borrow an equation or construct one.

A review of several papers where acoustics were used to obtain abundance estimates showed that a majority of researchers dealing with small schooling species created their own target strength to length relationships (Barange et al. 1994; Degan and Wilson 1995; Fleischer et al. 1997; Rudstam et al. 1987). In two papers involving larger game species, Rose and Leggett (1988) created their own target strength to length relationship using methods similar to those presented here and Daum and 
Osborne (1997) used Love's (1971) equation. There was one exception to this trend. Brandt et al. (1991) used Love's equation to describe the target strength to length relationship for Lake Michigan small, schooling, pelagic species. This approach was later questioned by Fleischer et al. (1997) as an inappropriate use of Love's equation. As stated earlier, in this case Love's equation incorrectly estimates length for a given target strength when compared to the relationship developed by Fleischer et al. (1997) from comparing acoustic soundings to trawl data. Another factor that makes Love's equation inappropriate for Lake Michigan is Love's equation was derived by using marine species and there may be significant differences between the back scattering of marine and freshwater species (McClatchie et al. 1996).

The borrowing of inappropriate target strength to length relationships can be a significant source of error in acoustic abundance estimates. This can be shown by examining the effect of using Foote's (1980), Love's (1971) and the combined equation to break acoustic estimates of fish density into size classes for a transect in the Hudson River (Figure 4). In this field example, where most of the fish targets were either striped bass or white perch, Foote's equation underestimates length for any given target strength value (Figure 3), thereby causing densities at the small size ranges to be overly high. This also has the effect of spreading the distribution over a wider range of the lower size classes. Foote's equation estimates higher density values for all sizes compared to either Love's or the combined equation, in some cases an order of magnitude higher. It should also be noted that density distributions from Foote's equation covered more size classes that Love's equation or the combined equation. This is due to Foote's equation taking higher target strengths and placing those values 
in lower size classes. In essence, by borrowing inappropriate target strength to length relationships a researcher can significantly skew the acoustic estimates of length and abundance.

Errors associated with incorrect target strength to length relationships can affect managers in several different ways. First, the borrowing of a target strength equation may lead to incorrect estimates of fish sizes, biomass, and numbers, when allocating numbers to different size classes. This could have the effect of causing a manager to improperly allocate a fishery resource, resulting in either the crash of a stock or unsatisfied constituents. Secondly, from a legal standpoint, the borrowing of a target strength equation without proper evidence to back up its use can reduce the manager's legal footing should a conflict in interpretation of acoustic data arise. Finally, considering the ease with which a target strength to length equation can be generated for a given taxa, it makes little sense to borrow one that may or may not be appropriate. 


\section{Literature Cited}

Barange, M., I. Hampton, S.C. Pillar, and M.A. Soule. 1994. Determination of composition and vertical structure of fish communities using in situ measurements of acoustic target strength. Canadian Journal of Fisheries and Aquatic Sciences 51:99-109.

Brandt, S.B., D.M. Mason, V.E. Patrick, R.L. Argyle, L. Wells, P.A. Unger, D.J. Stewart. 1991. Acoustic measures of the abundance and size of pelagic planktivores in Lake Michigan. Canadian Journal of Fisheries and Aquatic Sciences 48:894-908.

Brandt, S.B. 1996. Acoustic assessment of fish abundance and distribution. Pages 385432 in B.R. Murphy and D.W. Willis, editors, Fisheries Techniques 2nd edition, American Fisheries Society, Bethesda, MD.

Clay, C.S. and J.K. Horne. 1994. Acoustic models of fish, the Atlantic cod (Gadus morhua). Journal of the Acoustical Society of America 96: 1661-1668.

Daum, D.W. and B.M. Osborne. 1997. Use of fixed-location, split-beam sonar to describe temporal and spatial patterns of adult fall chum salmon migration in the Chandalar River, Alaska. North American Journal of Fisheries Management 18: 477-486.

Degan, D.J. and W. Wilson. 1995. Comparison of four hydroacoustic frequencies for sampling pelagic fish populations in Lake Texoma. North American Journal of Fisheries Management 15:924-932.

Edwards, J.I. and Armstrong, F. 1984. Target strength experiments on caged fish. Scottish Fisheries Bulletin 48: 12-20.

Fleischer, G.W., R.L. Argyle, and G.L. Curtis. 1997. In situ relations of target strength to fish size for great lakes pelagic planktivores. Transactions of the American Fisheries Society 126:786-794.

Foote, K.G. 1980. Importance of the swimbladder in acoustic scattering by fish: a comparison of gadoid and mackerel target strengths. Journal of the Acoustical Society of America 67: 2084-2089.

Foote, K.G. 1990. Spheres for calibrating an eleven frequency acoustic measurement system. Journal du Counseil International pour l'Exploration de la Mer 46:284286.

Jech, J.M. and J. Luo. 2000. Digital echo visualization and information system (DEVIS) for fisheries acoustics data. Journal of Fisheries Research 47:115-124. 
Jech, J.M., D.M. Schael and C.S. Clay. 1995. Applications of three sound scattering models to threadfin shad (Dorosoma petenense). Journal of the Acoustical Society of America 98: 2262-2269.

Love, R.H. 1971. Dorsal-aspect target strength of an individual fish. Journal of the Acoustical Society of America 49(3): 816-823.

McClatchie, S., J. Alsop, and R.F. Coombs. 1996. A re-evaluation of relationships between fish size, acoustic frequency, and target strength. ICES Journal of Marine Science 53:780-791.

Midttun, L. 1984. Fish and other organisms as acoustic targets. . Rapp. P.-v. Reun. Cons. int. Explor. Mer. 184: 25-33.

Nakken, O. and Olsen, K. 1977. Target strength measurements of fish. Rapp. P.-v. Reun. Cons. int. Explor. Mer. 170: 52-69.

Rose, G.A. and W.C. Leggett. 1988. Hydroacoustic signal classification of fish schools by species. Canadian Journal of Fisheries and Aquatic Sciences 45:597-604.

Rudstam, L.G., C.S. Clay, and J.J. Magnuson. 1987. Density and size estimates of cisco, Coregonus artedii, using analysis of echo peak PDF from a single transducer sonar. Canadian Journal of Fisheries and Aquatic Sciences 44:811821.

Setzler-Hamilton, E. M. and L. Hall, Jr. 1991a. White perch Morone americana. Pages 12-1 to 12-25 In Habitat requirements for Chesapeake Bay living resources. S. L. Funderbruk, J. A. Mihursky, S. J. Jordan, and D. A. Riley, editors. Chesapeake Research Consortium, Solomons, Maryland.

Setzler-Hamilton, E. M. and L. Hall, Jr. 1991b. Striped bass Morone saxatilis. Pages 13-1 to 13-25 In Habitat requirements for Chesapeake Bay living resources. S. L. Funderbruk, J. A. Mihursky, S. J. Jordan, and D. A. Riley, editors. Chesapeake Research Consortium, Solomons, Maryland. 
Table 1. Mean density of fish (as estimated by the combined, Love's and Foote's equation and divided into four size classes) from an across river transect of data from near the Tappan Zee bridge on the Hudson River from December, 1995.

\begin{tabular}{cccc} 
& \multicolumn{3}{c}{ Density (fish/m2) as estimated by: } \\
Size Class & Combined & Love & Foote \\
\hline \hline $12-90 \mathrm{~mm}$ & 1.783 & 3.376 & 8.464 \\
$90-160 \mathrm{~mm}$ & 0.043 & 0.040 & 0.228 \\
$160-300 \mathrm{~mm}$ & 0.030 & 0.035 & 0.044 \\
$300-1000 \mathrm{~mm}$ & 0.004 & 0.008 & 0.052
\end{tabular}


Figure 1. A visual representation of the collection and subsequent analysis of acoustic data for determination of target strength of a given fish. 


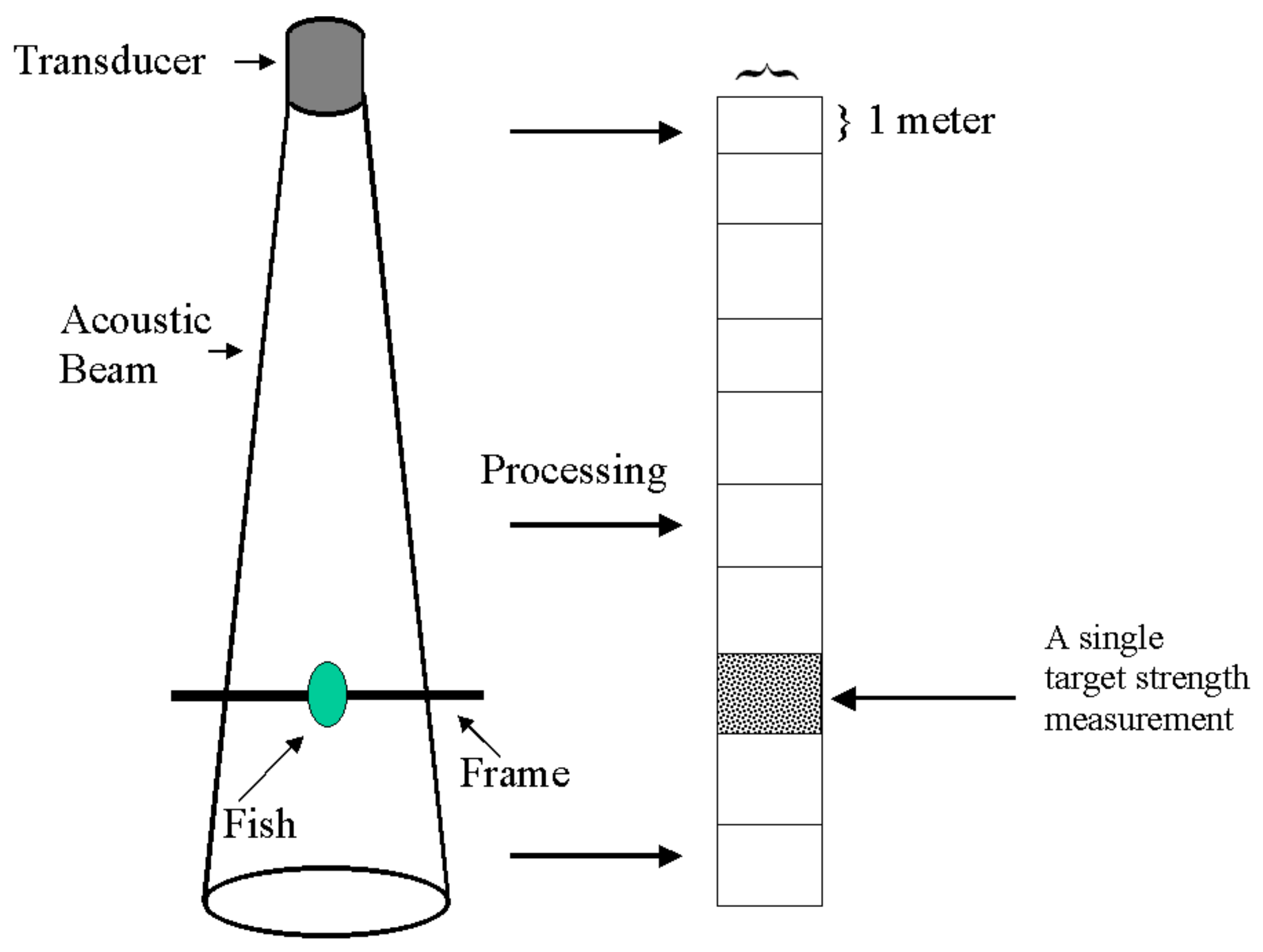


Figure 2. Maximum dorsal aspect target strength in decibels plotted against the log base 10 of total length $(\mathrm{cm})$ for striped bass, white perch, and striped bass and white perch combined. 


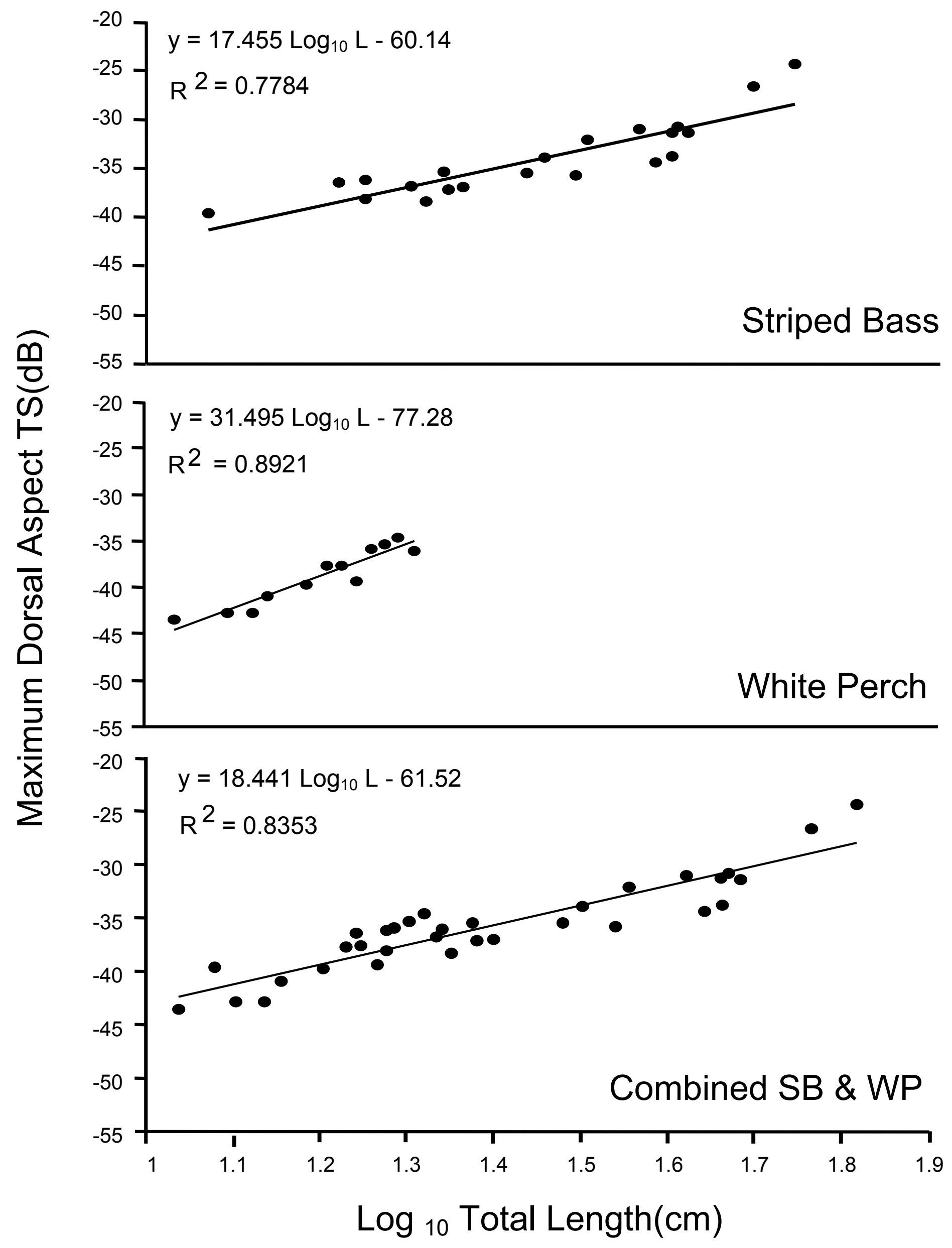


Figure 3. Predicted maximum dorsal aspect target strength plotted against actual length for all fish measured as estimated by Love's equation, Foote's equation, and the combined striped bass/white perch equation. 


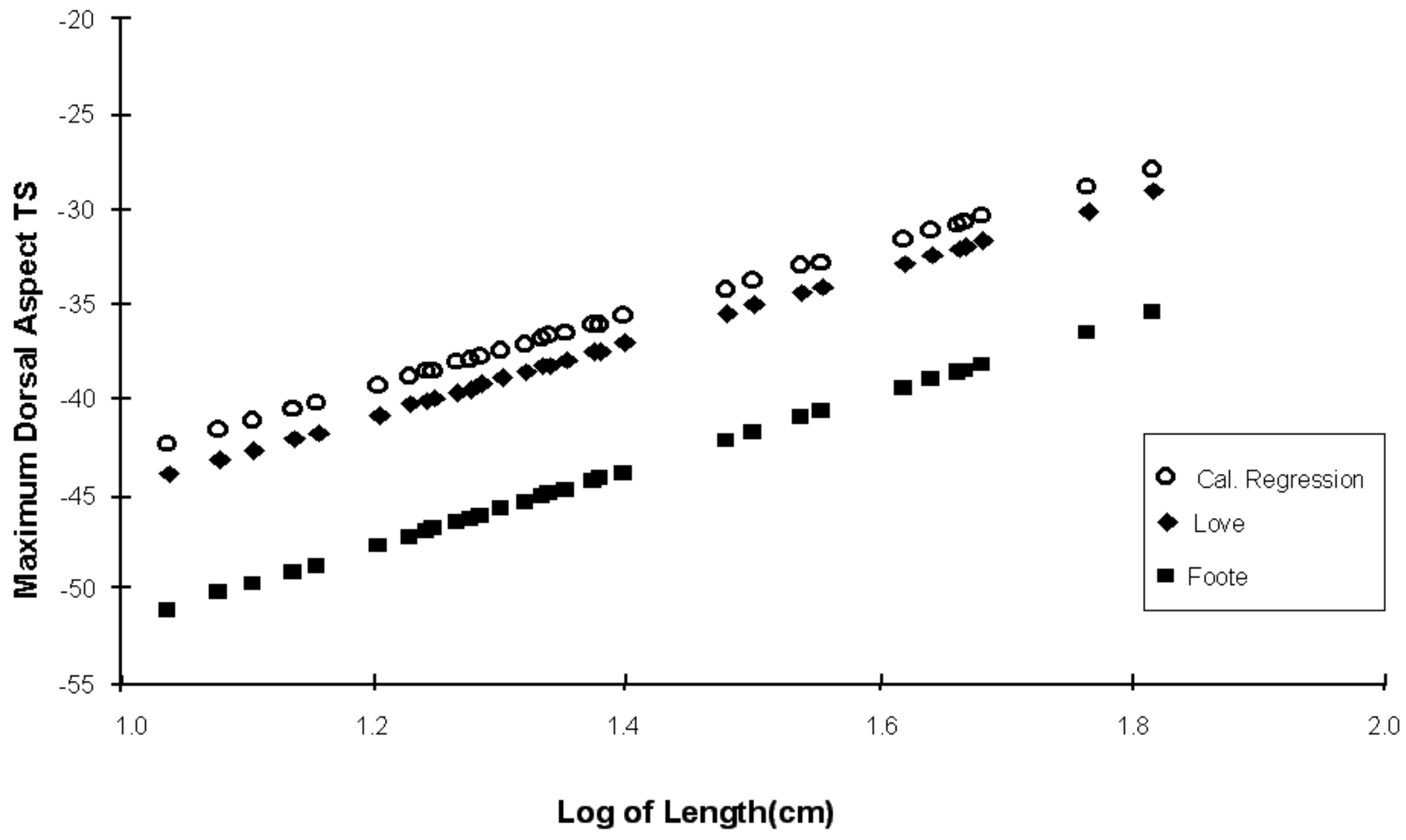




\title{
Chapter 2:
}

Overwintering Abundance and Spatial Ecology of Striped Bass in the Hudson River Estuary Using Hydroacoustic Techniques

\author{
Abstract \\ Striped bass (Morone saxtilis) are an economically and ecologically important \\ species known to overwinter in the Hudson River. Estimation of striped bass \\ abundance is a critical step in the development of any Hudson River management plans \\ and the wintertime provides the perfect opportunity to assess the size of the Hudson \\ River striped bass population. A hydroacoustic survey was developed and used in \\ December of 1995 and 1997 to determine the distribution and size of the overwintering \\ striped bass stocks in the Hudson River. The results from this survey were \\ subsequently compared with a concurrent wintertime tagging study to verify the \\ hydroacoustic results. Our analysis showed that in 1995 and 1997 striped bass showed \\ a trend toward decreasing densities further North in the river, with little to no striped \\ bass present North of the Croton-Haverstraw region. Our hydroacoustic results \\ compared favorably with the tagging study in 1995 with the two population estimates \\ being within $2 \%$ of one another. This study has shown that hydroacoustics can be a \\ valuable tool for population estimation in a large river system.
}




\section{Introduction}

Striped bass are a biologically and economically important species along the U.S. Atlantic coast (Setzler-Hamilton and Hall 1991). Coastal stocks of striped bass underwent a well-documented decline in abundance during the 1980's before a fishing moratorium allowed the recovery of striped bass on the East coast (Richards and Rago 1999). While the Hudson River does not contribute as many individual striped bass to the coastal stock as the Chesapeake Bay, it still provides a substantial number of recruits to the coastal population and is therefore a concern in overall Atlantic coast striped bass stock health (Berrgren and Lieberman 1978; VanWinkle et al. 1988).

The abundance of striped bass in the Hudson River is not only important for the health of striped bass stocks, but also to the health of other equally important Hudson River fishery stocks that striped bass may prey upon or compete with for resources. In Chesapeake Bay, striped bass feed upon Atlantic menhaden (Brevoortia tyrannus), Atlantic croaker (Micropogonias undulatus), spot (Leiostomus xanthurus), and blue crab (Callinectes sappidus), all of which support valuable fisheries (Hartman and Brandt 1995a). Striped bass may also compete with other piscivores such as bluefish (Pomatomus saltatrix) and weakfish (Cynoscion regalis) (Setzler-Hamilton and Hall 1991; Hartman and Brandt 1995b). Due to these potential competitive and predative interactions between striped bass and other species, it is important to obtain accurate measures of their abundance so the level of interactions can be quantified. Hydroacoustics represents a fisheries-independent sampling technique for assessing the abundance of striped bass. Hydroacoustics have been used for population estimates of fishes in large river systems (Lyons 1998), large lake systems (Argyle 
1992), estuarine systems (Luo and Brandt 1993), and marine systems (Methven and Piatt 1991). Hydroacoustics have been used to examine species ranging from pelagic planktivores (Mason et al. 1995) to salmonids (Thorne and Johnson 1993) and the technology has become a well-established and accepted means of estimating fish abundance and distribution (Brandt 1996).

Before applying hydroacoustics methodology on large scales as would be needed to assess coast-wide abundance of striped bass, it is important to evaluate the effectiveness of this technique on a smaller scale. The Hudson River represents a reasonably tractable estuary on the U.S. East coast that is home to resident striped bass. In addition, many fish overwinter in this river (Smith 1985). The Hudson River striped bass stock is also of interest because of the potential for these fish to impact other fishes. There is documentation that striped bass consume alosids (Manooch 1973; Gardinier and Hoff 1982) and they do so during the winter (Dunning et al. 1997). Considering this, it is vitally important to have a good understanding of the overwintering abundance of Hudson River striped bass in order to effectively manage them and their top-down effects (Carpenter et al. 1985). Therefore, the objectives of this study were as follows. First, to determine the overwintering spatial distribution of striped bass in the Hudson River using both trawls and hydroacoustics. Second, to estimate the overwintering abundance of Hudson River striped bass using hydroacoustics. The final objective was to validate the hydroacoustic estimates of abundance with a concurrent mark and recapture tagging study. 


\section{Methods}

All sampling took place during December in the Hudson River, south of the MidHudson Bridge. Winter was chosen for the study for two reasons. First, as evidenced by their diets, much of the predation by striped bass upon alosids in the Hudson River likely occurs between late summer and winter (Dunning et al. 1997). Therefore, in trying to place bounds on the predation impacts of striped bass upon alosids, a winter population assessment allows the most proximal temporal period to use in placing predation estimates into absolute terms. Winter was also the best time to assess striped bass abundance acoustically due to behavioral changes that make these fish more susceptible to down-looking acoustics. In winter, striped bass move into the main channel of estuaries and typically suspend in the water column. Such behavior was noted by commercial fishermen in the Chesapeake Bay and verified in pilot studies at the Chesapeake Biological Laboratory (K. Hartman, West Virginia University, unpublished data). In 1995 the sampled area of the river started at river mile (RM) 75 near Poughkeepsie, NY and ended at RM 0 off the southern tip of Manhattan, NY (the Battery). In 1997 the sampled area of the river started at RM 38 near Croton Bay, NY, as there were no striped bass found north of this location in 1995 or 1997. In both years the river was partitioned into sections (Figure 1) in order to maintain consistency with other fisheries studies in the Hudson River.

\section{Acoustic Sampling}

Acoustic sampling was conducted using a Simrad(r) EY500 echo-sounder equipped with a $120 \mathrm{kHz}$ split-beam transducer. A laptop computer was used to collect data in the field and data were subsequently stored to magneto optical disks for future 
analysis. The transducer was towed alongside the research vessel using a tow body submerged approximate $0.6 \mathrm{~m}$ under the water's surface. The transducer was set to pulse (ping) three times per second with a four-millisecond pulse width. The minimum threshold for acoustic data was -70 decibels $(\mathrm{dB})$. Bottom tracking threshold was set to $-20 \mathrm{~dB}$ and all data within $0.5 \mathrm{~m}$ of the tracked bottom was ignored. The beam width alongship was 7.0 degrees and the athwartship beam width was 7.1 degrees. Single target detection parameters were set to $-60 \mathrm{~dB}$ minimum echo level, 0.8 minimum echo length, 1.6 maximum echo length, and $3.0 \mathrm{~dB}$ maximum phase deviation. The acoustic system was calibrated using a copper sphere according to standard procedures (Foote 1990; Brandt 1996).

In 1995, acoustic data were collected during daylight hours over a five-day period from 02 December to 06 December. A roughly continuous zigzag transect was used starting at RM 75 and ending at RM 0 . This transect focused primarily on the river channel.

In 1997 acoustic data were collected during daylight hours over a two-day period from 04 December to 06 December. Fewer days were required to sample in 1997 due to a reduced study area resulting from a better understanding of striped bass latitudinal distribution. A continuous zigzag transect was run from RM 38 to RM 0 . This transect ran shore to shore with four across-river runs in the Croton-Haverstraw region and ten in all other regions. There were fewer across-river transects in the Croton-Haverstraw region due to the increased width of this region when compared to the others as well as the shorter length of this region. 


\section{Biological Sampling}

Mid-water trawls and limited gill netting were used for collection of fish to verify acoustic targets. Gill netting was used in 1995 to determine if, during the daytime, striped bass were acoustically inaccessible due to proximity to the bottom. Gill nets in mesh sizes from $50 \mathrm{~mm}$ to $152 \mathrm{~mm}$ stretched mesh in approximately $12.5 \mathrm{~mm}$ increments were set on the bottom during slack tide. The net was pulled at the end of slack tide (<30 minutes) and data on fish species and vertical location in the net were recorded. Fish located in the bottom $0.5 \mathrm{~m}$ of the gill net panel were assumed to be too close to differentiate from the bottom. Thus, if striped bass were not located in the bottom $0.5 \mathrm{~m}$ of the gill net it was assumed that they were acoustically accessible during daylight hours. A total of 9 gill net sets were placed between Peekskill (RM 43) and the Harlem River (RM 14) in 1995. No gill nets were set in the lower 13 miles of the river due to dangers from high commercial navigation traffic in this area.

Mid-water trawls were fished in each region to verify the species identity of pelagic targets within each acoustic size group. The mid-water trawl consisted of a 6.4 $\mathrm{m}$ headrope and footrope with an upper body of $5 \mathrm{~cm}$ stretch mesh, a lower body of 3.6 $\mathrm{cm}$ stretched mesh, a $3.2 \mathrm{~cm}$ stretched mesh cod end with a $0.6 \mathrm{~cm}$ stretch mesh cod end liner. This net was designed to spread $4.9 \mathrm{~m}$ at optimum tow. In 1995, 2 trawls were made in the Battery region, 7 trawls in the Yonkers region, 4 trawls in the Tappan Zee region, and 1 trawl in the Croton-Haverstraw region. Trawls were also conducted in three of the four regions North of Croton-Haverstraw, 1 trawl in the Indian Point region, 2 trawls in the Cornwall region, and 3 trawls in the Poughkeepsie region. In 1997, 4 trawls were made in the Battery region, 13 in the Yonkers region, 9 in the Tappan Zee 
region, and 1 in the Croton-Haverstraw region. The unequal sample sizes between regions and years were due to variation in the catch patterns in the river. In 1995 more trawls were needed in order to assess general striped bass distributions and using this information in 1997 allowed for more spatially-targeted trawl deployment. Heavy commercial boat traffic, specifically in the Battery region, and river morphometry also played a significant role in reducing the total number of trawls possible in a region.

Catch data from the trawls were used to partition the acoustic density estimates into striped bass versus other species. To facilitate this partitioning we broke the catch composition into size classes that corresponded to observed size classes of different cohorts of striped bass. Abundance estimates were made based upon geographic regions used in fish studies sponsored by the New York Power Authority (NYPA) utilities. Trawl and acoustic data were summarized by these "Utilities" geographic regions to maintain continuity with other Hudson River fisheries investigations.

\section{Acoustic Processing}

Digital Echo Visualization and Information System (DEVIS) was used for all acoustic processing (Jech and Luo 2000). Digital Echo Visualization and Information System converts the raw Simrad data files into absolute fish density using echo squared integration. The data are divided into arrays, which are defined by a horizontal distance across the river and the vertical distance down (depth). Each bin in the array represented approximately $20 \mathrm{~m}$ horizontal distance by $0.5 \mathrm{~m}$ vertical distance. Voltages from echo integration were converted to densities of fish based upon measures of voltage returns that satisfied the criteria for individual targets (Jech and Luo 2000). Due to physical near field limitations of the hydroacoustic transducer and 
the depth of the transducer in the water, the first $2 \mathrm{~m}$ of water are eliminated from the processing as well as the $0.5 \mathrm{~m}$ directly above the bottom. Therefore, reported densities and acoustic echogram do not include the first $2 \mathrm{~m}$ and the bottom $0.5 \mathrm{~m}$ of the water column.

Individual targets were classified by size from a previously determined white perch/striped bass target strength to length regression (see Chapter 1). Individual fish lengths were then used to estimate density of each size class, for each bin in the array. A total of four size classes were used: 12 to $(90 \mathrm{~mm}(12-90 \mathrm{~mm}),>90$ to $(160 \mathrm{~mm}(90-$ $160 \mathrm{~mm}),>160$ to $(300 \mathrm{~mm}(160-300 \mathrm{~mm})$, and >300 to $(1000 \mathrm{~mm}(300-1000 \mathrm{~mm})$. These size classes correspond to size ranges of fish generally smaller than striped bass (12-90 mm), age-0 striped bass $(90-160 \mathrm{~mm})$, age- 1 striped bass $(160-300 \mathrm{~mm})$, and age-2+ striped bass (300-1000 mm) based upon ranges of striped bass sizes (for each age) observed in research collections during the acoustic surveys in 1995. In 1997 in the Yonkers, Tappan Zee and Croton-Haverstraw regions some age-0 striped bass were captured in the 12-90 mm class and thus, age-0 densities in 1997 included some fish from this size group.

To obtain density values, all bins within a region were averaged to determine the mean density for each region by size class. The density values were then scaled by the percent composition of striped bass, in each size class and region as determined from the trawl data. For example, if striped bass represented $70 \%$ of all fish $160-300 \mathrm{~mm}$ long caught in trawls within a region then only $70 \%$ of the density value for that size was considered striped bass for that region. The total fish density and striped bass density were multiplied by the volume of center channel water (areas deep enough for acoustic 
sampling; approximately $=5 \mathrm{~m}$ ) in each region ( $\mathrm{J}$. Young, Consolidated Edison, personal communication) to estimate abundance of all fish or striped bass in a particular region (Table 1). Confidence intervals (95\%) were place on both the density and abundance values using the variance in acoustic density calculated from all cells within a particular region.

\section{Environmental Sampling}

In both 1995 and 1997 a Sea-Bird CTD was used to collect vertical temperature and salinity profiles in the river. In 1995 a total of 12 vertical profiles were taken from $\mathrm{RM} 0$ to RM 75, with at least one profile per defined river region. In 1997 a total of 18 vertical profiles were taken from RM 0 to RM 38, with 3 in Croton-Haverstraw (the smallest region) and 5 in each region South of Croton-Haverstraw. These data were then compared to vertical density profiles of striped bass using an analysis of variance (ANOVA, $a=0.05$ ) to examine any relationships between vertical striped bass distribution and temperature or salinity profiles.

\section{Results}

Striped bass distributions.

Based upon midwater trawl and gill net collections, over-wintering striped bass distributions in 1995 and 1997 appear restricted to the lower quarter of the Hudson River (Figure 2 and 3). In 1995 no striped bass were collected in trawls or gill nets north of RM 32. In 1997, the furthest north a striped bass was captured was RM 38. Due to the lack of striped bass caugth north of RM 32 in 1995 and north of RM 38 in 1997, all acoustic and trawl data from regions north of Croton-Haverstraw have been excluded from this paper. 
Based upon the midwater trawls, striped bass were a more common component of the catch in the Yonkers region in 1995. Most of the age-0 sized fish $(90-160 \mathrm{~mm})$ in 1995 were collected in the Yonkers region (RM 12 - 23), while age-0 sized striped bass represented only $1.5 \%$ of the catch in Tappan Zee and were not collected in either the Battery or Croton-Haverstraw (Figure 2). Among the age-1 (160-300 mm) size group, striped bass increased in trawl composition from north to south (Figure 2). No striped bass in this size group were caught in Croton-Haverstraw, but their contribution rose to $100 \%$ moving south towards the Battery region. Few fish numbers over $300 \mathrm{~mm}$ were collected in any of the trawls or gill nets from 1995. Most of these were striped bass, with the exception of one sturgeon caught at the lead line in one of the gill nets. Given the relative absence of other species in acoustically accessible depths of the Hudson River in the 300 - $1000 \mathrm{~mm}$ size class during this time of year (Smith 1985), and the need to classify species identification to this size fraction for the acoustics, we assumed that all fish of this size were striped bass.

In 1997, catch of striped bass in trawls suggested that fish distributions were more evenly dispersed across regions than in 1995 (Figure 3). Striped bass were caught in all regions and were the only species caught in the $90-160 \mathrm{~mm}$ size in the Battery. In 1997, some age-0 sized striped bass were less than $90 \mathrm{~mm}$. Thus the 12-90 $\mathrm{mm}$ size group includes some age- 0 striped bass. Age- 0 striped bass represented $<5 \%$ of the catch in all regions within the $12-90 \mathrm{~mm}$ size group. Among the age-1 size class, striped bass were collected in Yonkers through Croton-Haverstraw regions with no catch in the Battery for any species. Striped bass accounted for $25-42 \%$ of the 
age-1 sized catch in Yonkers and Tappan-Zee. As in 1995, we assumed all fish 300 $1000 \mathrm{~mm}$ were striped bass.

A total of 9 gill net sets captured numerous fish of different species, however only 1 striped bass was caught. This single striped bass was caught above $0.5 \mathrm{~m}$ from the bottom (near the float line) and in the Tappan Zee region. Lack of other striped bass in any gill net sets and the presence of large numbers of striped bass sized targets in the acoustic data, plus the presence of striped bass in the midwater trawls, allowed us to consider all striped bass to be sufficiently off bottom as to be accessible to our daytime hydroacoustics.

\section{$\underline{\text { Hydroacoustic Estimates }}$}

1995 sampling

In 1995 total fish density showed no apparent trend when compared to latitude (Figure 4). The 12-90 $\mathrm{mm}$ size class shows the only visually obvious trends in latitudinal gradient for all acoustically accessible fish. For this size class it is apparent that there are peaks in density and thereby the highest densities of fish in the Battery region and the Croton-Haverstraw region. Latitudinal density of 90-159, 160-299, and 300-1000 mm size groups show that fish are not homogenously distributed. Latitudinal density of the $300-1000 \mathrm{~mm}$ size group suggests a higher frequency of large fish in the lower $1 / 3$ to $1 / 2$ of the study reach (Figure 4 ).

When total fish density is combined with the size-specific species composition from trawls to arrive at just striped bass density, there does appear to be an inverse trend of decreasing striped bass density with increasing latitude (Figure 5). Striped bass showed higher densities in more southerly latitudes, with only the occasional spike 
in density further north. This general trend did not manifest itself in most southerly latitudes for the $90-160 \mathrm{~mm}$ size class. This is due to no striped bass being captured in the trawls south of the Yonkers region.

1997 sampling

In 1997 total fish density decreased with increasing latitude (Figure 6). All size classes showed at least some peaks in density in the more southerly latitudes and few if any peaks in the more northerly latitudes. This was especially evident in both the 90$160 \mathrm{~mm}$ and $300-1000 \mathrm{~mm}$ size classes where only one major peak was seen in the latitudes covered by the Battery region and no large peaks were seen north of that point. In the $12-90 \mathrm{~mm}$ and $160-300 \mathrm{~mm}$ size classes there was a more even distribution of peaks across at least the latitudes covered by the Battery and Yonkers regions, with the $160-300 \mathrm{~mm}$ size class showing the most even distribution of peak densities across those two regions.

The same trend is visible in the latitudinal distribution of striped bass, where density declined from south to north (Figure 7). The $12-90 \mathrm{~mm}$ and $160-300 \mathrm{~mm}$ size classes showed the most even distribution of striped bass density across the latitudes that comprise the Yonkers region. The $90-160 \mathrm{~mm}$ and $300-1000 \mathrm{~mm}$ size classes showed more uneven distributions in the southern-most latitudes were only one strong peak is located in the latitudes that made up the Battery region and a more even distribution north of that area.

$\underline{\text { Vertical distribution }}$

An analysis of variance of the vertical temperature and salinity profiles and their interaction versus vertical fish distributions by size class and region showed no 
consistently significant results in either 1995 or 1997 (Table 2). In both 1995 and 1997 temperature had the most significant interactions with vertical fish distributions. However, due to the inconsistencies of these results no sweeping statements can be made about the effect of temperature or salinity on vertical fish distributions. An ANOVA was also used to compare water density (a factor that incorporates both temperature and salinity) to vertical density of fish with no significant results found.

\section{Regional Fish Density and Abundance}

In 1995 density and abundance of all acoustically assessable fish varied by size class and region (Table 3). For the $12-90 \mathrm{~mm}$ size class there seems to be a downward trend of density and abundance from the Battery region to the Tappan Zee region, with a high density of 0.7087 fish/m3 or 134.9 million fish in the Battery region to a low density of $0.0574 \mathrm{fish} / \mathrm{m} 3$ or 11.5 million fish in the Tappan Zee region. However this trend fails to hold in the next most northern region, Croton-Haverstraw where both the density ( $0.7774 \mathrm{fish} / \mathrm{m} 3)$ and abundance (245.1 million) of fish is higher than in any other region. The 160-300 mm size class starts to show an opposite trend with the Battery having the lowest density of $0.0011 \mathrm{fish} / \mathrm{m} 3$ and densities increasing to a high of $0.0021 \mathrm{fish} / \mathrm{m} 3$ in the Tappan Zee region. Again this trend fails to hold true in the Croton-Haverstraw region, which has a density of $0.0018 \mathrm{fish} / \mathrm{m} 3$ (lower than that of the Tappan Zee region) and an abundance of 184,000 , which is lower than any other region for that size class. The only consistent trends are found in the $300-1000 \mathrm{~mm}$ size class where there is an almost constant decrease in density from the Battery region north to Croton-Haverstraw, which has the same density as the Tappan Zee region. In this size 
class, abundance does show a constant trend with a high of 88,000 fish in the Battery region decreasing constantly to a low of 15,000 fish in the Croton-Haverstraw region.

There was a trend towards decreasing density and abundance of striped bass from southerly to northerly regions in all size classes and regions where striped bass were captured in trawls in 1995 (Table 4). For all regions in the 12-90 mm size class, the Battery and Croton-Haverstraw regions in the $90-160 \mathrm{~mm}$ size class, and the CrotonHaverstraw region in the $160-300 \mathrm{~mm}$ size class, no striped bass were captured in trawls. Therefore, we assume there to be no striped bass of these sizes classes in these regions. The $300-1000 \mathrm{~mm}$ size class showed a general decrease in striped bass density from the Battery regions with a high of $0.0005 \mathrm{fish} / \mathrm{m} 3$ to the Tappan Zee and Croton-Haverstraw regions, which both had a density of $0.0002 \mathrm{fish} / \mathrm{m} 3$. For the $300-$ $1000 \mathrm{~mm}$ size class, abundance showed a more definite trend of decreasing absolute abundance from south to north, with a high of 88,000 fish in the Battery region to a low of 15,000 fish in the Croton-Haverstraw region.

There was a tendency towards decreasing density and abundance of all acoustically accessible fish in most size classes from southerly to northerly regions (Table 5) for the 1997 survey. The $90-160 \mathrm{~mm}$ size class was the exception to this generalization, where the highest density $(0.0085 \mathrm{fish} / \mathrm{m} 3)$ and abundance $(1.7$ million fish) was found in the Yonkers region. The decreasing density and abundance trend was most evident in the $300-100 \mathrm{~mm}$ size class, where the highest density $(0.00022$ fish/m3) and abundance (42,000 fish) were found in the Battery region and the lowest density ( $0.00003 \mathrm{fish} / \mathrm{m} 3)$ and abundance (3,000 fish) was found in the CrotonHaverstraw region. The $12-90 \mathrm{~mm}$ and $160-300 \mathrm{~mm}$ size classes showed similar 
density gradients from south to north with decreasing densities and abundances from the Battery to the Tappan Zee regions, but with an increase in density and abundance in the Croton-Haverstraw region when compared to the Tappan Zee region.

In 1997, striped bass density and abundance showed a fairly regular decline in density from southerly to northerly regions (Table 6). In the 90-160 mm, 160-300 mm and 300$1000 \mathrm{~mm}$ size classes this decline can be clearly seen, where the highest density and abundance of striped bass is in the Battery region (or next most northerly regions with striped bass in it) and the lowest density and abundance of striped bass is in the Croton-Haverstraw region. This decline was least evident in the $12-90 \mathrm{~mm}$ size class where a high density of $0.0007 \mathrm{fish} / \mathrm{m} 3$ and abundance of 133,000 striped bass was found in the Yonkers region and the next lowest density of $0.0006 \mathrm{fish} / \mathrm{m} 3$ and abundance of 52,000 was found in the Croton-Haverstraw region. The highest density of striped bass was found in the $90-160 \mathrm{~mm}$ size class and not in the $12-90 \mathrm{~mm}$ size class, which typically has the highest densities when looking at all acoustically accessible fish. This is due in large part to very few $12-90 \mathrm{~mm}$ striped bass being caught relative to the other fish captured in trawls.

In 1995 and 1997 the same pattern in total fish abundance was evident with the largest number of individuals found in the $12-90 \mathrm{~mm}$ size class and decreasing to the lowest number of individuals found in the $300-1000 \mathrm{~mm}$ size class. In 1995, population estimates of total fish abundance by size class ranged from 245.1 million individuals in the $12-90 \mathrm{~mm}$ size class to 184,000 individuals in the $300-1000 \mathrm{~mm}$ size class and a total population estimate of $\mathbf{2 4 8 . 5}$ million individuals for all size classes (Table 3 ). The 1997 data showed the same decreasing trend of abundance from the smallest to the 
largest size class as the 1995 estimates with a high of 53.5 million individuals in the 12$90 \mathrm{~mm}$ size class and a low of 60,400 individuals in the $300-1000 \mathrm{~mm}$ size class with a total population estimate of 56.6 million individuals for all acoustically accessible fish (Table 5).

In both 1995 and 1997 there was no pattern in striped bass abundance across size classes or years. In 1995, the abundance of striped bass ranged from a high of 392,000 individuals in the $160-300 \mathrm{~mm}$ size class to a low of 0 individuals in the $12-90$ $\mathrm{mm}$ size class with a total striped bass abundance of 755,000 individuals across all size classes. The 1997 abundance did not reflect similar patterns to that found in 1995. 1997 population estimates of striped bass ranged from a high of 1.2 million individuals in the $90-160 \mathrm{~mm}$ size class to a low of 5,000 individuals in the $160-300 \mathrm{~mm}$ size class with a total population estimate of 1.5 million individual striped bass across all size classes, almost twice that found in 1995.

\section{$\underline{\text { Acoustic comparison }}$}

A comparison between a wintertime tagging study (Dunning NY Power Authority, personal communication) and hydroacoustic estimates of striped bass abundance showed results that were very close. In 1995, striped bass abundance was estimated to be 755,000 individuals with hydroacoustics. This compares to an estimate of striped bass abundance of 737,870 individuals from the wintertime tagging study (Dunning NY Power Authority, personal communication). That places the hydroacoustic estimate within $2 \%$ of the wintertime tagging study. It should be noted that the tagging study estimated striped bass abundance from the Battery region south into the lower bay, while the hydroacoustic estimates were for the Battery region north to RM 38 . These 
two estimates can still be considered comparable. The acoustic estimates were from early winter when striped bass would have been moving into the lower portion of the river from the entire river or from coastal locations, while the tagging estimates were restricted to the Battery region, but encompassed the November - March period when striped bass would have been overwintering in the river. If this is the case, it shows that under the1995 conditions hydroacoustics provided a comparable estimate of striped bass abundance to the utilities sponsored tagging study in the Hudson River. At the time of this writing, estimates from the 1997 tagging study were not available so no comparisons can be made with the 1997 hydroacoustic estimates.

\section{Discussion}

Striped bass were found to primarily overwinter in the lower Hudson River. Based upon gill nets, midwater trawls (striped bass $<300 \mathrm{~mm}$ ) and hydroacoustics (striped bass $>300 \mathrm{~mm}$ ) it appears that virtually all striped bass are located in the southern 38 miles of the river. Evidence of overwintering striped bass in the Hudson River has been provided by several studies (Merriman 1941; Raney et al. 1954; Clark 1968). However, only Clark (1968) was able to show, through a tagging study, that striped bass do move into the upper bay area of New York harbor in the Hudson River. Clark's study was not able to show movement of striped bass into the river proper during winter due to the limitations of 1954 fishing regulations on striped bass. More recently, studies by the New York Power Authority have shown striped bass to make use of much of the lower Hudson River during the winter (Dunning et al. 1997). Those results correspond well with the results from our winter hydroacoustic and trawl data, 
which show striped bass making use of the Hudson River as far north as the CrotonHaverstraw region.

An understanding of the spatial distribution of striped bass in the Hudson River is key to future management efforts directed toward this species. Our results show that smaller striped bass are more likely to disperse further north in the river, while larger striped bass typically stay nearer the mouth of the river (Figures 4-7). However, overall results show that striped bass are found more towards the southerly latitudes of the river. There is also evidence that the vertical distribution of striped bass is controlled by environmental factors. We were unable to show any consistent statistically significant relationship between salinity, temperature, their interaction, or water density with vertical fish distributions across regions (Table 2). Even though there is no apparent relationship with the environmental variables, there does appear to be some factor that causes fish to layer vertically in the water column (Appendix I). In 1995, most fish appear to be occupying an area in the middle third of the water column. In 1997, there was a much less clear relationship between vertical distribution and depth. The fish in 1997 were much more evenly dispersed and when fish were clustered they appeared to be in layers closer to the surface. This change in vertical distribution between years may well be due to an environmental variable or combination of variables we were unable to measure at the time, such as turbidity or current.

The distributional ecology and the exact cause of the apparent vertical layering behavior is potentially an important one to resource managers on the river. The Hudson River is an industrialized river used as a source of cooling water (Klauda 1988). Low water temperatures in winter may make fish more susceptible to impingement at water 
intake structures due to reduced activity and muscle capacity at low temperatures (Stevens 1979). Therefore, knowledge of the distributions of fish in the Hudson River and factors that affect winter distributions may be important in designing and citing future industrial operations requiring cooling water.

The verification of hydroacoustic estimates of fish abundance is an important part of an acoustic study and has been done numerous times (Thorne 1983). Verification is usually done in a two-part study, where one aspect is to measure abundance with a "standard" method and then to measure abundance with hydroacoustic methods. This allows for the direct comparison of hydroacoustic results to other methods, including trawling, gill nets and rotenone (Thorne 1983; Rudstam et al. 1987,1988; Jacobson et al. 1990; Rudstam and Johnson 1992; Hartman et al. 2000). In the present study these methods of verification would have been difficult and costly. Trawling and gill netting in the Hudson is difficult, especially on the scale needed for verification, and the use of rotenone was impractical. Therefore, we made use of another concurrent study that also measured the abundance of striped bass. This was done by comparing the hydroacoustic estimates against striped bass abundance estimates from a wintertime tagging study (Dunning, NY Power Authority, personal communication) designed to measure the abundance of striped bass and Atlantic tomcod (Microgadus tomcod).

The results from the comparison between this wintertime tagging study and hydroacoustic estimates of abundance in 1995 show that a combination of hydroacoustics and trawling can provide a good estimate of overwintering striped bass abundance. Unfortunately a similar comparison cannot be made with the 1997 hydroacoustic estimates as no results from the 1997 wintertime tagging study are 
available. There is reason to believe that even if results from the wintertime tagging study were available they would not compare favorably to the hydroacoustic estimates. This maybe due to heavy storm conditions in the Hudson River just prior to the 1997 sampling. These storms caused an increase in water flow as well as increased turbidity during the 1997 sampling period. We believe this is responsible for the change in the vertical distribution of fish from 1995 to 1997 and may have caused the striped bass to move inshore, which is a more difficult habitat for the down-looking hydroacoustics to sample. If the fish moved deep and stayed close to the bottom they would have been located in the $0.5 \mathrm{~m}$ area on the bottom that cannot be detected with the hydroacoustic system used. In future work gill nets should be used during all sampling efforts to ensure the accessibility of fish to the hydroacoustics. If the fish moved into more shallow areas, two problems would have presented themselves. First if the fish were occupying the top $2 \mathrm{~m}$ of water, the hydroacoustic system would not have detected them due to a combination of the depth the transducer is deployed and the $1 \mathrm{~m}$ near field on the $120 \mathrm{kHz}$ system. A second problem would be if fish moved into shallow water such as near shore areas, which are more difficult to sample with the vessels, and acoustic equipment we had available. With the $120 \mathrm{kHz}$ system used there is the physical $2.5 \mathrm{~m}$ depth limitation, which includes both the $2 \mathrm{~m}$ lost at the surface and the $0.5 \mathrm{~m}$ lost at the bottom, but also there is a practical limitation of collection enough data outside the $2.5 \mathrm{~m}$ physical limit to make the collection cost effective. For the purposes of this study that practical limitation was approximately $5 \mathrm{~m}$. Given the addition of a side looking component to the acoustic data, both the physical and practical limitations imposed by shallow water can be overcome. 
The quality of the abundance and distribution estimates of overwintering striped bass in the Hudson River provided by hydroacoustic techniques gives managers more information when making management decisions involving striped bass and other species in the Hudson River. For example, these estimates of abundance and distribution can be used in conjunction with bioenergetics modeling to examine the predatory effect of striped bass in the Hudson River. Overwintering abundance estimates can be use to back-calculate the abundance of striped bass at other key times of the year, such as when an important recreational and commercial species like American shad (Alosa sapidissima) are out-migrating from the river. Then using this back-calculated abundance estimate of striped bass together with data on the daily ration of striped bass in the Hudson a bioenergetics model can be created to examine the predatory effect of striped bass on out-migrating alosids. With further data on the abundance of these out migrating alosids managers can determine the degree with which striped bass will effect alosid populations in the river. This gives managers not only information on striped bass populations in the Hudson River, but also what the potential effects of future management decisions centered around increasing the size of the striped bass stocks will be on other key species in the river.

The use of hydroacoustic techniques for measuring distribution and abundance of Hudson River striped bass are not limited to modeling or the river itself. To obtain a better estimate of all striped bass associated with the Hudson River, hydroacoustic sampling can be focused on coastal areas around New York and New Jersey. This would give a more complete picture of the overwintering abundance of Hudson River striped bass stocks. From the river data we know that striped bass tended to occupy 
more southerly latitudes in the river, therefore coastal sampling would likely provide better estimates of striped bass stocks in the area.

These techniques are not exclusive to the Hudson River or striped bass, many states and agencies now use hydroacoustics as an essential tool in various fisheries assessments. On the Great Lakes, hydroacoustic techniques are used to assess the status of pelagic fish populations, as well as to verify the effectiveness of current trawling techniques (Argyle 1992; M.H. Hoff, USGS, personal communication). South Carolina managers make use of hydroacoustics to assess not only pelagic species, but also catfish populations (Kasul et al. 1994). Washington state managers make use of hydroacoustic sampling techniques to manage marine fisheries (Pedersen and Boettner 1992). In Washington, hydroacoustics have grown from experimental use to being the main tool for mid-season management decisions that can have great impact on the health of several marine fisheries.

As in the above examples, hydroacoustic techniques provide an excellent opportunity to make fisheries independent estimates of the population size of Atlantic coast striped bass stocks. Our small scale study on the Hudson River could easily be used as a framework for a larger survey of the Atlantic coast striped bass stock. Using a combination of already published data and pilot studies, areas of high striped bass densities could be determined and used as focal points for a larger coastal survey. Then trawl and hydroacoustic data would be collected in these focal areas in order to determine the size and distribution of the coastal striped bass stock. Our study also provides important information as to the timing for population estimates of striped bass stocks. We've been able to establish that the month of December is a valid sampling 
time and provides a good estimate that encompasses multiple age classes of striped bass in the river. Increasing the number of sampling periods during the winter in the Hudson would allow for the continued refinement of the best sampling time during the year. Once the best time to sample has been firmly established, future sampling efforts can be focused during this time to reduce the amount of effort used and increase the efficiency of the effort.

These techniques are not limited to just the Hudson River. Combining Hudson River data with similar studies in areas such as the Chesapeake Bay and Delaware Bay along with a GIS, a big picture can be established as to the population size of the Atlantic coast striped bass stock. Making these sorts of data available to the various agencies responsible for striped bass stocks along the Atlantic coast would allow for more inter-agency cooperation in order to ensure the future of striped bass on the U.S. East coast. 


\section{Literature Cited}

Argyle, R.L. 1992. Acoustics as a tool for the assessment of Great Lakes forage fishes. Fisheries Research 14:179-196.

Brandt, S.B. 1996. Acoustic assessment of fish abundance and distribution. Pages 385432 in B.R. Murphy and D.W. Willis, editors, Fisheries Techniques 2nd edition, American Fisheries Society, Bethesda, MD.

Berggen, T.J. and J.T. Lieberman. 1978. Relative contribution of Hudson, Chesapeake, and Roanoke striped bass, Morone saxatillis, stocks to the Atlantic coast fishery. Fishery Bulletin 76(2):335-345.

Carpenter, S.R., J.F. Kitchell, and J.R. Hodgson. 1985. Cascading trophic interactions and lake productivity. Bioscience. 35: 634-639.

Clark, J. 1968. Seasonal movements of striped bass contingents of Long Island Sound and the New York Bight. Transactions of the American Fisheries Society. 97:320343.

Dunning, D.J., J.R. Waldman, R.E. Quentin, and M.T. Mattson. 1997. Use of Atlantic tomcod and other prey by striped bass in the lower Hudson River estuary during the winter. Transactions of the American Fisheries Society 126: 857-861.

Foote, K.G. 1990. Spheres for calibrating an eleven frequency acoustic measurement system. Journal du Counseil International pour l'Exploration de la Mer 46:284286.

Gardinier, M.N., and J.B. Hoff. 1982. Diets of striped bass in the Hudson River estuary. N.Y. Fish and Game Journal. 29: 152-165.

Hartman, K.J., B.W. Nagy, R.C. Tipton, and S. Morisson. 2000. Verification of hydroacoustic estimates of fish abundance in Ohio River lock chambers. North American Journal of Fisheries Management 20:1049-1056.

Hartman, K. J. and S. B. Brandt. 1995a. Trophic resource partitioning, diets, and growth of sympatric estuarine predators. Transactions of the American Fisheries Society 124:520-537.

Hartman, K. J. and S. B. Brandt. 1995b. Predatory demand and impact of striped bass, bluefish, and weakfish in the Chesapeake Bay: applications of bioenergetics models. Canadian Journal of Fisheries and Aquatic Sciences 52:1667-1687.

Jacobson, P.T., C.S. Clay, J.J. Magnuson. 1990. Size, distribution, and abundance by deconvolution of single-beam acoustic data. Rapp. P.-v. Reun. Cons. perm. int. Explor. Mer. 189: 304-311. 
Jech, J.M. and J. Luo. 2000. Digital echo visualization and information system (DEVIS) for fisheries acoustics data. Journal of Fisheries Research 47:115-124.

Kasul, R.L., J.P. Kirk, S.D. Lamprecht, and J.W. Preacher. 1994. A late spring survey of pelagic prey in Lake Moultrie, South Carolina--implications for management. Proceedings of the Annual Conference of the Southeastern Association of Fish and Wildlife Agencies: 464-473

Klauda, R. J. 1988. Section 2: study area, focal fish species, and power plants. American Fisheries Society Monograph 4:9-10.

Luo, J. and S.B. Brandt. 1993. Bay anchovy production and consumption in midChesapeake Bay based on a bioenergetics model and acoustic measures of fish abundance. Marine Ecology Progress Series 98: 223-236.

Lyons, J. 1998. A hydroacoustic assessment of fish stocks in the River Trent, England. Fisheries Research 35: 85-90.

Manooch, C.S., III. 1973. Food habits of yearling and adult striped bass, Morone saxatilis (Walbaum) from Albermarle Sound, North Carolina. Chesapeake Science. 2: 142-205.

Mason, D.M., A. Goyke, and S.B. Brandt. 1995. A spatially explicit bioenergetics measure of habitat quality for adult salmonines: Comparison between Lakes Michigan and Ontario. Canadian Journal of Fisheries and Aquatic Sciences 52: 1572-1583.

Merriman, D. 1941. Studies on the striped bass (Roccus saxatilis) of the Atlantic coast. U.S. Fish and Wildlife Service, Fisheries Bulletin 50(35): 1-77.

Methven, D.A. and J.F. Piatt. 1991. Seasonal abundance and vertical distribution of capelin (Mallotus villosus) in relation to water temperature at a coastal site off eastern Newfoundland. ICES Journal of Marine Science 48: 187-193.

Pedersen, M.G. and J.F. Boettner. 1992. Application of hydroacoustic technology to marine fishery management in Washington State. Fisheries Research 14: 209219.

Raney, E.C., W.C. Woolcott, and A.G. Mehring. 1954. Migratory pattern and racial structure of the Atlantic coast striped bass. Transactions of the 19th North American Wildlife Conference: 376-396.

Richards, R.A. and P.J. Rago. 1999. A Case History of Effective Fishery Management: Chesapeake Bay Striped Bass. North American Journal of Fisheries Management 19:356-375. 
Rudstam, L.G. and B.M. Johnson. 1992. Development, evaluation and transfer of new technology. Pages 507-523 in J.F. Kitchell, editor, Food web management: a case study of Lake Mendota, Springer-Verlag, New York, N.Y.

Rudstam, L.G., C.S. Clay, and J.J. Magnuson. 1987. Density and size estimates of cisco, Coregonus artedii, using analysis of echo peak PDF from a single transducer sonar. Canadian Journal of Fisheries and Aquatic Science 44: 811821

Rudstam, L.G., T. Lindem, and S. Hansson. 1988. Density and in situ target strength of herring and sprat: a comparison between two methods of analyzing single-beam sonar data. Fisheries Research 6: 305-315.

Setzler-Hamilton, E. M. and L. Hall, Jr. 1991. Striped bass Morone saxatilis. Pages 131 to 13-25 In Habitat requirements for Chesapeake Bay living resources. S. L. Funderbruk, J. A. Mihursky, S. J. Jordan, and D. A. Riley, editors. Chesapeake Research Consortium, Solomons, Maryland.

Smith, C. L. 1985. Inland fishes of New York state. New York State Department of Environmental Conservation, Albany.

Stevens, E. D. 1979. The effect of temperature on tail beat frequency of fish swimming at constant velocity. Canadian Journal of Zoology 57:1628-1635.

Thorne, R.E. 1983. Hydroacoustics. Pages 239-259 in L.A. Nielsen and D.L. Johnson, editors, Fisheries Techniques 1st edition, American Fisheries Society, Bethesda, MD.

Thorne, R.E. and G.E. Johnson. 1993. A review of hydroacoustic studies for estimation of salmonid downriver migration past hydroelectric facilities on the Columbia and Snake rivers in the 1980's. Reviews in Fisheries Science 1: 27-56.

VanWinkle, W., K.D. Kumar, and D.S. Vaughan. 1988. Relative contribution of Hudson River and Chesapeake Bay striped bass stocks to the Atlantic coastal population. American Fisheries Society Monograph 4:255-266. 
Table 1. Volume of water per region as used in the conversion of fish density to fish abundance. Volumes represent strata $>5 \mathrm{~m}$ in depth by utility-defined river regions (from J. Young, Consolidated Edison Power Company)

\begin{tabular}{cc} 
Region Name & Volume $\left(\mathrm{m}^{3}\right)$ \\
\hline \hline Battery & 190264951 \\
Yonkers & 202765521 \\
Tappen Zee & 200126473 \\
Croton-Haverstraw & 93826649
\end{tabular}


Table 2. Number of fish from five species caught in a total of nine gillnet sets in the Hudson River, separated into those caught below and above the $0.5 \mathrm{~m}$ mark of the bottom.

\begin{tabular}{ccc}
\hline Species & $\begin{array}{c}\text { Number Caught } \\
\leq 0.5 \mathrm{~m}\end{array}$ & $\begin{array}{c}\text { Number Caught } \\
>0.5 \mathrm{~m}\end{array}$ \\
\hline \hline Atlantic tomcod & 2 & 0 \\
gizzard shad & 0 & 1 \\
shortnose sturgeon & 2 & 0 \\
striped bass & 0 & 1 \\
white perch & 11 & 22 \\
\hline
\end{tabular}


Table 3. Results from an ANOVA comparing fish density at 4 different size classes to temperature $(T)$, salinity $(S)$ and the interaction of salinity and temperature $(\mathrm{S}: \mathrm{T})$ across 4 different regions in 1995(A) and 3 regions in 1997(B). All values are $p$-values from the ANOVA, a NS equals a non-significant result at the 0.05 level

\begin{tabular}{|c|c|c|c|c|c|c|}
\hline $\mathrm{A}$ & Region & Variable & $12-90 \mathrm{~mm}$ & $90-160 \mathrm{~mm}$ & $160-300 \mathrm{~mm}$ & $300-1000 \mathrm{~mm}$ \\
\hline \multirow{3}{*}{\multicolumn{2}{|c|}{ Battery }} & $\overline{\bar{T}}$ & NS & 0.006 & NS & NS \\
\hline & & $S$ & NS & NS & NS & NS \\
\hline & & $\mathrm{T}: \mathrm{S}$ & NS & NS & NS & NS \\
\hline \multirow{3}{*}{\multicolumn{2}{|c|}{ Yonkers }} & $\mathrm{T}$ & NS & NS & NS & NS \\
\hline & & $S$ & NS & NS & NS & NS \\
\hline & & $\mathrm{T}: \mathrm{S}$ & NS & 0.031 & 0.028 & 0.049 \\
\hline \multirow{3}{*}{\multicolumn{2}{|c|}{ Tappen Zee }} & $\mathrm{T}$ & NS & 0.003 & 0.020 & 0.049 \\
\hline & & $S$ & 0.002 & 0.020 & NS & NS \\
\hline & & $\mathrm{T}: \mathrm{S}$ & $<0.0001$ & NS & NS & NS \\
\hline \multirow{3}{*}{\multicolumn{2}{|c|}{ Croton-Haverstraw }} & $\mathrm{T}$ & 0.006 & 0.013 & 0.019 & NS \\
\hline & & S & 0.035 & NS & NS & NS \\
\hline & & $\mathrm{T}: \mathrm{S}$ & 0.022 & NS & NS & NS \\
\hline $\mathrm{B}$ & Region & Variable & $12-90 \mathrm{~mm}$ & $90-160 \mathrm{~mm}$ & $160-300 \mathrm{~mm}$ & $300-1000 \mathrm{~mm}$ \\
\hline \multirow{3}{*}{\multicolumn{2}{|c|}{ Battery }} & $\overline{\bar{T}}$ & 0.040 & 0.000 & 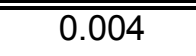 & 0.045 \\
\hline & & $S$ & NS & 0.042 & NS & 0.049 \\
\hline & & $\mathrm{T}: \mathrm{S}$ & 0.005 & 0.000 & NS & NS \\
\hline \multirow{3}{*}{\multicolumn{2}{|c|}{ Yonkers }} & $\mathrm{T}$ & NS & 0.030 & NS & NS \\
\hline & & $S$ & 0.000 & 0.034 & NS & NS \\
\hline & & $\mathrm{T}: \mathrm{S}$ & 0.003 & NS & NS & NS \\
\hline \multirow{3}{*}{\multicolumn{2}{|c|}{ Tappen Zee }} & $\mathrm{T}$ & 0.000 & 0.002 & 0.019 & NS \\
\hline & & $S$ & NS & NS & NS & NS \\
\hline & & $\mathrm{T}: \mathrm{S}$ & NS & NS & NS & NS \\
\hline
\end{tabular}


Table 4. Total fish density and abundance by size class and river region during December 1995 hydroacoustic surveys with 95\% confidence intervals. Size classes correspond to fish too small to be striped bass $(12-90 \mathrm{~mm})$, age- 0 striped bass $(90-160 \mathrm{~mm})$, age- 1 striped bass $(160-300 \mathrm{~mm})$, and age-2+ striped bass $(300-1000 \mathrm{~mm})$.

Density (fish $/ \mathrm{m}^{3} \pm 95 \%$ C.I.)

\begin{tabular}{|c|c|c|c|c|c|c|c|}
\hline Size Range & \multicolumn{2}{|l|}{ Battery } & \multicolumn{2}{|c|}{ Yonkers } & \multicolumn{2}{|c|}{ Tappan Zee } & Croton-Haverstraw \\
\hline$\overline{12-90 m m}$ & \multicolumn{2}{|c|}{$0.70875 \pm 0.31603$} & \multicolumn{2}{|c|}{$0.12750 \pm 0.01266$} & \multicolumn{2}{|c|}{$0.05740 \pm 0.00197$} & $0.77749 \pm 0.02813$ \\
\hline $90-160 \mathrm{~mm}$ & \multicolumn{2}{|c|}{$0.00216 \pm 0.00021$} & \multicolumn{2}{|c|}{$0.00150 \pm 0.00008$} & \multicolumn{2}{|c|}{$0.00428 \pm 0.00026$} & $0.00582 \pm 0.0020$ \\
\hline $160-300 \mathrm{~mm}$ & \multicolumn{2}{|c|}{$0.00113 \pm 0.00012$} & \multicolumn{2}{|c|}{$0.00124 \pm 0.00008$} & \multicolumn{2}{|c|}{$0.00205 \pm 0.00010$} & $0.00182 \pm 0.00009$ \\
\hline $300-1000 \mathrm{~mm}$ & \multicolumn{2}{|c|}{$0.00046 \pm 0.00006$} & \multicolumn{2}{|c|}{$0.00024 \pm 0.00003$} & \multicolumn{2}{|c|}{$0.00016 \pm 0.00002$} & $0.00016 \pm 0.00005$ \\
\hline \multicolumn{8}{|c|}{ Abundance (\#'s of fish $\pm 95 \%$ C.I.) } \\
\hline Size Range & Battery & & ikers & Tappa & & Croton-Haverstraw & Total \\
\hline$\overline{12-90 \mathrm{~mm}}$ & $\overline{c 134,851,806 \pm 60,129,084}$ & 25,851 & $\pm 2,068,708$ & $111,487,059$ & $\overline{3,226}$ & $\overline{72,949,375 \pm 4,856,776}$ & $245,140,033 \pm 67,547,794$ \\
\hline $90-160 \mathrm{~mm}$ & $410,401 \pm 39,395$ & 303 & $\pm 13,459$ & 856,942 & 008 & $546,259 \pm 35,280$ & $2,116,939 \pm 154,141$ \\
\hline $160-300 \mathrm{~mm}$ & $215,190 \pm 23,230$ & & $\pm 13,233$ & 410,860 & 032 & $170,671 \pm 15,307$ & $1,047,135 \pm 76,803$ \\
\hline $300-1000 \mathrm{~mm}$ & $87,902 \pm 11,243$ & & $\pm 4,671$ & 32,621 & & $15,294 \pm 8,420$ & $184,075 \pm 29,294$ \\
\hline Total & $135,565,300 \pm 60,202,951$ & 26,453 & $\pm 2,100,072$ & $12,787,481$ & 9,226 & $73,681,598 \pm 4,915,782$ & $248,488,183 \pm 67,808,032$ \\
\hline
\end{tabular}


Table 5. Striped bass density and abundance by size class and river region during December 1995 hydroacoustic surveys with 95\% confidence intervals. Size classes correspond to fish too small to be striped bass $(12-90 \mathrm{~mm})$, age -0 striped bass $(90-160 \mathrm{~mm})$, age- 1 striped bass $(160-300 \mathrm{~mm})$, and age-2+ striped bass $(300-1000 \mathrm{~mm})$.

Density (fish $/ \mathrm{m}^{3} \pm 95 \%$ C.I.)

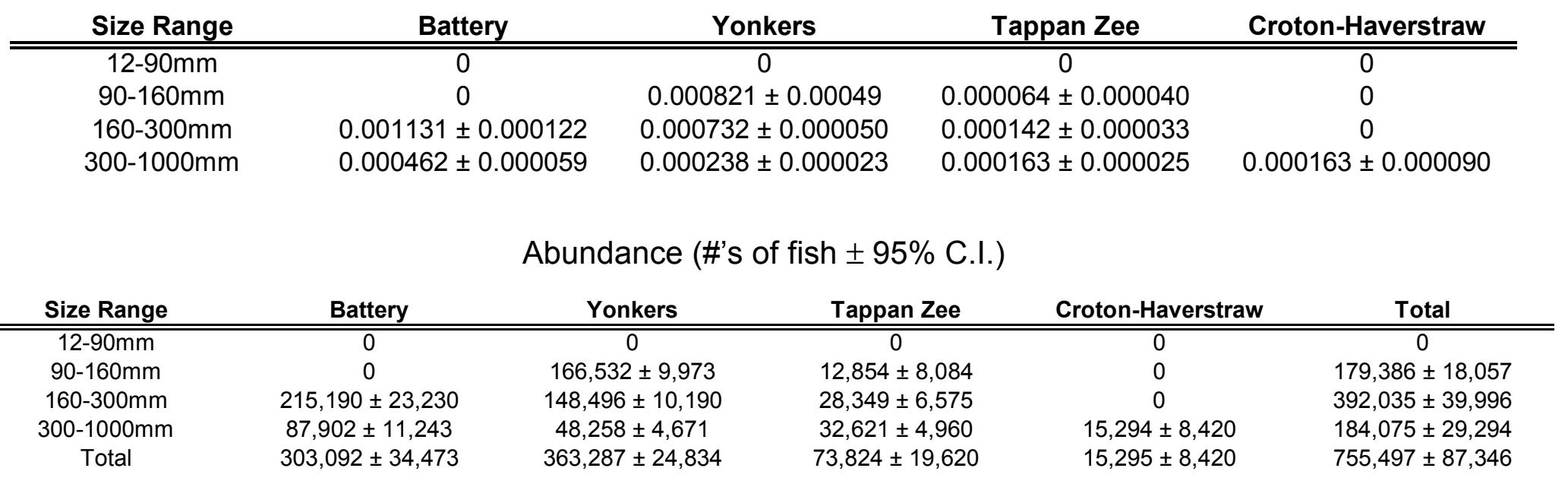


Table 6. Total fish density and abundance by size class and river region during December 1997 hydroacoustic surveys with 95\% confidence intervals. Size classes correspond to fish too small to be striped bass $(12-90 \mathrm{~mm})$, age- 0 striped bass $(90-160 \mathrm{~mm})$, age- 1 striped bass $(160-300 \mathrm{~mm})$, and age-2+ striped bass $(300-1000 \mathrm{~mm})$.

\begin{tabular}{ccccc}
\multicolumn{5}{c}{ Density $\left(\mathrm{fish} / \mathrm{m}^{3} \pm 95 \%\right.$ C.I. $)$} \\
Size Range & Battery & Yonkers & Tappan Zee & Croton-Haverstraw \\
\hline \hline $12-90 \mathrm{~mm}$ & $0.20851 \pm 0.09674$ & $0.03647 \pm 0.00163$ & $0.00832 \pm 0.00165$ & $0.05081 \pm 0.01222$ \\
$90-160 \mathrm{~mm}$ & $0.00358 \pm 0.00173$ & $0.00853 \pm 0.00010$ & $0.00090 \pm 0.00028$ & $0.00353 \pm 0.00076$ \\
$160-300 \mathrm{~mm}$ & $0.00044 \pm 0.00016$ & $0.00017 \pm 0.00004$ & $0.00016 \pm 0.00012$ & $0.00037 \pm 0.00016$ \\
$300-1000 \mathrm{~mm}$ & $0.00022 \pm 0.00013$ & $0.00004 \pm 0.00003$ & $0.00004 \pm 0.00004$ & $0.00003 \pm 0.00003$
\end{tabular}

Abundance (\#'s of fish $\pm 95 \%$ C.I.)

\begin{tabular}{cccccc} 
Size Range & Battery & Yonkers & Tappan Zee & Croton-Haverstraw & Total \\
\hline \hline $12-90 \mathrm{~mm}$ & $39,671,384 \pm 18,405,430$ & $7,394,859 \pm 330,872$ & $1,665,653 \pm 330,514$ & $4,767,520 \pm 1,146,704$ & $53,499,415 \pm 20,213,521$ \\
$90-160 \mathrm{~mm}$ & $680,958 \pm 329,077$ & $1,729,590 \pm 20,321$ & $180,714 \pm 56,410$ & $330,927 \pm 71,035$ & $2,922,189 \pm 476,843$ \\
$160-300 \mathrm{~mm}$ & $84,478 \pm 30,955$ & $34,470 \pm 9,069$ & $32,220 \pm 24,043$ & $34,932 \pm 14,844$ & $186,100 \pm 78,912$ \\
$300-1000 \mathrm{~mm}$ & $41,858 \pm 24,269$ & $7,502 \pm 6,594$ & $7,805 \pm 7,743$ & $3,246 \pm 2,651$ & $60,412 \pm 41,257$ \\
Total & $40,478,678 \pm 18,789,731$ & $9,166,421 \pm 366,855$ & $1,886,392 \pm 418,711$ & $5,136,624 \pm 1,235,236$ & $56,668,115 \pm 20,910,533$
\end{tabular}


Table 7. Striped bass density and abundance by size class and river region during December 1997 hydroacoustic surveys with 95\% confidence intervals. Size classes correspond to fish too small to be striped bass $(12-90 \mathrm{~mm})$, age- 0 striped bass $(90-160 \mathrm{~mm})$, age- 1 striped bass $(160-300 \mathrm{~mm})$, and age-2+ striped bass $(300-1000 \mathrm{~mm})$.

\begin{tabular}{ccccc}
\multicolumn{4}{c}{ Density $\left(\mathrm{fish} / \mathrm{m}^{3} \pm 95 \%\right.$ C.I. $)$} \\
Size Range & Battery & Yonkers & Tappan Zee & Croton-Haverstraw \\
\hline \hline $12-90 \mathrm{~mm}$ & 0 & $0.00066 \pm 0.00022$ & $0.00013 \pm 0.00021$ & $0.00056 \pm 0.00128$ \\
$90-160 \mathrm{~mm}$ & $0.00358 \pm 0.00173$ & $0.00213 \pm 0.00005$ & $0.00040 \pm 0.00019$ & $0.00004 \pm 0.00008$ \\
$160-300 \mathrm{~mm}$ & 0 & $0.00002 \pm 0.00001$ & 0 & $0.00001 \pm 0.00003$ \\
$300-1000 \mathrm{~mm}$ & $0.00022 \pm 0.00013$ & $0.00004 \pm 0.00003$ & $0.00004 \pm 0.00004$ & $0.00003 \pm 0.00003$
\end{tabular}

Abundance (\#'s of fish $\pm 95 \%$ C.I.)

\begin{tabular}{cccccc} 
Size Range & Battery & Yonkers & Tappan Zee & Croton-Haverstraw & Total \\
\hline \hline $12-90 \mathrm{~mm}$ & 0 & $133,107 \pm 44,391$ & $26,650 \pm 41,807$ & $52,443 \pm 120,267$ & $212,201 \pm 206,466$ \\
$90-160 \mathrm{~mm}$ & $680,958 \pm 329,077$ & $432,397 \pm 10,160$ & $79,153 \pm 37,333$ & $3,640 \pm 7,450$ & $1,196,149 \pm 384,021$ \\
$160-300 \mathrm{~mm}$ & 0 & $3,826 \pm 3,022$ & 0 & $943 \pm 2439$ & $4,769 \pm 5,461$ \\
$300-1000 \mathrm{~mm}$ & $41,858 \pm 24,269$ & $7,502 \pm 6,594$ & $7,805 \pm 7,743$ & $3,246 \pm 2,651$ & $60,412 \pm 41,257$ \\
Total & $722,817 \pm 353,346$ & $576,833 \pm 64,167$ & $113,608 \pm 86,884$ & $60,272 \pm 132,808$ & $1,473,531 \pm 637,204$
\end{tabular}


Figure 1. Map of the Hudson River showing the eight different regions of the study area with their respective names. 


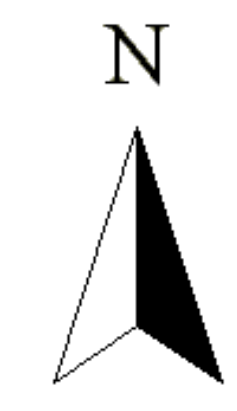

\section{Poughkeepsie}

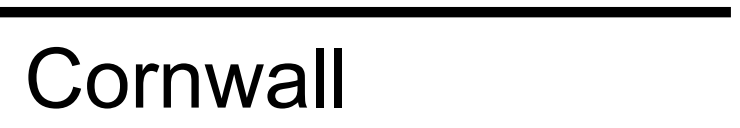

West Point

\section{Indian Point}

\section{Croton-Haverstraw}

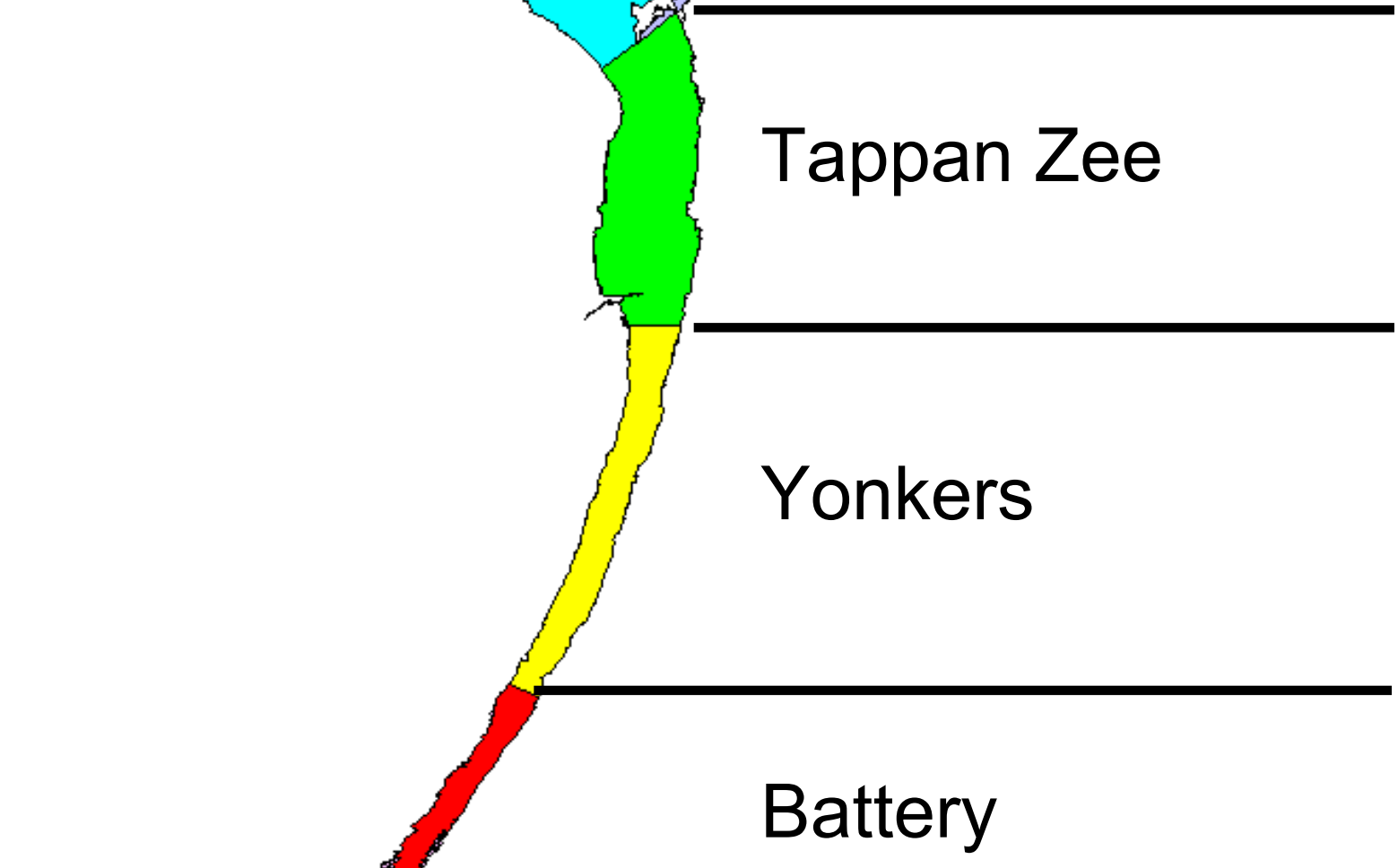

20 Kilometers 
Figure 2. Percent composition of fish species collected in trawls during 1995 by size range and by river region. 


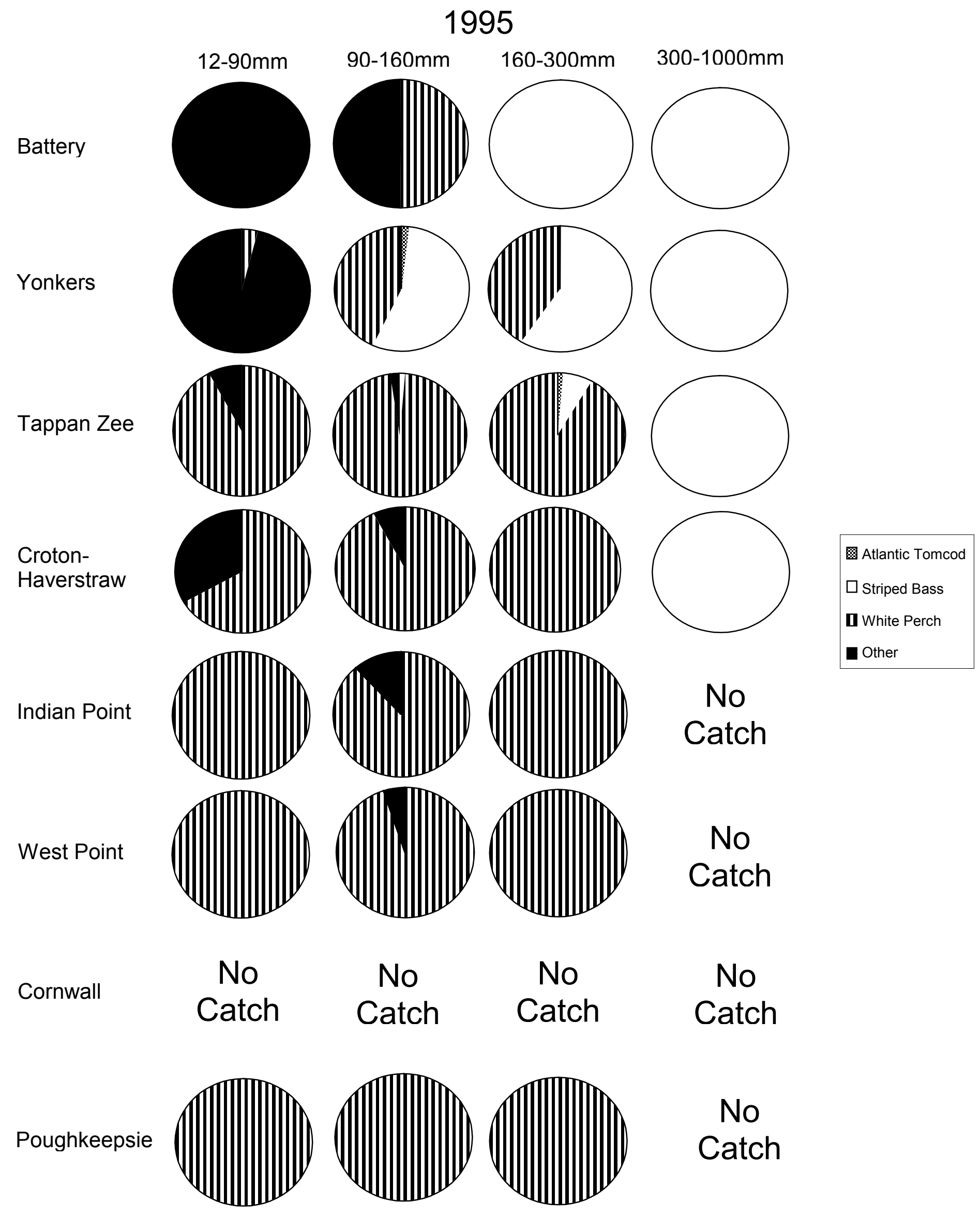


Figure 3. Percent composition of fish species collected in trawls during 1997 by size range and by river region. 


\section{7}

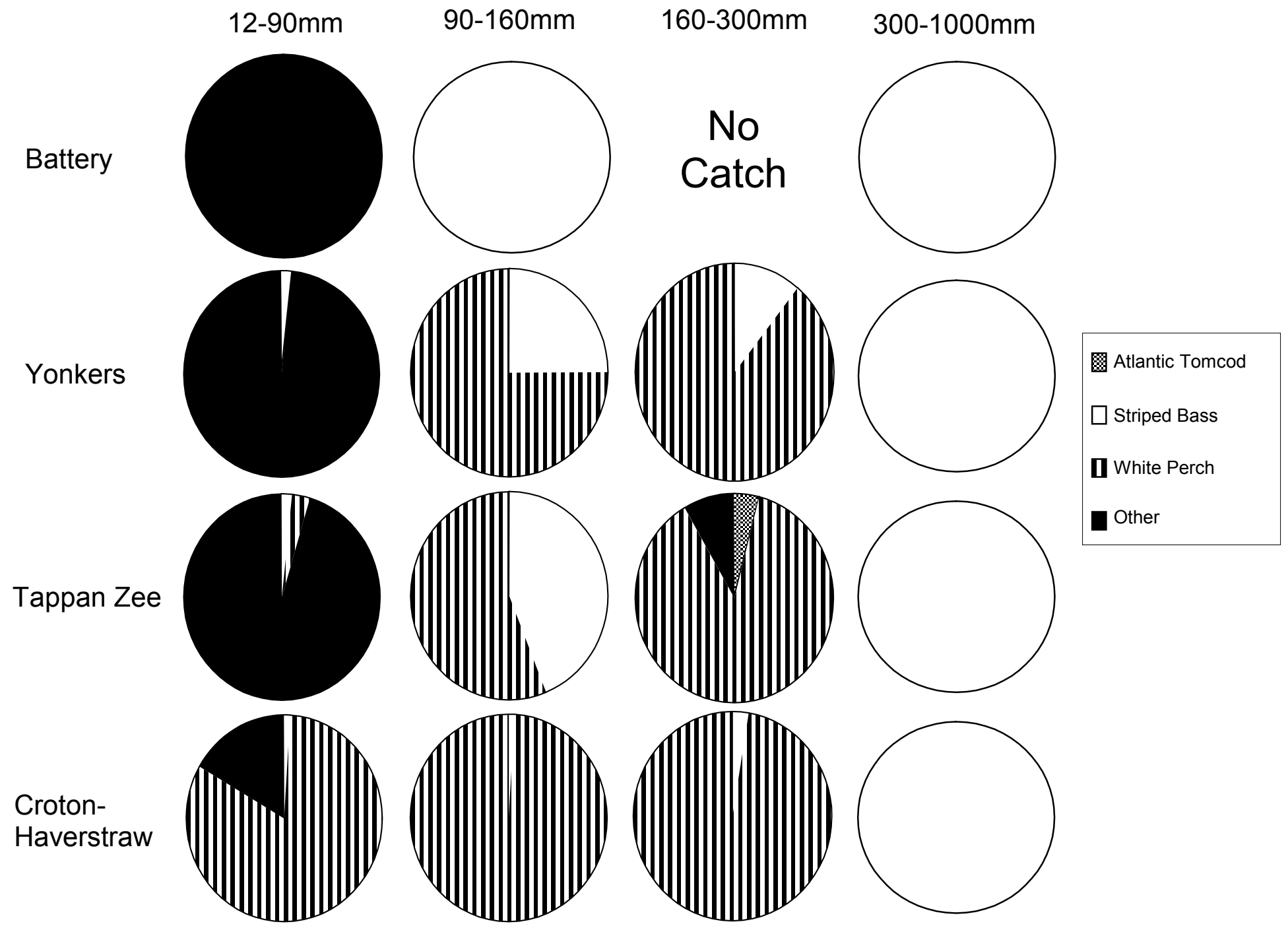


Figure 4. Latitudinal density distribution of all acoustically accessible fish in December of 1995 including four size classes: $12-90 \mathrm{~mm}, 90-160 \mathrm{~mm}, 160-300 \mathrm{~mm}$ and $300-1000 \mathrm{~mm}$, from the Battery to Croton-Haverstraw, where the vertical dashed lines represent the transition between regions. 


\section{2-90mm Size Class}

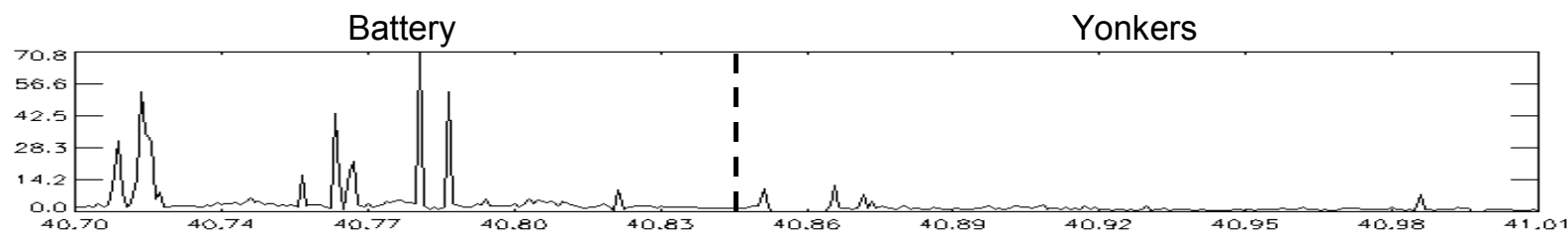

Tappan Zee

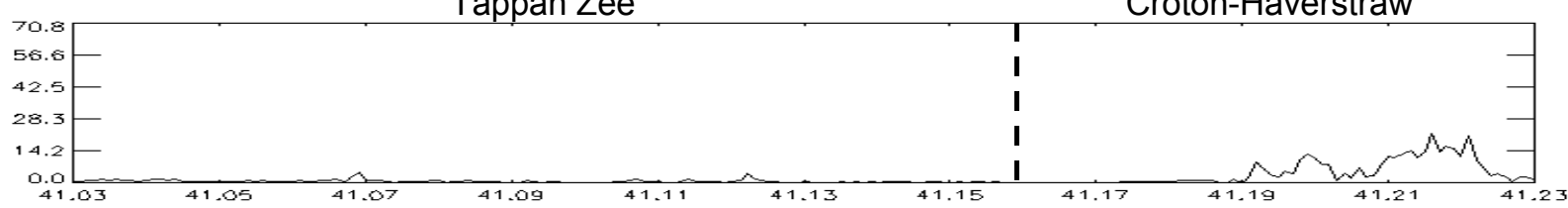

90-160mm Size Class
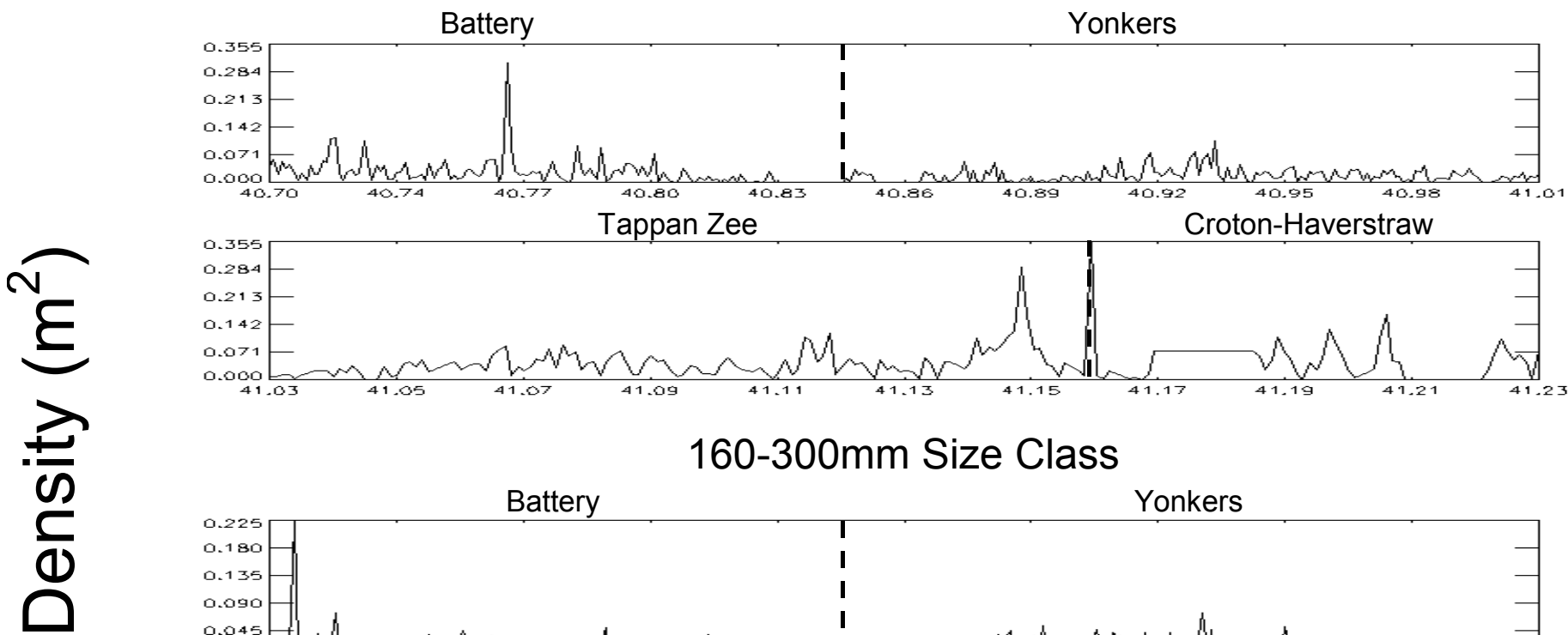

160-300mm Size Class

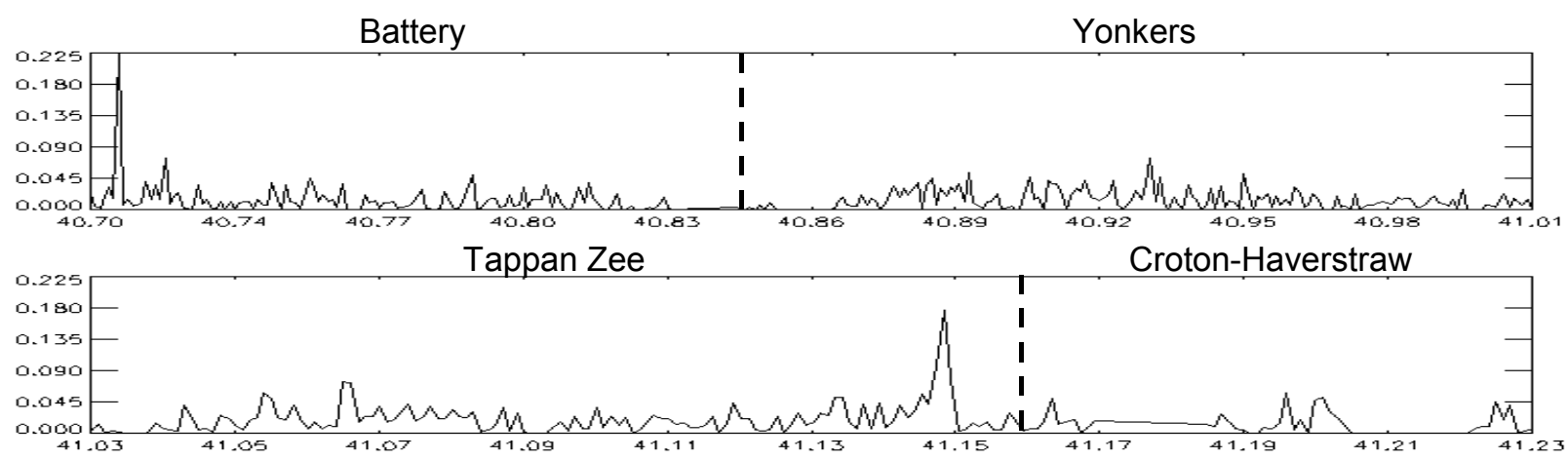

300-1000mm Size Class
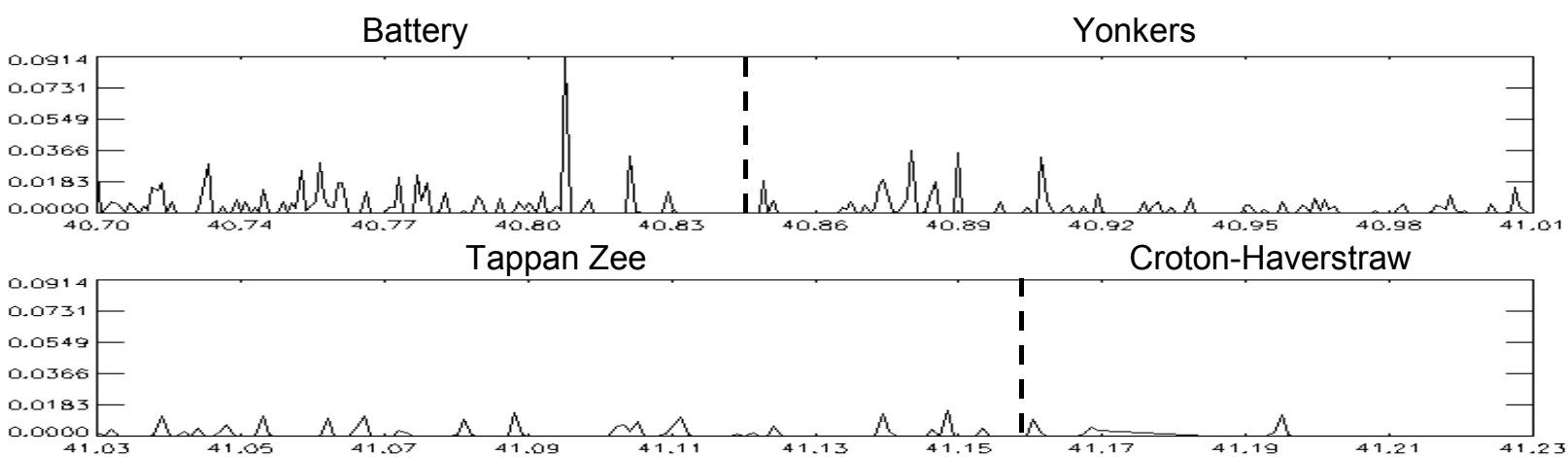

\section{Latitude}


Figure 5. Latitudinal density distribution of striped bass in December of 1995 including three size classes: $90-160 \mathrm{~mm}, 160-300 \mathrm{~mm}$ and $300-1000 \mathrm{~mm}$, from the Battery to Croton-Haverstraw, where the vertical dashed lines represent the transition between regions. 


\section{0-160mm Size Class}
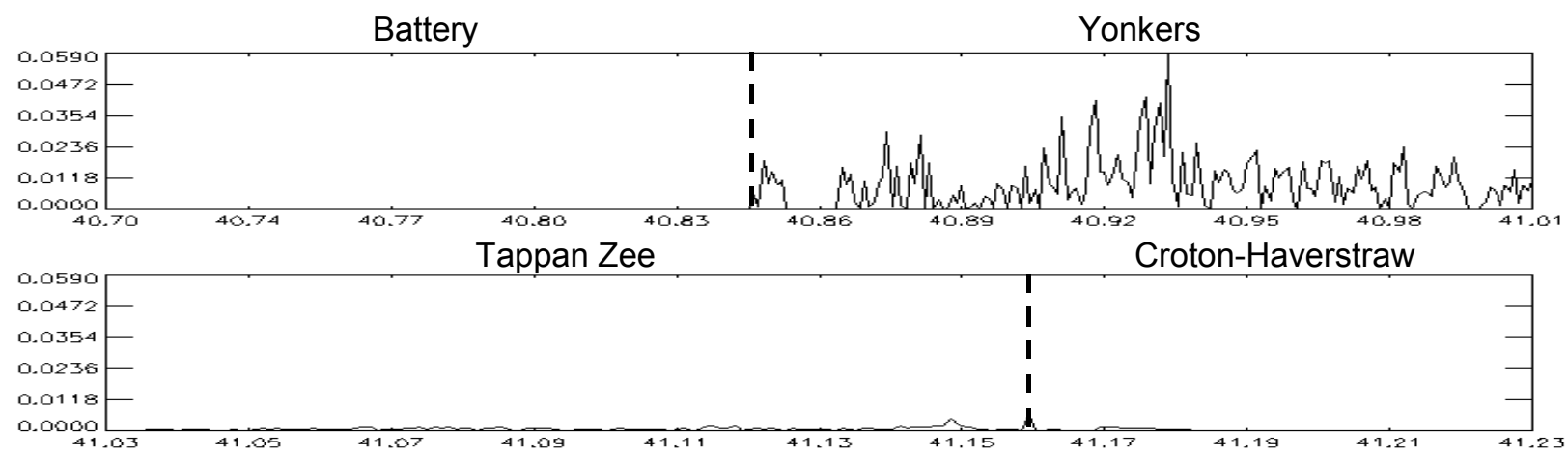

160-300mm Size Class
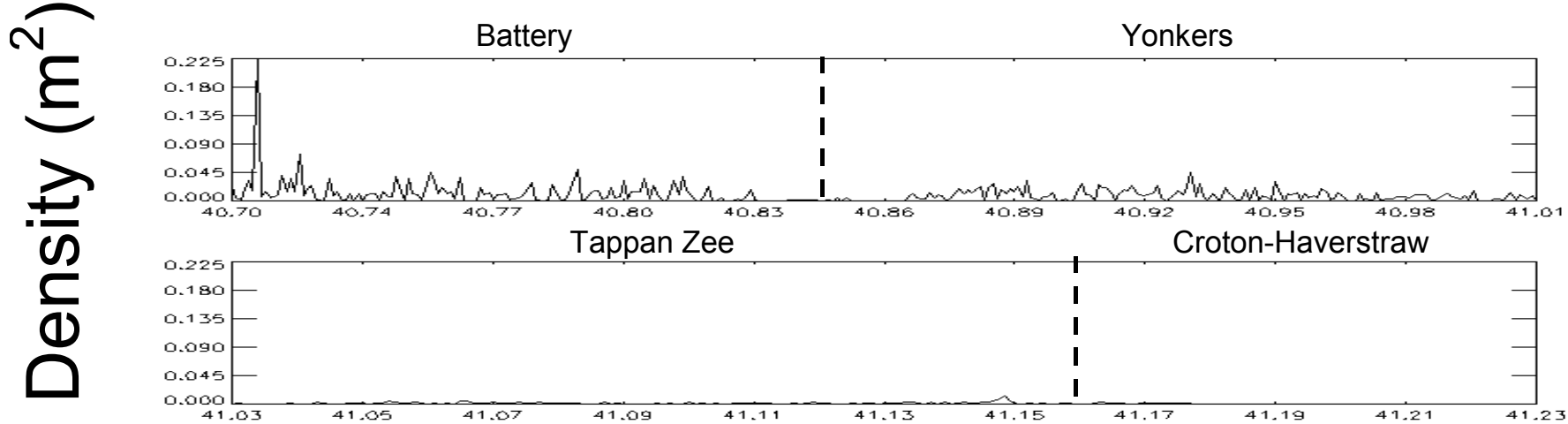

\section{0-1000mm Size Class}
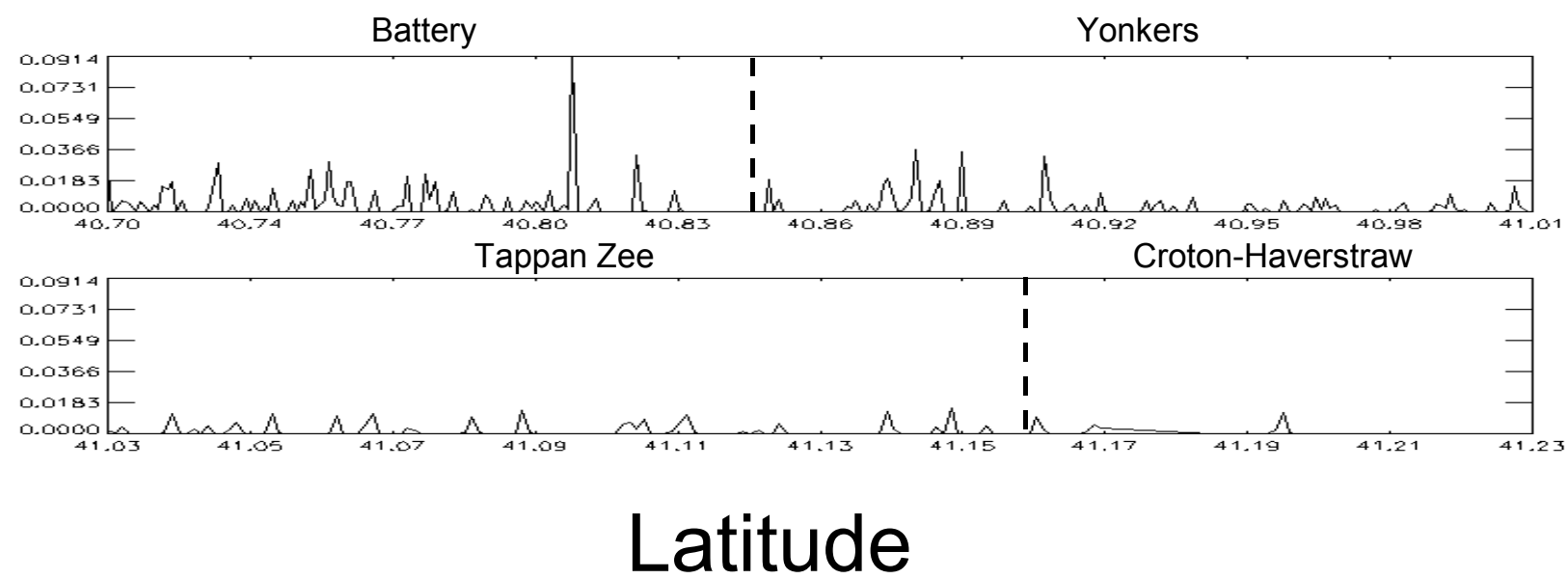
Figure 6. Latitudinal density distribution of all acoustically accessible fish in December of 1997 including four size classes: $12-90 \mathrm{~mm}, 90-160 \mathrm{~mm}, 160-300 \mathrm{~mm}$ and $300-1000 \mathrm{~mm}$, from the Battery to Croton-Haverstraw, where the vertical dashed lines represent the transition between regions. 


\section{2-90mm Size Class}

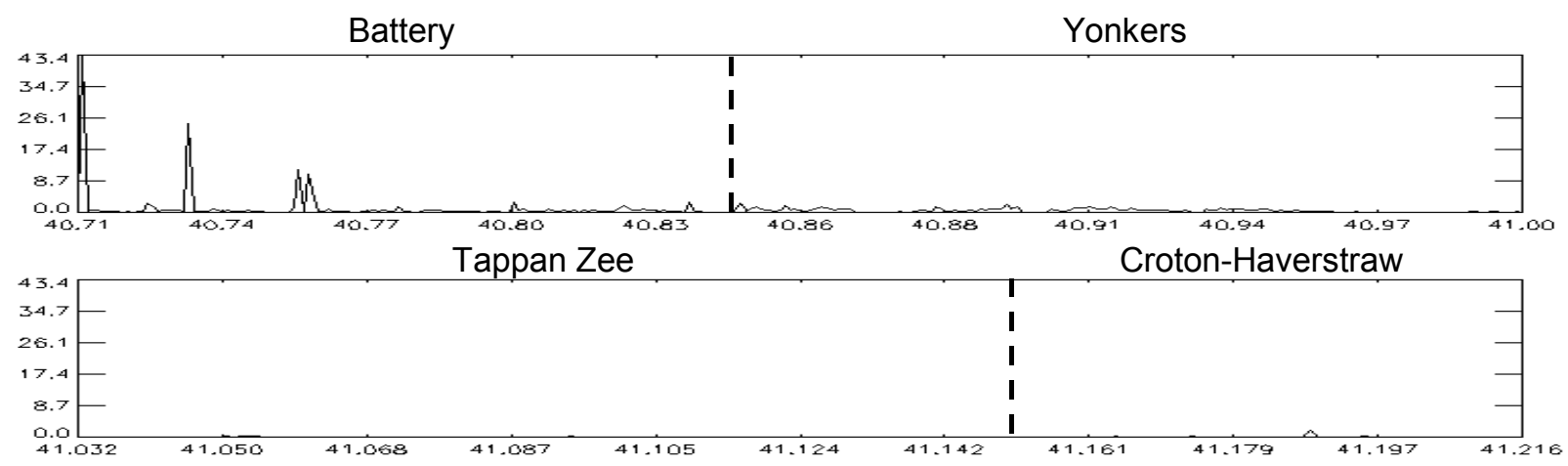

90-160mm Size Class
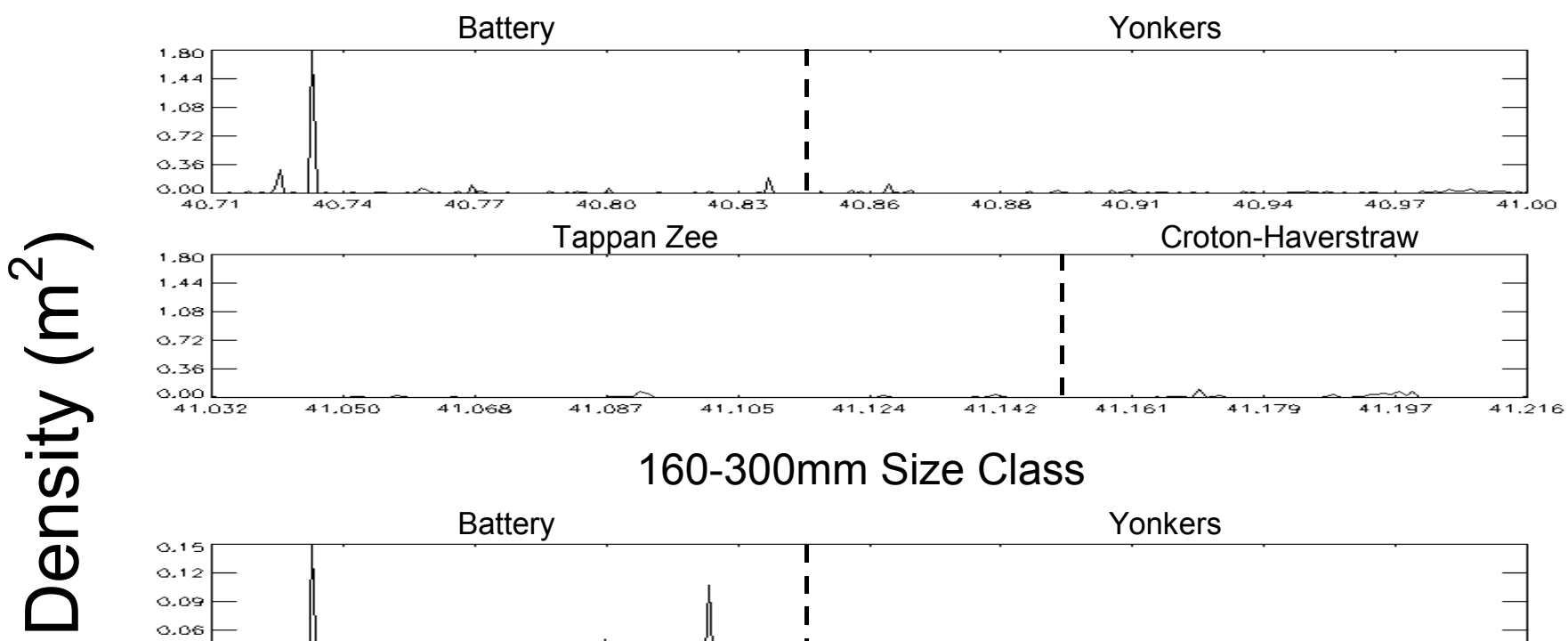

\section{0-300mm Size Class}
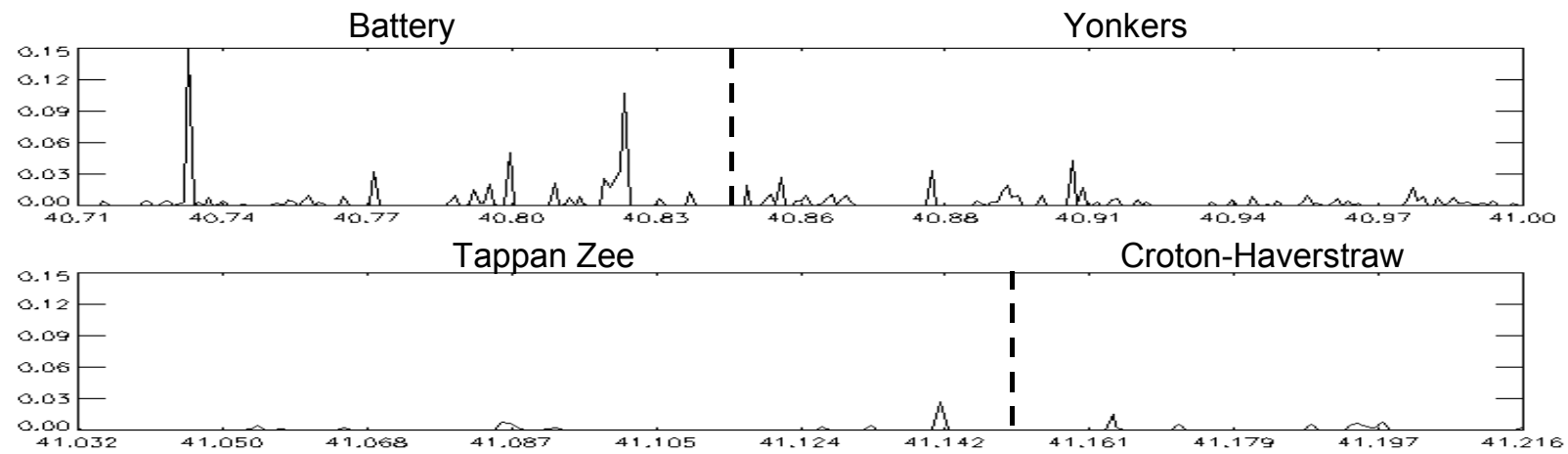

\section{0-1000mm Size Class}
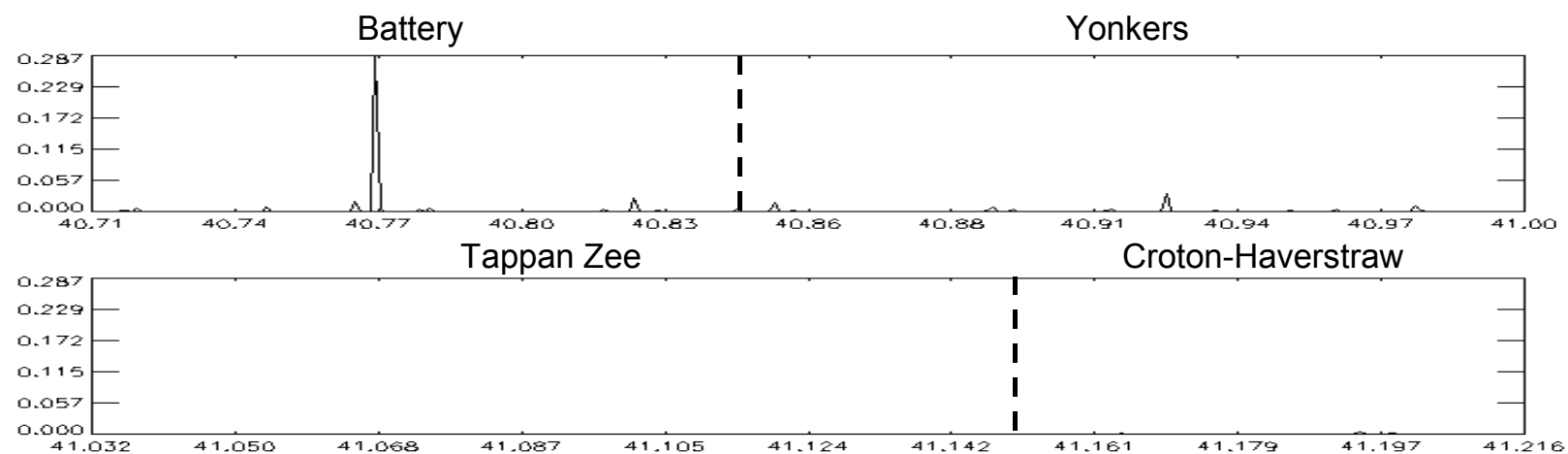
Figure 7. Latitudinal density distribution of striped bass in December of 1997 including four size classes: $12-90 \mathrm{~mm}, 90-160 \mathrm{~mm}, 160-300 \mathrm{~mm}$ and $300-1000 \mathrm{~mm}$, from the Battery to Croton-Haverstraw, where the vertical dashed lines represent the transition between regions. 


\section{2-90mm Size Class}

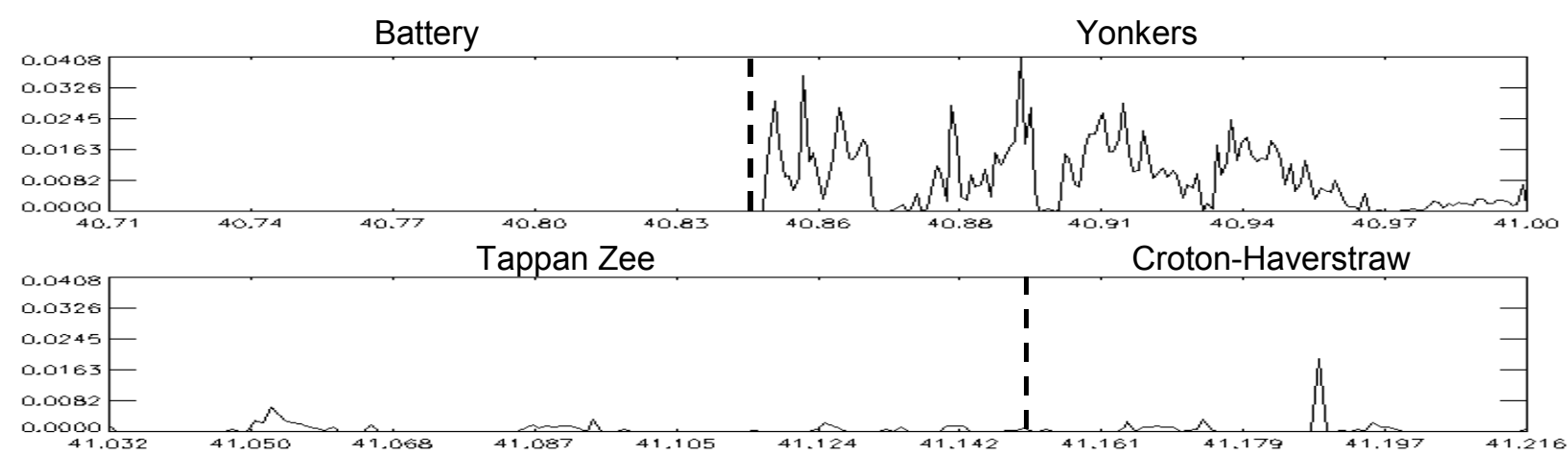

90-160mm Size Class
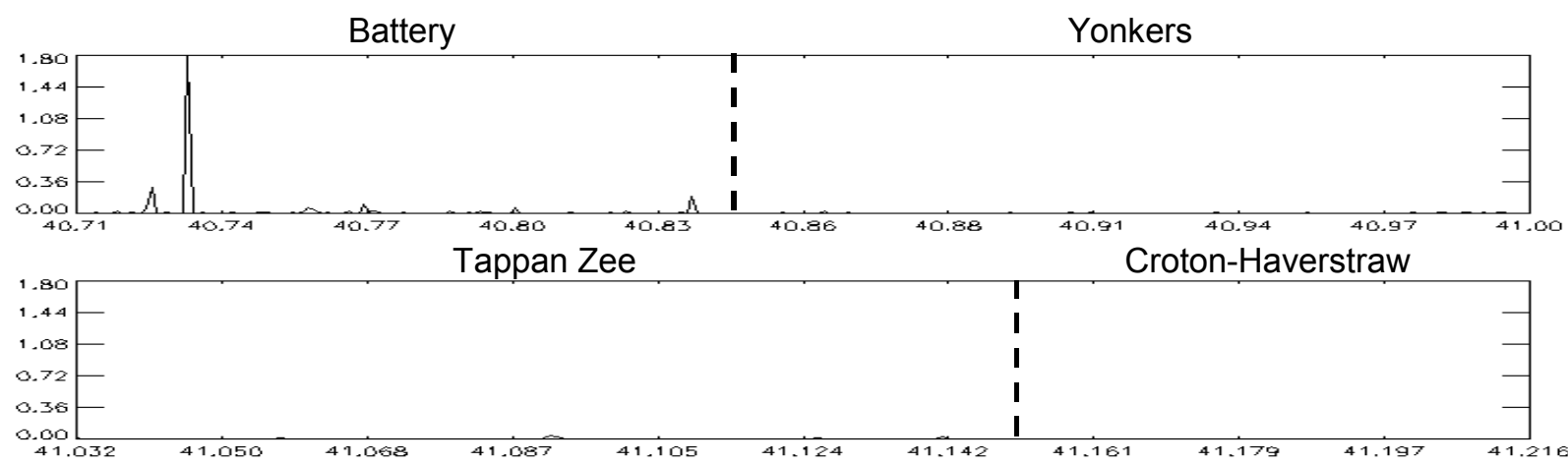

\section{0-300mm Size Class}
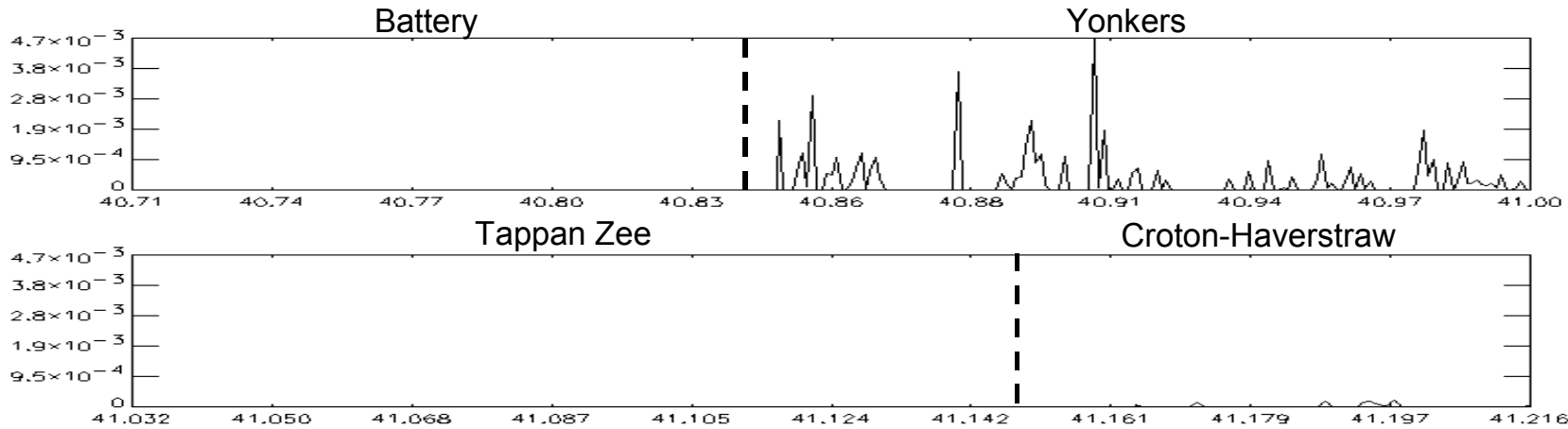

300-1000mm Size Class
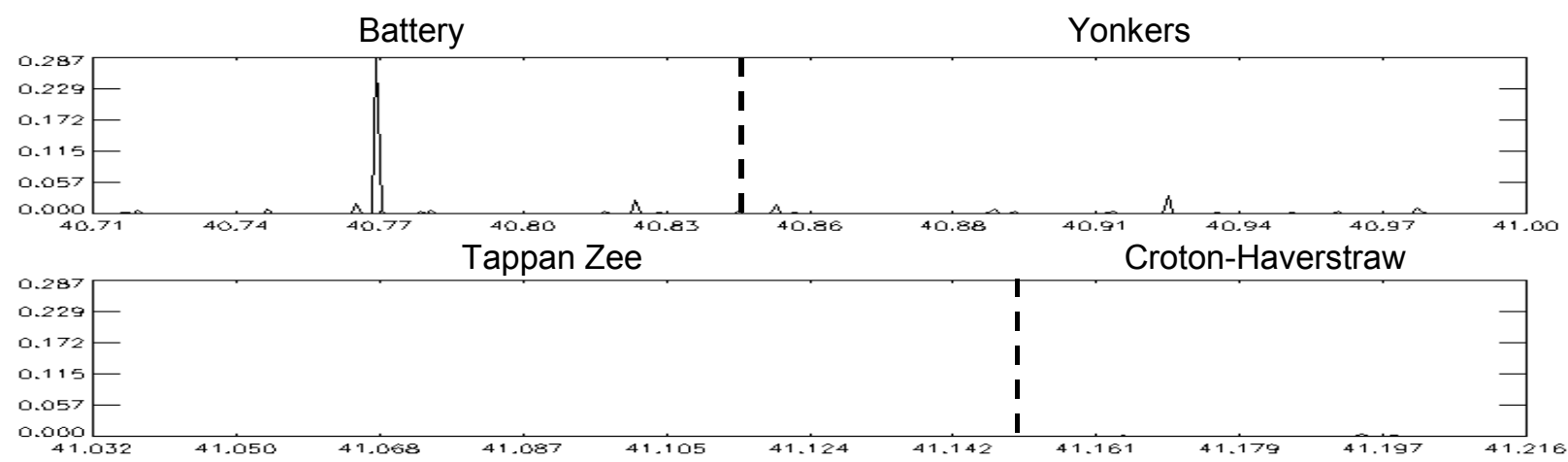

\section{Latitude}




\section{Chapter 3:}

Evaluation of potential top-down effects of striped bass on outmigrating alosid populations in the Hudson River estuary using a bioenergetics model.

\section{Abstract}

American shad (Alosa sapidissima) and striped bass (Morone saxatilis) are both important game species known to populate the Hudson River. In the Hudson River these species have shown inverse trends in population size. Striped bass have recovered from large population declines in the early 1980 's, following a fishing moratorium on this popular game species. This increase in striped bass populations could increase the predatory demand of striped bass on American shad as well as other alosids. We postulate that in the Hudson River this predatory demand could in large part be from resident striped bass and those preparing to overwinter in the river while YOY American shad are outmigrating. We applied a bioenergetics model to test this hypothesis using $10 \%$ and $50 \%$ levels of consumption by striped bass on alosids to bound our estimates. We showed that age-1 and 2 striped bass have the ability to consume between 25 and 125 metric tons (1995) or between 5 and 29 metric tons (1997) of alosid biomass. This is a significant amount of the estimated 15.3 metric tons of alosid biomass in the river (in 1991). Through this technique we were able to show that even at lower levels of consumption striped bass can pose a significant threat to outmigrating alosids. Consideration of top-down effects, such as this one, can drastically change the way competitive species are managed. 


\section{Introduction}

American shad (Alosa sapidissima) are a large anadromous herring species known to spawn in the Hudson River (Klauda et al. 1991). Adults enter the river to spawn in the spring and the resulting young out migrate in the summer and fall typically starting in July and ending in October or November depending on water temperature (Klauda et al. 1991). Limburg (2001) showed that there was a discrepancy between the numbers of young-of-the-year (YOY) leaving the river and the numbers of those YOY returning as adults, with the greatest losses occurring with those YOY leaving between the end of August and the end of September. This suggests that there is some form of mortality occurring on YOY shad during this period, which is reducing the number of adults returning to the river. One reason specifically cited by Limburg (2001) for this loss is predation on the outmigrating YOY shad. From previous work (Chapter 2) we know that striped bass (Morone saxatilis) overwinter in the southern portion of the Hudson River and likely start concentrating in the lower river during the summer and fall. From studies by Manooch (1973), Gardinier and Hoff (1982), and Dunning et al. (1997) we know that striped bass do consume alosids and that striped bass consume alosids during the summer to winter period. Therefore, it would stand to reason that striped bass have the potential to consume YOY American shad, blueback herring (Alsoa aestivalis) and other alosids as they migrate out of the river.

Striped bass populations have increased in the Hudson River, which may increasingly affect alosids. Much of the increase in striped bass is due to a fishing moratorium from 1985-1990 (Richards and Rago 1999). With increases in striped bass population abundance, Hudson River alosids are faced with an increased predatory risk 
as they leave the river and enter the ocean. This predatory challenge could have major impacts on an already diminished stock of fish (St. Pierre 1977; ASMFC 1985). Due to the importance of American shad and striped bass as recreational and commercial species, an understanding of their interactions at this critical time of out migration could influence future management goals and objectives for these species.

Unfortunately, quantifying the true effect of overwintering striped bass on American shad purely through experimental methods would be a daunting task, both logistically and financially. Therefore, another approach is needed. Through the use of a bioenergetics model for striped bass, along with data on the size of the striped bass population in the Hudson, it is possible to determine the potential effect of striped bass on American shad as well as other out migrating alosids. Therefore, the objective of this study is to determine the potential predatory impact of overwintering striped bass on out migrating alosids in the Hudson River using a bioenergetic approach.

\section{Methods}

We used a combination of reported site-specific data, hydroacoustic estimates of striped bass population size, and a published bioenergetics model for striped bass (Hartman and Brandt 1995a) to estimate potential impact of striped bass on outmigrating juvenile alosids in the Hudson River. The years 1995 and 1997 were chosen because of the availability of acoustic estimates of striped bass abundance in those years (Chapter 2). All model runs were completed using Fish Bioenergetics version 3.0 software (Hansen et al. 1997). This program makes use of the balanced energy equation of Winberg (1956) ( where $G$ is growth, $C$ is consumption, $R$ is metabolism, SDA is specific dynamic action, $F$ is egestion, and $U$ is excretion). The 
balanced energy equation is quantified with a number of parameters, which relate both the predator and the prey to each other as well as their environment (Ney 1990). The bioenergetics model can estimate the amount of food $(\mathrm{g})$ needed for a certain aged fish to reach a particular size, given water temperature, diet, and predator and prey energy content.

Data is entered into the model based on simulation days. Here the simulation began on September 1 (day 1) and ended on December 31 (day 122) for both 1995 and 1997. The program will linearly interpolate data between days to determine a value for every simulation day. We also made use of age-dependent bioenergetic model parameters as reported for striped bass from Chesapeake Bay (Hartman and Brandt 1995a). We ran the model for age- 1 and age-2 striped bass. Age- 1 and age-2 striped bass were chosen for this study due to the availability of current estimates of their abundance in the area of interest and because they represent the majority of the striped bass population in the Hudson River (Chapter 2).

Site-specific data used in the model include temperature, size-at-age, and population size of striped bass. Growth data for striped bass was estimated from length-at-age information reported for Hudson River striped bass (McFadden et al. 1978). The bioenergetics model uses weight (g) as an input and converts all units to energy using predator energy density values (joules/g). Thus, length-at-age data was converted to wet weight using length-weight relationships from McFadden et al. (1978). Linear interpolation of weight between annual point estimates was used in the bioenergetics model as estimates of mass for consumption estimation (Figure 1). The temperature data used were from the Battery region of the Hudson (river mile 0 to 11), 
as compiled from the striped bass and Atlantic tomcod (Microgadus tomcod) monitoring program (E. Radle, New York Department of Environmental Conservation, personal communication). The monitoring program dataset provided us with approximately 4 temperature readings for each month in 1995 and 1997 (Figure 2). Energy density values for striped bass at age were taken from Chesapeake Bay values of 5873 joules for age-1 striped bass and 6109 joules for age-2 striped bass (Hartman and Brandt 1995a). Population estimates for striped bass in 1995 and 1997 were determined from hydroacoustic estimates of abundance in December of each year (Chapter 2). These estimates were back-calculated to determine the number of striped bass on September 1st using a mortality rate of $24.3 \%$ per year as reported by Holland and Yelverton (1973) for costal North Carolina striped bass. For 1995, age-1 striped bass started the simulation at 422,000 individuals and ended the simulation at 385,000 individuals, while age-2 striped bass started the simulation at 198,000 individuals and ended the simulation at 181,000 individuals. In 1997, age-1 striped bass started the simulation at 5,136 individuals and ended the simulation at 4,683 individuals, while age-2 striped bass started the simulation at 65,000 individuals and ended the simulation at 59,000 individuals.

The bioenergetics model was used to provide estimates of alosids consumed under two different consumption levels. The consumption levels chosen were $10 \%$ and $50 \%$ of the total striped bass diet. These consumption levels were chosen to bound a reasonable range of alosid consumption by striped bass. The obvious true bounds on the consumption level are from $0 \%$ to $100 \%$ of the striped bass diet. However, bounding the possible consumption to $10 \%$ to $50 \%$ of the striped bass diet gives what 
we feel is a reasonable estimate of the impact of striped bass on alosids at this time. In the Chesapeake Bay Atlantic menhaden (Brevoortia tyrannus) which is morphologically similar to alosids made up from $35 \%$ to $98 \%$ of age- 1 and age- 2 striped bass diets during this period of the year (Hartman and Brandt 1995b). Dunning et al. (1997) examined the stomach contents of approximately 1700 striped bass from the Hudson River during the winter. The authors found that blueback herring (Alosa aestivalis) were found in the stomachs of $1 \%$ to $7.3 \%$ of striped bass, depending on size. The authors also found that the family Clupeidae comprised $2.4 \%$ to $34.2 \%$ of the striped bass stomach contents. These values support the bounds we placed on striped bass consumption of alosids. This is especially true when considering that 1580 of the 1703 striped bass collected in the Dunning et al. (1997) study were from water temperatures less than $10 \mathrm{oC}$, which would likely occur later in the year than when alosids are outmigrating from the Hudson. Thus, the $10-50 \%$ range would be considered appropriate, perhaps even conservative. From the bioenergetics model, the resulting biomass $(\mathrm{g})$ of alosids consumed by striped bass were then converted to number of fish consumed by dividing the total weight of consumed alosids by the mean weight of out migrating alosids of $5.8 \mathrm{~g}$ (Marcy et al. 1976; Schmidt et al. 1988).

\section{Results}

Age-2 striped bass had a larger estimated consumption of alosids than did age-1 striped bass for both years (Figure 3). In 1995, age-1 striped bass were estimated to consume between $8,686 \mathrm{~kg}(10 \%$ diet $)$ and $43,430 \mathrm{~kg}$ ( $50 \%$ diet) of alosid biomass. This translates into between approximately 1.5 million and 7.5 million individual alosids being consumed by age- 1 striped bass under the $10 \%$ and $50 \%$ bounds, respectively. 
Age-2 striped bass consumed $16,702 \mathrm{~kg}$ (10\% diet) and $83,512 \mathrm{~kg}$ (50\% diet) of estimated alosid biomass in 1995. This biomass of alosids would represent between 2.8 million and 14.4 million individual alosids consumed by age-2 striped bass in 1995 . Age-2 striped bass were estimated to consume approximately twice the amount of alosids biomass and individuals as age-1 striped bass for 1995 .

In 1997, the bioenergetics model estimated age-1 striped bass to consume between $110 \mathrm{~kg}$ (10\% diet) and $549 \mathrm{~kg}$ (50\% diet) of alosid biomass. Converting the biomass estimates to numbers of individuals yields between 19,000 and 95,000 individual alosids being consumed by age-1 striped bass in 1997. Age-2 striped bass were estimated to consume between $5,769 \mathrm{~kg}$ (10\% diet) and $28,847 \mathrm{~kg}$ ( $50 \%$ diet) of alosid biomass in 1997. These estimates represent between 994,000 and 4.9 million individual alosids consumed by age-2 striped bass in 1997. Age-2 striped bass consumed 52 times the amount of alosid biomass and individuals as age-1 striped bass in 1997.

In 1995, the total estimate of consumed alosids exceeded that of 1997. In 1995, age-1 and age-2 striped bass combined were estimated to consume between $25,388 \mathrm{~kg}$ (10\% diet) and 126,942 kg (50\% diet) of alosid biomass. This represents between 4.3 million and 21.9 million individual alosids consumed by striped bass in 1995. In 1997, striped bass consumed between $5,879 \mathrm{~kg}$ ( $10 \%$ diet) and $29,396 \mathrm{~kg}$ ( $50 \%$ diet) of alosid biomass or between 1.0 million and 5.1 million individual alosids. In 1995, striped bass were estimated to consume approximately four times the biomass of alosids than did striped bass in 1997. 
Peak total daily consumption of alosids by the age- 1 and age- 2 striped bass population varied by both year and season. The highest daily population consumption of alosids for striped bass in 1995 was estimated between $288 \mathrm{~kg}$ and 1,439 $\mathrm{kg}$ of alosid biomass or between 49,608 and 248,039 individual alosids. Highest daily population consumption for striped bass occurred on November 2 (simulation day 63), when water temperature was $15.30 \mathrm{C}$. The maximum daily population consumption of alosids in 1997 was between $62 \mathrm{~kg}$ and $308 \mathrm{~kg}$ of alosid biomass or between 10,612 and 53,063 individual alosids. Maximum daily population consumption by striped bass in 1997 occurred on October 27 (simulation day 57), when water temperature was 16.10C.

\section{Discussion}

Through this exercise we have been able to show that striped bass in the Hudson River have the potential to consume a massive biomass of alosids in the last 4 months of the year. Not surprisingly, the amount of alosids consumed is directly related to the numbers of striped bass present as well as the percentage of the diet comprised of alosids. There was a striking difference in the amount of alosids consumed between 1995 and 1997. Approximately 4.3 times as much alosid biomass and numbers of alosids were consumed in 1995 when compared to 1997. The higher numbers of striped bass present in the lower Hudson River in 1995 account for this difference. There were approximately 620,000 age-1 and age-2 striped bass in the Hudson in 1995 as opposed to 70,000 age-1 and age-2 striped bass in 1997 (Chapter 2). The percentage of the striped bass diet made up by alosids is slightly more difficult to come by, but as stated earlier the studies by Hartman and Brandt (1995b) and Dunning et al. (1997) provide us with reasonable, if not conservative, bounds. 
Another consideration when examining the effect of striped bass consumption on the alosid population is the numbers or biomass of alosids in the lower Hudson during this critical time. One estimate puts the biomass of American shad in the lower Hudson in October at 1.70 metric tons and the biomass of blueback herring at 13.6 metric tons (EA Engineering, Science, and Technology 1991). These two alosid species are the major alosids found in the lower Hudson and have a combined biomass of 15.3 metric tons. Looking at the 1995 results between 25 (10\% diet) and 126 (50\% diet) metric tons of alosids could be consumed by age 1 and 2 striped bass from September to December. For 1997 between 5 and 29 metric tons of alosids could be consumed from September to December. Thus, for both years striped bass have the potential to consume virtually all of the alosids in the lower river in the first part of the striped bass overwintering period. This presents a serious obstacle to alosid populations out migrating to the ocean.

Striped bass are not, however, the only species of fish in the lower Hudson River during the month of September through December that consume alosids. Limberg (1996) lists 6 other species present in the lower river in September and October that prey on American shad and blueback herring, including white perch (Morone americana), bluefish (Pomatomus saltatrix), Atlantic tomcod, weakfish (Cynoscion regalis), American eel (Angullia rostrata), and white catfish (Ameiurus catus). Considering the impact that these predators along with striped bass can have on alosids in the Hudson, it becomes imperative for managers to consider this predatory gauntlet when determining management plans for the river. Failure to consider the inter-species 
relations in management could lead to disastrous results for American shad, which is itself an important recreational species.

Low numbers of American shad leaving the river equate to low numbers of adults returning to the river to spawn (Ricker 1975). This has the potential to create a tailspin effect on an already declining American shad stock. To avoid this situation managers need to look at the river from an ecosystem standpoint and consider the potential top down effects of striped bass on the other species in the river (Carpenter et al. 1985). Other studies have used a bioenergetics modeling approach to evaluate predatory impact and the potential of interspecific relations to affect fisheries management decisions. Hartman and Margraf (1993) made use of biogenetics modeling to show that walleye (Stizostedion vitreum) can control yellow perch (Perca flavescens) recruitment in Lake Erie. The authors were able to show, through the bioenergetics model, that it may not be possible to maintain large stocks of both walleye and yellow perch in the western basin of Lake Erie. LaBar (1993) used bioenergetics models to predict the effect of an increase in lake trout (Salvelinus namaycush) numbers on rainbow smelt (Osmerus mordax). Through modeling he was able to show that the increase in lake trout would cause a significant increase in consumption of rainbow smelt, but this increase in consumption would have a minimal effect on the rainbow smelt population. Hartman and Brandt (1995c) examined predatory demand of striped bass, bluefish, and weakfish in the Chesapeake Bay. Using bioenergetic models, the authors were able to provide evidence that bluefish are more successful predators than either striped bass or weakfish and that prey availability may have more control over predator use of the Chesapeake than temperature. 
Managers can use bioenergetics models to predict the potential impact of numerous management decisions before committing time, energy and money on more extensive studies. For example, using a bioenergetics model managers can determine the potential success of stocking programs before committing time and money to the stocking. The model would allow managers to determine optimum size and/or time for the stocking of various fish species (Wahl 1999). Bioenergetics models can also be incorporated into much more complex situations, such as an examination of an entire food web or ecosystem. Using a separate modeling frame work to house numbers estimated from bioenergetic models on individual species, it is possible to examine how numerous species interact with one another and their habitat (Kitchell et al. 2000). Using a similar approach it would be possible to look at the interactions of not only striped bass with various alosid populations in the Hudson River, but also with any other species who's bioenergetic requires and relationships with other species can be quantified. While the scale of such an exercise is completely outside the scope of this project, it would provide valuable insight into the Hudson River ecosystem and role of striped bass in that ecosystem. 


\section{Literature Cited}

ASMFC (Atlantic States Marine Fisheries Commission). 1985. Fishery management plan of American Shad and river herrings. Atlantic States Marine Fisheries Commission, Fisheries Management Report No. 6. Washington, D.C., USA.

Carpenter, S.R., J.F. Kitchell, and J.R. Hodgson. 1985. Cascading trophic interactions and lake productivity. Bioscience. 35: 634-639.

Dunning, D.J., J.R. Waldman, R.E. Quentin, and M.T. Mattson. 1997. Use of Atlantic tomcod and other prey by striped bass in the lower Hudson River estuary during the winter. Transactions of the American Fisheries Society 126: 857-861.

EA Engineering, Science, and Technology. 1991. 1989 year class report for the Hudson River estuary monitoring program. Prepared for Consolidated Edison of New York, Inc. EA Engineering, Science, and Technology, Newburgh, New York.

Gardinier, M.N., and J.B. Hoff. 1982. Diets of striped bass in the Hudson River estuary. N.Y. Fish and Game Journal. 29: 152-165.

Hansen, P.C., T.J. Johnson, D.E. Schindler, and J.F. Kitchell. 1997. Fish bioenergetics model 3. University of Wisconsin, Sea Grant Institute, Technical Report WIS-SG92-250, Madison.

Hartman, K.J. and S.B. Brandt. 1995a. Comparative energetics and the development of bioenergetics model for sympatric estuarine piscivores. Canadian Journal of Fisheries and Aquatic Sciences. 52: 1647-1666.

Hartman, K.J. and S.B. Brandt. 1995b. Trophic resources partitioning, diets, and growth of sympatric estuarine predators. Transactions of the American Fisheries Society 124: 520-537.

Hartman, K.J. and S.B. Brandt. 1995c. Predatory demand and impact of striped bass, bluefish, and weakfish in the Chesapeake Bay: applications of bioenergetics models. Canadian Journal of Fisheries and Aquatic Sciences. 52: 1667-1687.

Hartman, K.J. and F.J. Margraf. 1993. Evidence of predatory control of yellow perch (Perca Flavescens) recruitment in Lake Erie, U.S.A. Journal of Fish Biology 43: 109-119.

Holland, B.F., and G.F. Yelverton. 1973. Distribution and biological studies of anadramous fishes offshore North Carolina. Div. Comme. Sport Fish., NC Dep. Nat. Econ. Resource Spec. Sci. Rep. 24. 132pp.

Kitchell, J.F., S.P. Cox, C.J. Harvey, T.B. Johnson, D.M. Mason, K.K. Schoen, K. Aydlin, C Bronte, M. Ebener, M. Hansen, M. Hoff, S. Schram, D. Schreiner, C.J. 
Walters. 2000. Sustainability of the Lake Superior fish community: Interactions in a food web context. Ecosystems 3: 545-560

Klauda, R.J., S.A. Fischer, L.W. Hall, J.A. Sullivan. 1991. American shad and hickory shad Alosa sapidissima and Alosa medirocris. Pages 9-1 to 9-27 in S.L. Funderburk, S.J. Jordan, J.A. Mihursky, and D. Riley, editors, Habitat Requirements for Chesapeake Bay Living Resources, 2nd edition,

LaBar, G.W. 1993. Use of bioenergetics models to predict the effect of increased lake trout predation on rainbow smelt following sea lamprey control. Transactions of the American Fisheries Society. 122: 942-950.

Limburg, K.E. 2001. Through the gauntlet again: demographic restructuring of American shad by migration. Ecology. 82: 1584-1596.

Limburg, K.E. 1996. Modelling the ecological constraints on growth and movement of juvenile American shad (Alosa sapidissima) in the Hudson River estuary. Estuaries. 19: 794-813.

Manooch, C.S., III. 1973. Food habits of yearling and adult striped bass, Morone saxatilis (Walbaum) from Albermarle Sound, North Carolina. Chesapeake Science. 2: 142-205.

Marcy, B.C., Jr. and P. Jacobson. 1976. Early life history studies of American shad in the lower Connecticut River and the effects of the Connecticut Yankee plant. American Fisheries Society Monographs 1: 141-168.

McFadden, J.T., Texas Instruments, Inc., and Lawler, Matusky \& Skelly Engineers. 1978. Influence of the proposed Cornwall pumped storage project and steam electric generating plants on the Hudson River estuary with emphasis on striped bass and other fish populations. Prepared for Consolidated Edison, Co. of NY. Inc.

Ney, J.J. 1990. Trophic economics in fisheries: assessment of demand-supply relationships between predators and prey. Aquatic Sciences Reviews 2: 55-81.

Richards, R.A. and P.J. Rago. 1999. A Case History of Effective Fishery Management: Chesapeake Bay Striped Bass. North American Journal of Fisheries Management 19:356-375.

Ricker, W. E. 1975. Computation and interpretation of biological statistics of fish populations. Bulletin of Fisheries Resources Board Canada 191: 382 pp

Schmidt, R.E., R.J. Klauda, and J.M. Bartels. 1988. Distributions and movements of the early life stages of three species of Alosa in the Hudson River, with comments on mechanisms to reduce interspecific competition. In: C.L. Smith (ed.). Fisheries 
research in the Hudson River. State University of NY Press, Albany, New York, p. 193-215.

St. Pierre, R. 1977. Preface. Pages vi-ix in R. St. Pierre, editor. Proceedings of a workshop on American shad, December 14-16, 1976, Amherst, Massachusetts. U.S. Government Printing Office, Washington, D.C.

Wahl, D.H. 1999. An ecological context for evaluating the factors influencing muskellunge stocking success. North American Journal of Fisheries Management 19: 238-248.

Winberg, G.G. 1956. Rate of metabolism and food requirements of fishes. Belorussiam University, Minsk. (Transl. Fish. Res. Board Can., Transl. Ser. No. 194, 1960). 
Figure 1. Individual weights in grams of age-1 (dashed line) and age-2 (solid line) striped bass per simulation day for 1995 and 1997. 

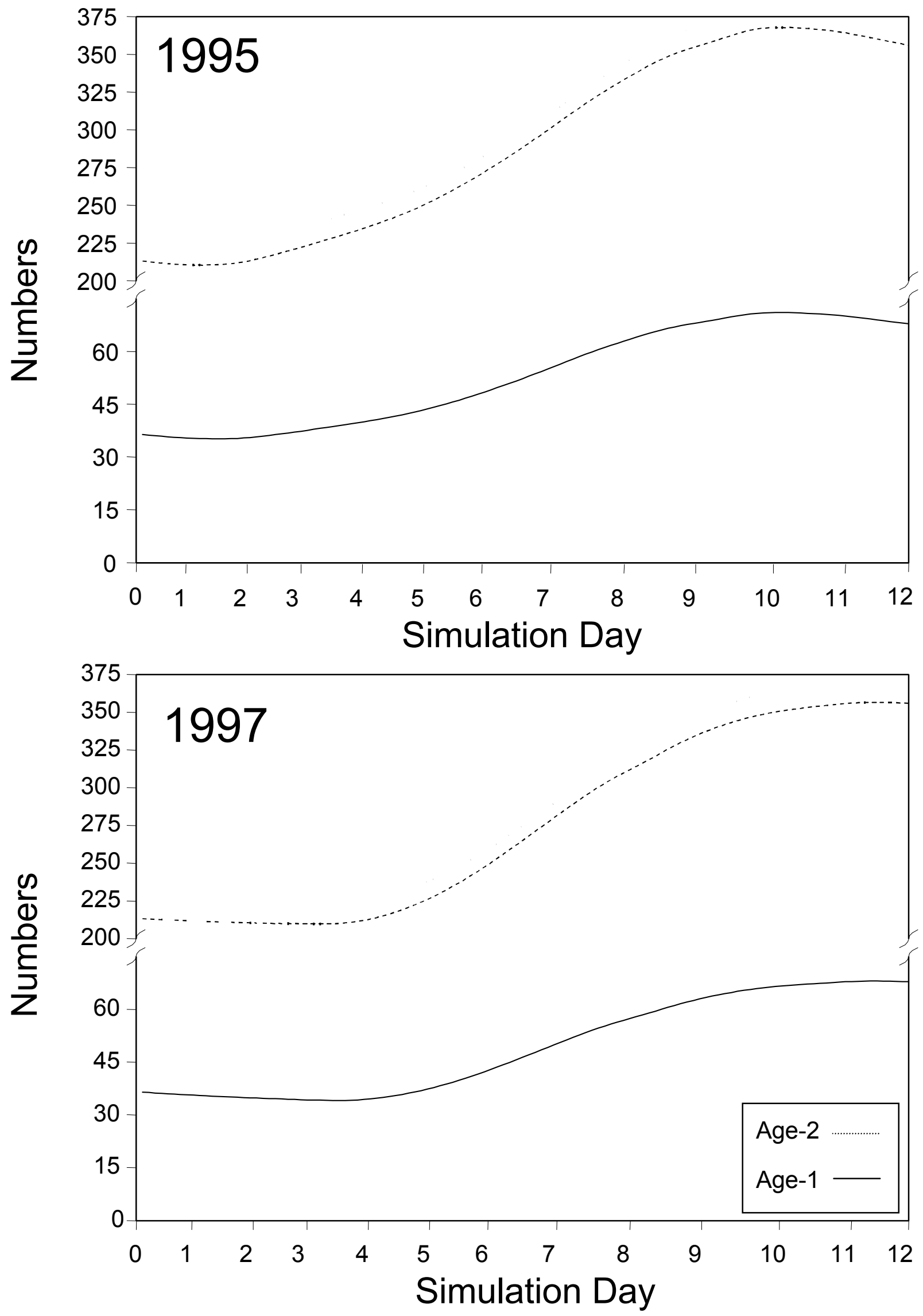
Figure 2. Temperature data per simulation day as interpolated by the biogenetics model. 


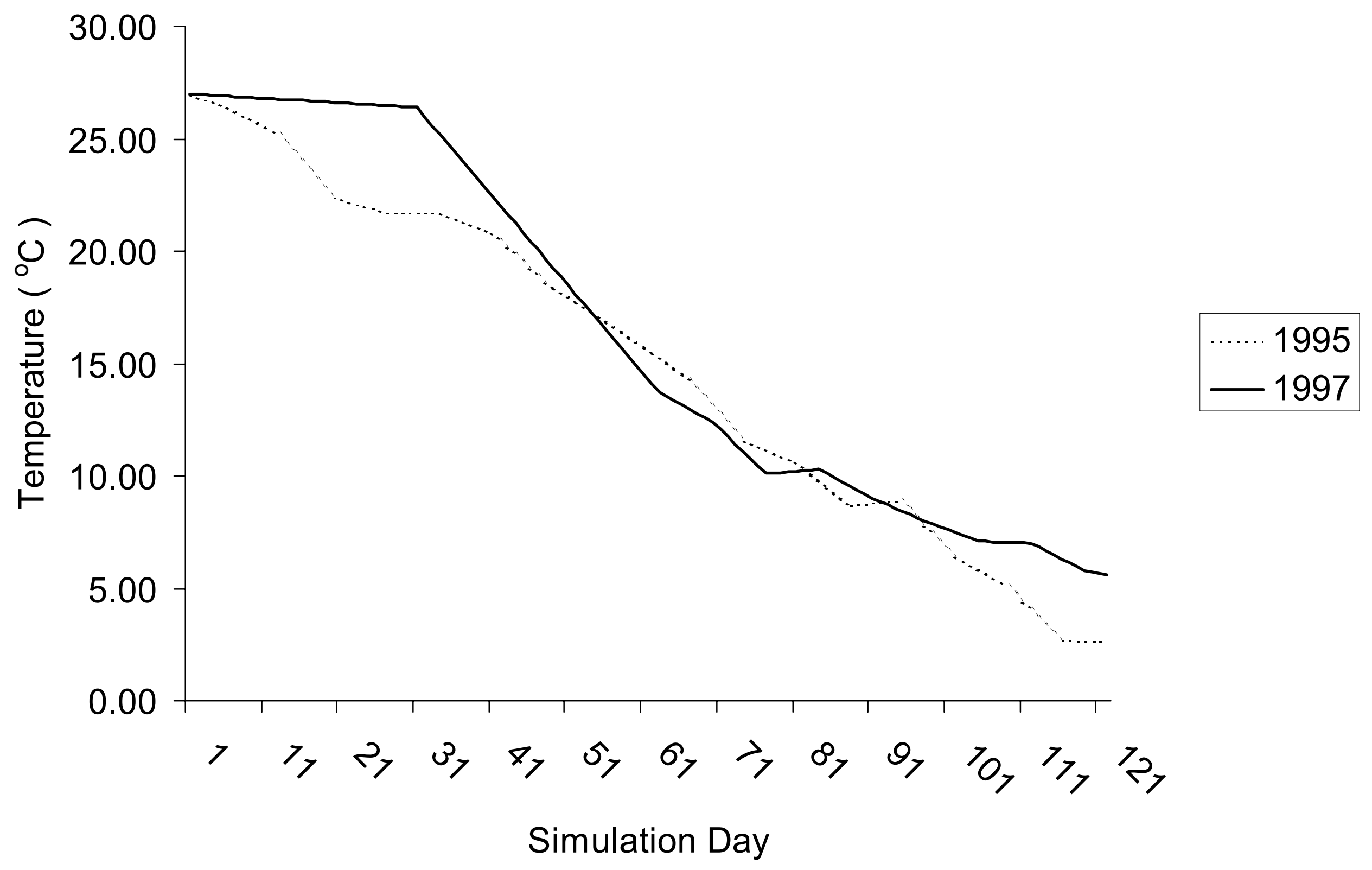


Figure 3. Weight $(\mathrm{kg})$ of alosids consumed by age- 1 and age- 2 striped bass for $10 \%$ and $50 \%$ consumption assumptions in 1995 and 1997 in comparison with estimates of natural production of age-0 American shad in 1991 (source: EA Engineering, Science, and Technology 1991). 


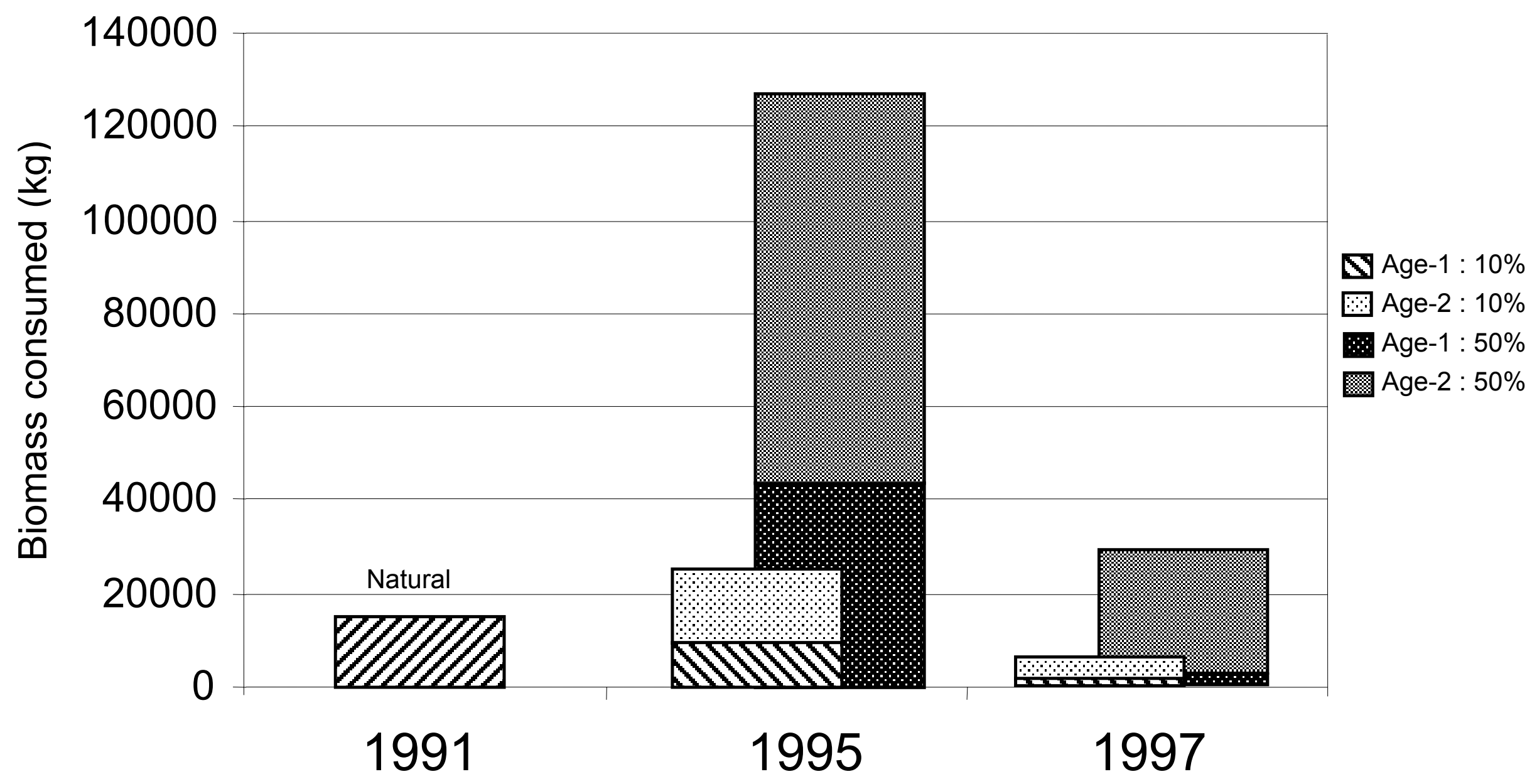




\section{Appendix:}


Figure 1. Vertical temperature (blue line, ${ }^{\circ} \mathrm{C}$ ) and salinity (red line, ppt) profiles compared to vertical striped bass distributions $\left(\mathrm{fish} / \mathrm{m}^{2}\right)$ for the Battery region in 1995. 


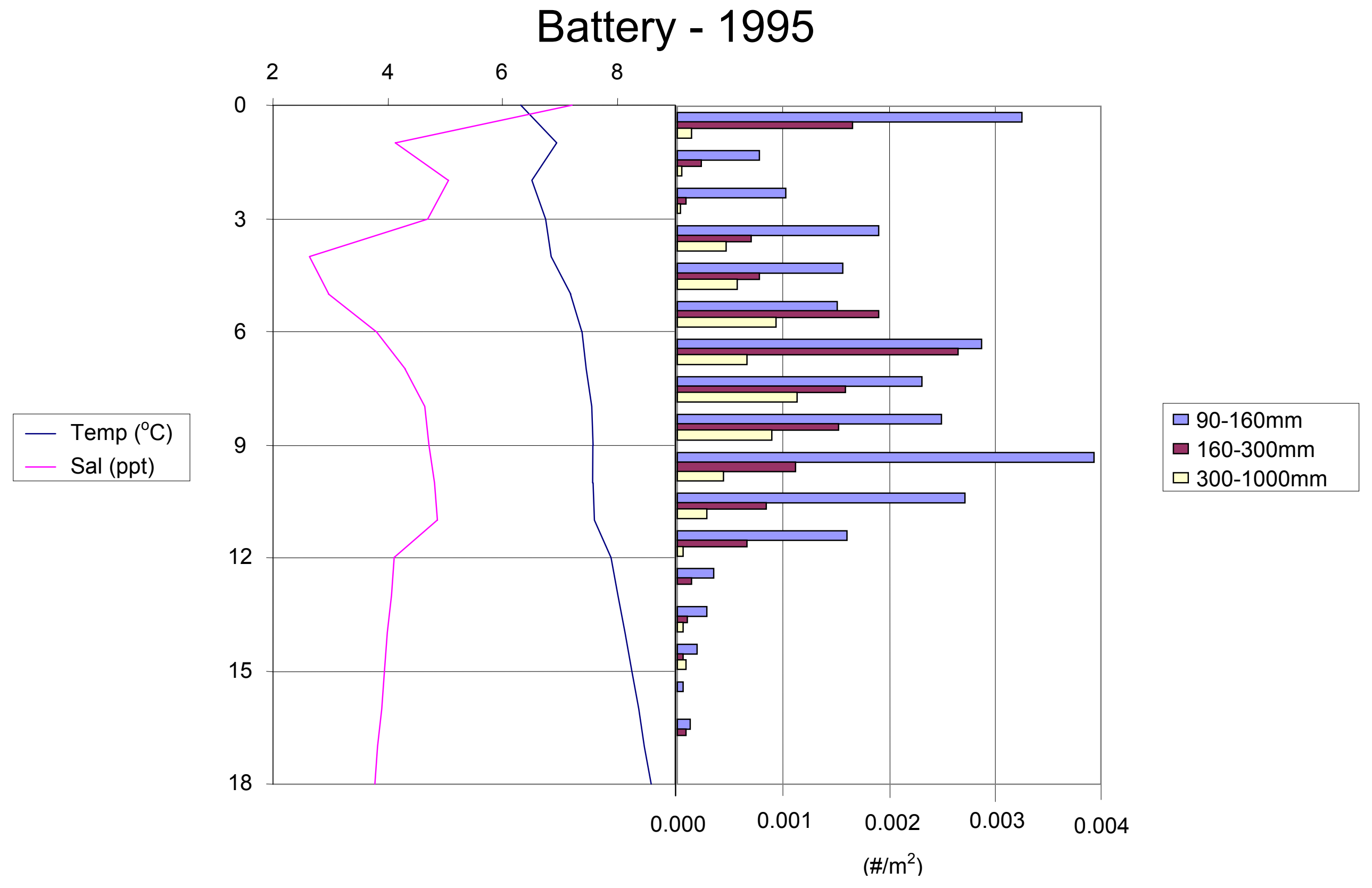


Figure 2. Vertical temperature (blue line, ${ }^{\circ} \mathrm{C}$ ) and salinity (red line, ppt) profiles compared to vertical striped bass distributions $\left(\mathrm{fish} / \mathrm{m}^{2}\right)$ for the Yonkers region in 1995. 


\section{Yonkers - 1995}

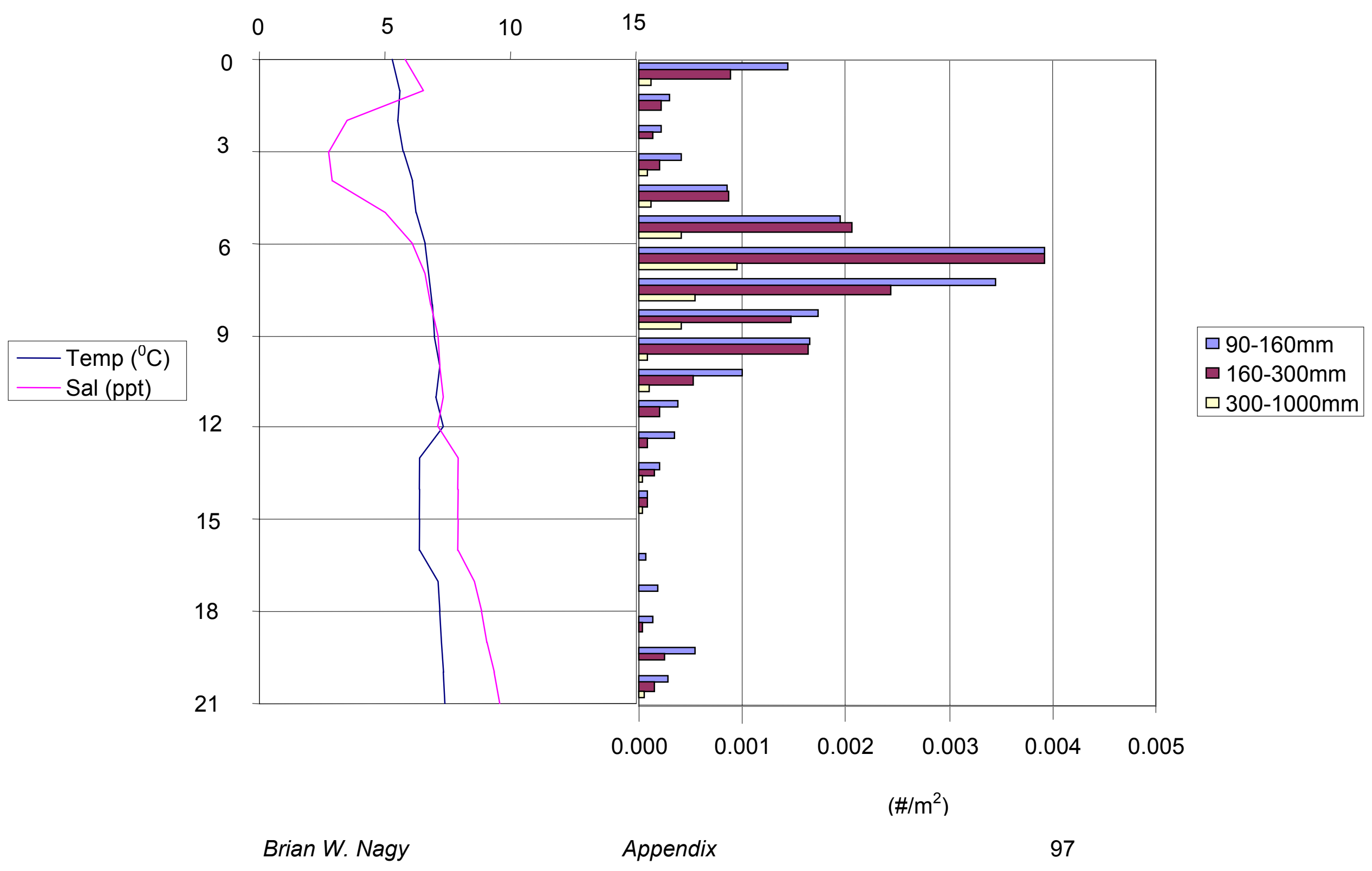


Figure 3. Vertical temperature (blue line, ${ }^{\circ} \mathrm{C}$ ) and salinity (red line, ppt) profiles compared to vertical striped bass distributions $\left(\mathrm{fish} / \mathrm{m}^{2}\right)$ for the Tappan Zee region in 1995. 


\section{Tappan Zee - 1995}

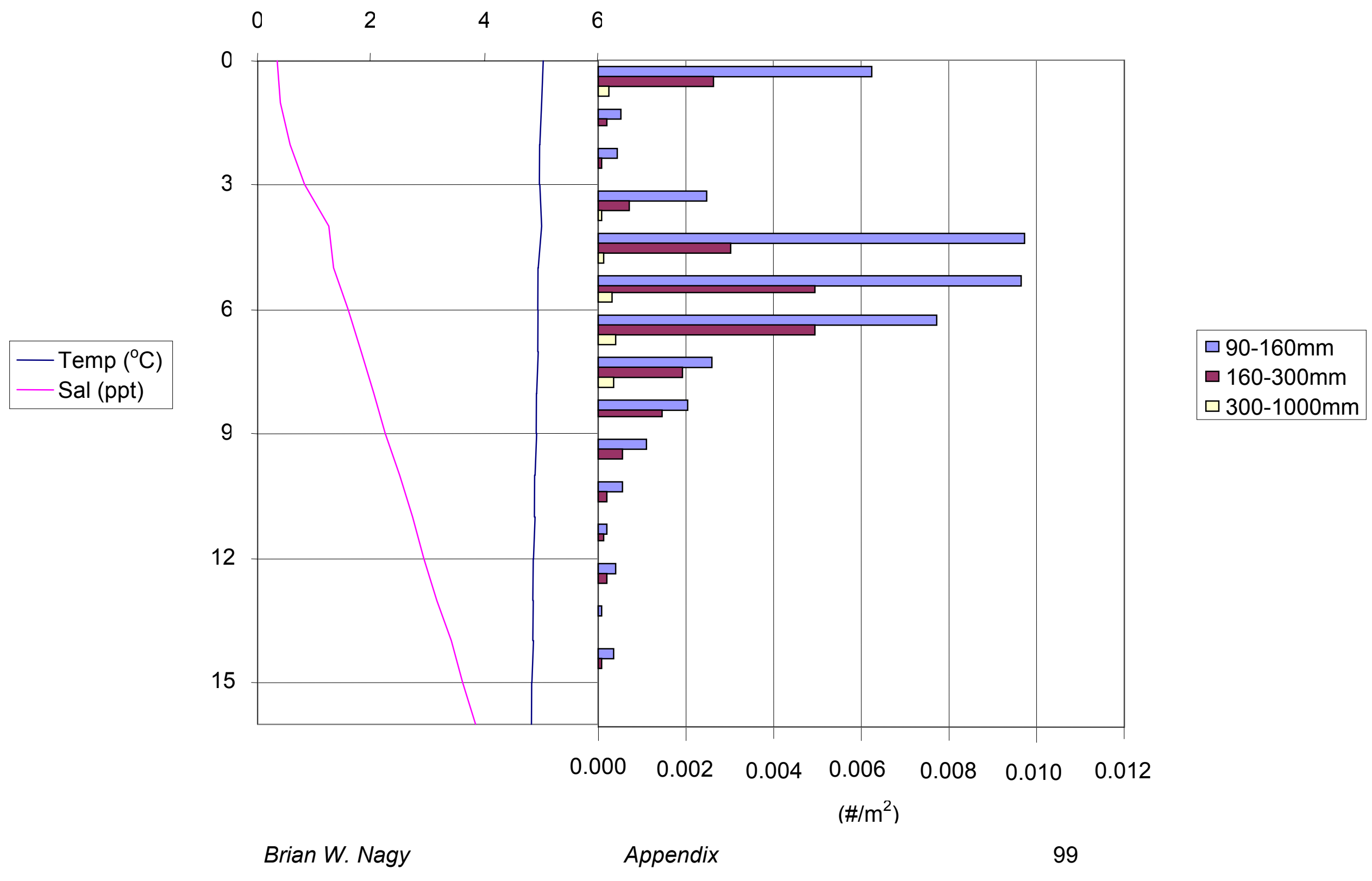


Figure 4. Vertical temperature (blue line, ${ }^{\circ} \mathrm{C}$ ) and salinity (red line, ppt) profiles compared to vertical striped bass distributions (fish $/ \mathrm{m}^{2}$ ) for the Croton Haverstraw region in 1995. 


\section{Croton Haverstraw - 1995}

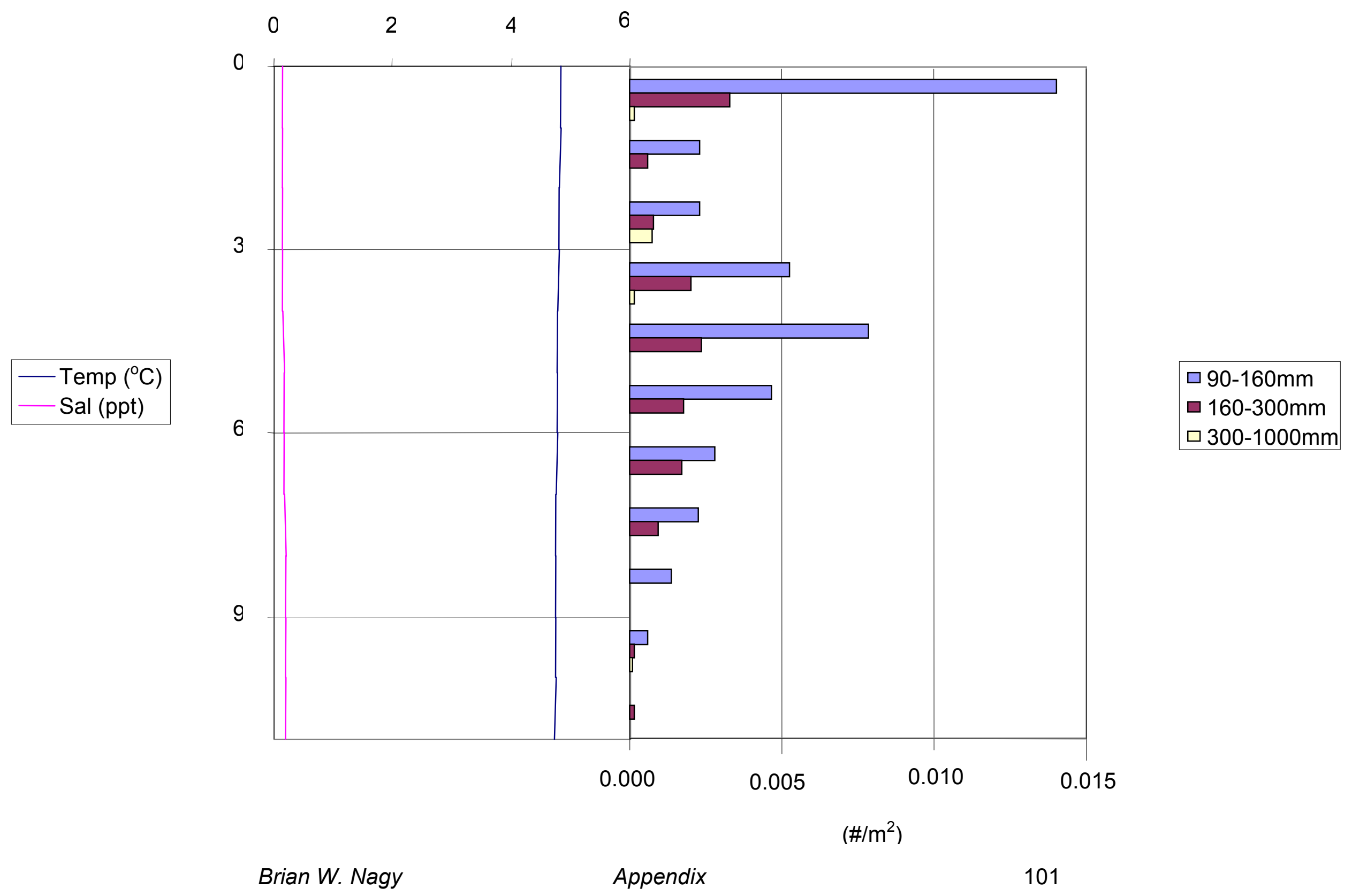


Figure 5. Vertical temperature (blue line, ${ }^{\circ} \mathrm{C}$ ) and salinity (red line, ppt) profiles compared to vertical striped bass distributions $\left(\mathrm{fish} / \mathrm{m}^{2}\right.$ ) for the Battery region in 1997. 


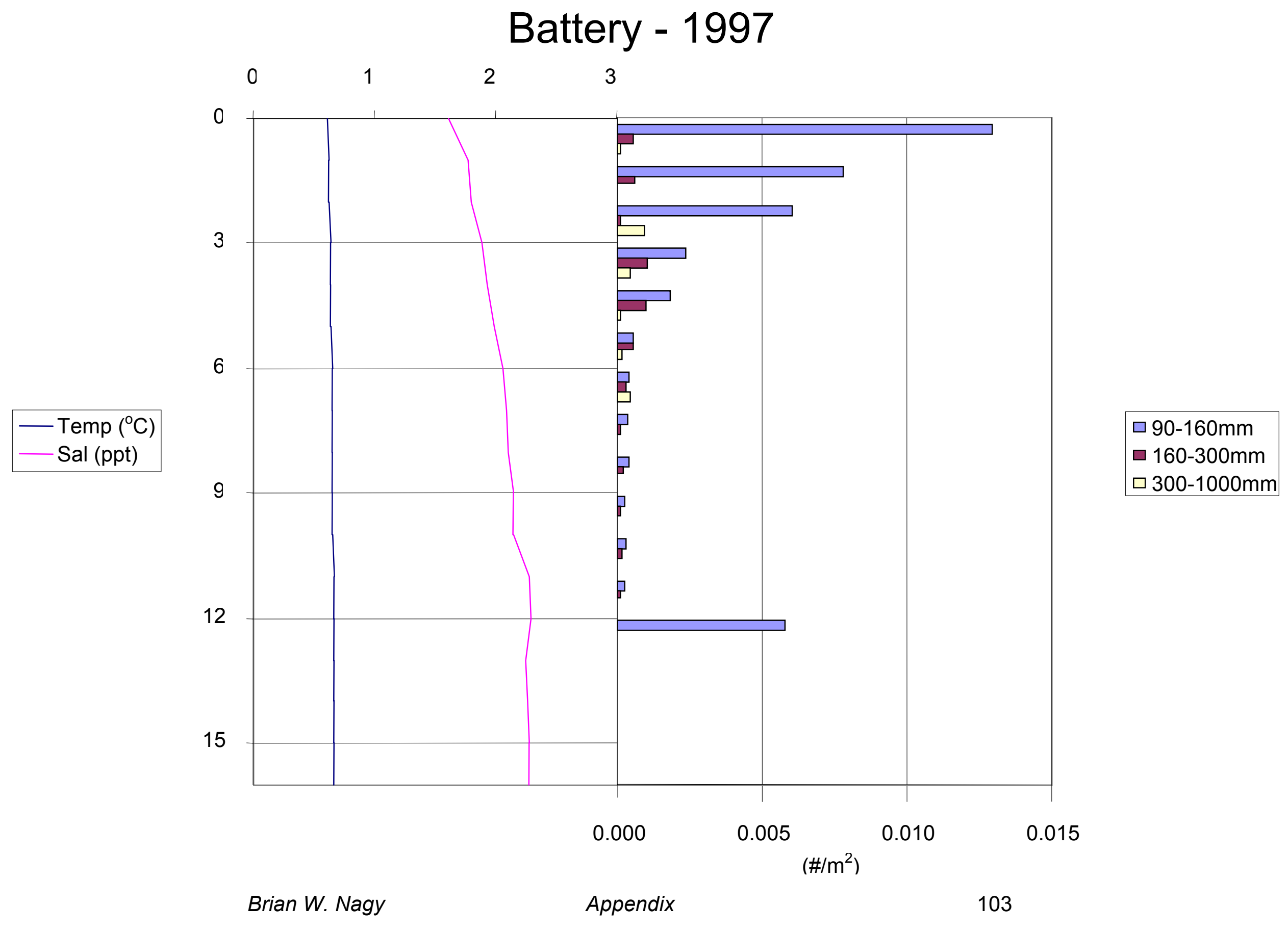


Figure 6. Vertical temperature (blue line, ${ }^{\circ} \mathrm{C}$ ) and salinity (red line, ppt) profiles compared to vertical striped bass distributions $\left(\mathrm{fish} / \mathrm{m}^{2}\right)$ for the Yonkers region in 1997. 


\section{Yonkers - 1997}

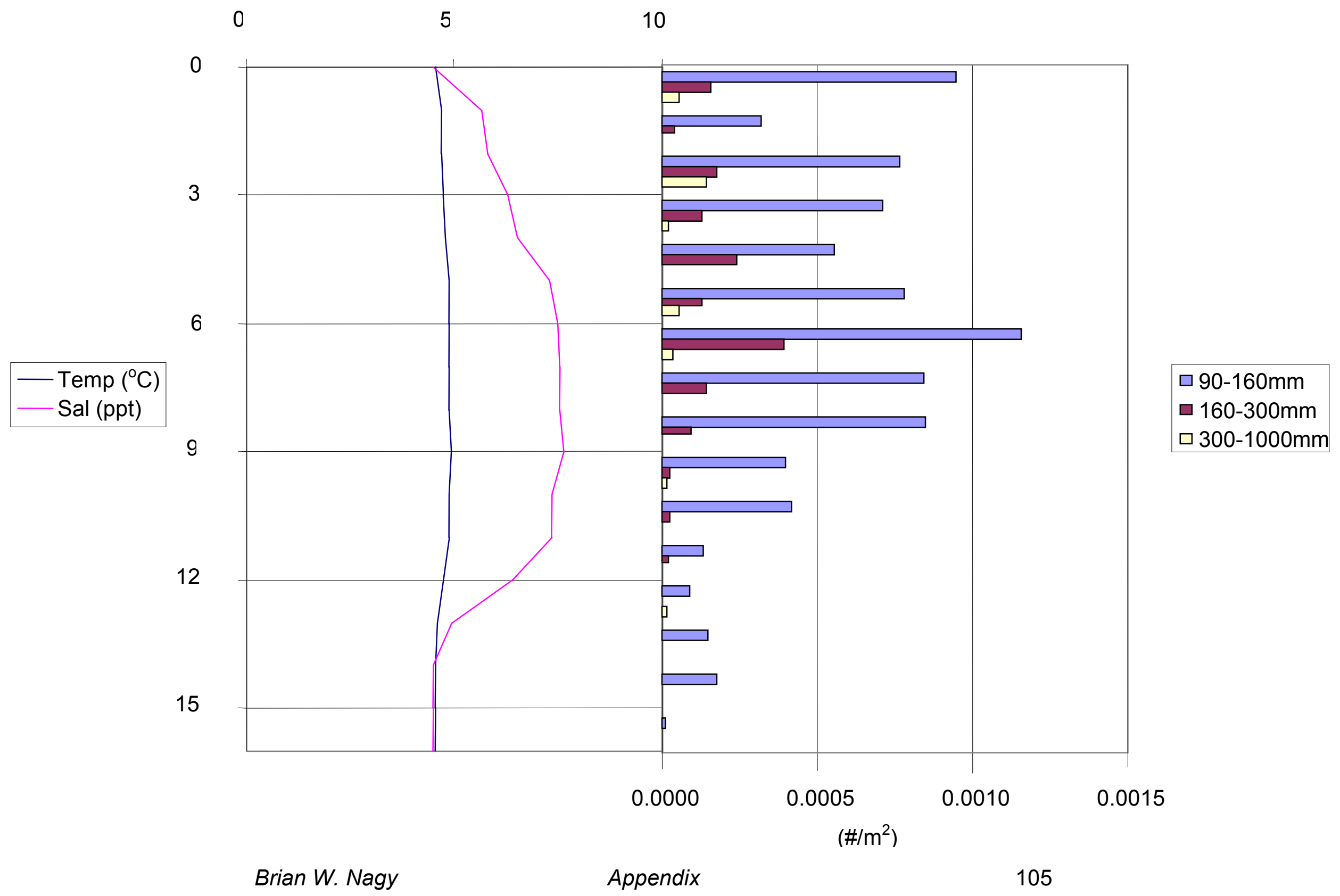


Figure 7. Vertical temperature (blue line, ${ }^{\circ} \mathrm{C}$ ) and salinity (red line, ppt) profiles compared to vertical striped bass distributions $\left(\mathrm{fish} / \mathrm{m}^{2}\right)$ for the Tappan Zee region in 1997. 
Tappan Zee - 1997

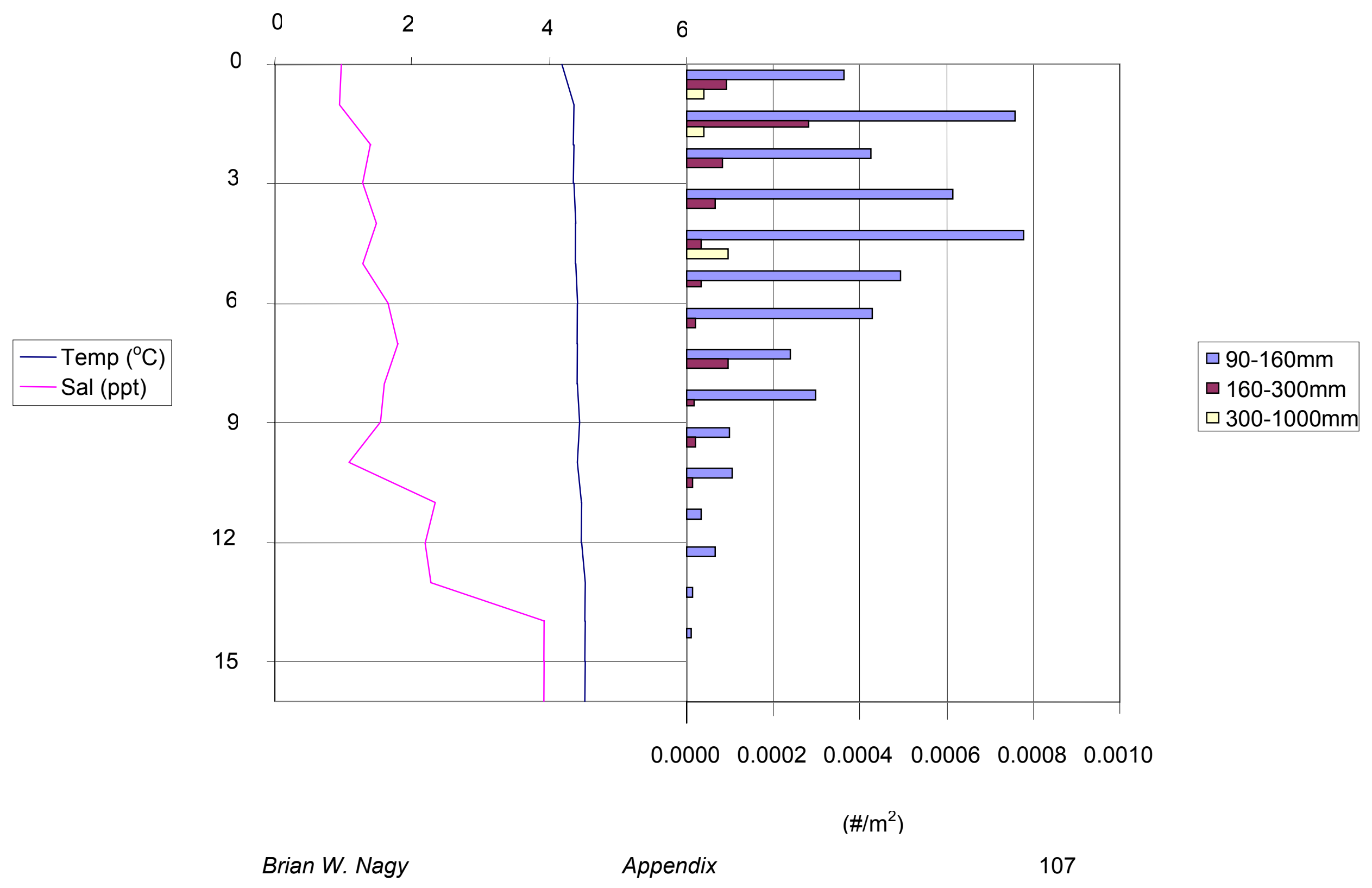




\section{Curriculum Vita:}

\section{Brian William Nagy}

E-mail: bnagy@ufl.edu

\section{Education:}

January 2002- $\quad$ University of Florida - Gainesville, Florida

Present Ph.D. in Fisheries and Aquatic Sciences

Dissertation: "Distributional Ecology of Pelagic Planktivorous Fishes

in Relation to Artificial Reefs in the Gulf of Mexico"

Major Professor: Dr. Doran M. Mason/Dr. William J. Lindberg

January 1997 West Virginia University - Morgantown, West Virginia

M.S. in Fisheries

Thesis: "Overwintering Abundance of Striped Bass in the Hudson

River Estuary Using Hydroacoustics"

Major Professor: Dr. Kyle J. Hartman

August $1994 \quad$ Michigan State University - East Lansing, Michigan

B.S. in Fisheries and Wildlife Management with a specialization in fisheries

Undergraduate Advisor: Dr. Tomas G. Coon

August $1992 \quad$ Lake Superior State University - Sault Ste. Marie, Michigan

B.S. in Fisheries and Wildlife Management

Undergraduate Advisor: Dr. Richard Fur

\section{Work Experience:}

January 2002 - Graduate Research Assistant - University of Florida, Department of Fisheries and Aquatic Sciences

Duties: Develop a dissertation project working with pelagic planktivores on the Suwannee regional reef system in the Gulf of Mexico. Lead field crews in the collection of data and the processing of data related to dissertation. Train others in the use of hydroacoustic gear and the methods used to process hydroacoustic data. Develop an overall software package for the analysis of hydroacoustic data from the big three hydroacoustic companies (BioSonics, $\mathrm{HTI}$ and Simrad). Integrate this software package into 
a larger database system designed to combine hydroacoustic data with other the ancillary data (trawls, physical profiles, etc.)

Director of Research: Dr. Doran M. Mason / Dr. William J. Lindberg

January $1997 \quad$ Graduate Research Assistant - West Virginia University

Division of Forestry, Wildlife and Fisheries Program

Duties: Collect and process all data related to thesis project, including hydroacoustic, biological and environmental data. Assist others within the lab in the analysis of hydroacoustic data. Develop software to make hydroacoustic data processing more efficient.

Director of Research: Dr. Kyle J. Hartman

April 1995 Laboratory Technician - Michigan State University

Duties: Maintain cultures of invertebrates, run various bioassays, operate atomic absorption spectrophotometer, and general laboratory maintenance

Supervisor: Dr. John P. Giesy

\section{Teaching Experience:}

Spring $2001 \quad$ Graduate Teaching Assistant - Michigan State University

Department of Fisheries and Wildlife

Course: FW 419 Applications of GIS in Natural Resource Management

Duties: Coordinate student laboratory exercises on the use of ArcView

Summer $2000 \quad$ Instructor - Purdue University

Department of Forestry and Natural Resources

Course: FNR 330 Natural Resource Summer Practicum

Duties: Design lectures and field exercises with the purpose of instructing students on a wide variety of fisheries techniques, including electrofishing (both backpack, barge and boat), seining, trap netting, cast netting, gill netting, hook and line sampling, and aging fish from scales and otoliths. Design lectures and laboratory exercises with the purpose of instructing students in methods of analyzing field data, including length-weight relationships, agelength keys, back calculation of age at size, and recruitment relationships.

Spring $2000 \quad$ Instructor - Purdue University 
Department of Forestry and Natural Resources

Course: FNR 545 Fisheries Science and Management

Duties: Design lectures and assignments with the purpose of

instructing students in a variety of fisheries science and

management topics. Please see attached the attached syllabus for a list of topics.

Fall 1999

Graduate Teaching Assistant - Purdue University

Department of Forestry and Natural Resources

Course: FNR 242 Ecology and Systematics of Fish and Mammals Lab

Duties: Instruct students, in a laboratory setting, in the identification of fishes.

Summer 1999 Graduate Teaching Assistant - Purdue University

Department of Forestry and Natural Resources

Course: FNR 330 Natural Resource Summer Practicum

Duties: Run field and laboratory exercises with the purpose of instructing students in a variety fisheries techniques, as well as provide some lectures on the same subject

Spring $1998 \quad$ Graduate Teaching Assistant - West Virginia University

Division of Forestry, Wildlife and Fisheries Program

Course: WMAN 214 Wildlife Ecosystem Ecology

Duties: Assist in the laboratory instruction of students, specifically in the analysis of data sets with computers.

Summer $1997 \quad$ Guest Lecture - West Virginia University

Division of Forestry, Wildlife and Fisheries Program

Course: Estuarine Ecology

Lecture: Estuarine chemistry

Research Experience:

January 2002- Graduate Research Assistant, University of Florida

Present

Department of Fisheries and Aquatic Sciences

Responsibilities: Collect all data relevant to dissertation project, including hydroacoustic, biological and physical. Process data related to dissertation project. Develop new methods for the collection and processing of hydroacoustic data. Develop software 
for the analysis of hydroacoustic data and ancillary data. Develop new uses of hydroacoustic technology for the examination of fish behavior and interactions.

Director of Research: Dr. Doran M. Mason

July 1998

Volunteer, West Virginia Division of Natural Resources

Responsibilities: Assist the WVDNR in a cove rotenone survey on East Lynn Lake near Huntington, West Virginia, as well as collecting acoustic data to determine the validity of a side looking conical beam for the estimation of fish densities.

March 1998

Volunteer, West Virginia University

Responsibilities: Assist with a mark-recapture study on walleye and sauger in the Monongahela River, West Virginia to investigate the affects of Army Corps of Engineers navigation dams on the movements of spawning Stizostedions.

October $1997 \quad$ Volunteer, West Virginia Division of Natural Resources Responsibilities: Assist the WVDNR with a river reach rotenone survey of Dunkard creek. Collect and enumerate non-game species as well as provide species richness and diversity estimates to the WVDNR.

September 1997 Volunteer, West Virginia Division of Natural Resources Responsibilities: Assist the WVDNR with lock rotenone surveys on the Ohio River. Also, collected and process hydroacoustic fisheries data for comparison with rotenone survey results.

January 1997 - Graduate Research Assistant, West Virginia University

August 1998

Division of Forestry, Wildlife and Fisheries Program

Responsibilities: Performed trawling (midwater and bottom), ichthyoplankton tows, hydrographic profiles, and hydroacoustic surveys in the Hudson River estuary, New York.

Director of Research: Dr. Kyle J. Hartman

\section{Additional Training and Experience:}

- National Association of Underwater Instructors open water SCUBA diver certified

- National Association of Underwater Instructors advanced SCUBA diver certified

- American Red Cross Adult CPR 
- National Safety Council First Aid

- Divers Alert Network oxygen provider

- International Diver Educators Association enriched air NITROX diver certified

- International Diver Educators Association advanced diver certified

- International Diver Educators Association dry suit certified

- International Diver Educators Association deep water certified

- International Diver Educators Association night diver certified

- American Academy of Underwater Sciences science diver

- Programming languages: Interactive Data Language (IDL), Visual Basic, HTML, Java, Javascript, and Matlab

- Computer software: ArcView, S-plus, SAS, Microsoft Office, and IMAGINE

\section{Professional Societies:}

American Fisheries Society, National Chapter

Xi Sigma Pi

\section{Selected Abstracts and Publications:}

Nagy, B.W., D.M. Mason and W.L. Lindberg. 2001. Pelagic Fish Distributions on an Artificial Reef System in the Gulf of Mexico. American Fisheries Society Southern Division Mid-year Meeting. Jacksonville, FL

Nagy, B.W. and D.M. Mason. 1999. Development of Acoustic Visualization and Information System (AVIS). Mid-West Fisheries and Wildlife Mid-year Meeting. Chicago, IL.

Nagy, B.W. and D.M. Mason. 1999. Pelagic Fish Distributions on an Artificial Reef System in the Gulf of Mexico. Shallow Water Fisheries Sonar Meeting. Seattle, WA.

Nagy, B.W., D.M. Mason and W.L. Lindberg. 1999. Pelagic Fish Distributions on an Artificial Reef System in the Gulf of Mexico. American Fisheries Society Southern Division Mid-year Meeting. Chattanooga, TN.

Hartman, K.J., B.W. Nagy, and R.C. Tipton. 2000. Verification of hydroacoustic estimates of fish abundance in Ohio River lock chambers. North American Journal of Fisheries Management 20:1049-1056. 
Nagy, B.W. and K.J. Hartman. 1998. Overwintering Abundance of Striped Bass in the Hudson River using Hydroacoustics. American Fisheries Society Annual Meeting. Hartford, CT.

Hartman, K. J., B. W. Nagy, and R. C. Tipton. 1998. Ground-Truthing River Hydroacoustics with Lock Rotenone Fish Sampling. Tri-State American Fisheries Society Meeting. Ashland, KY. March 1999.

Hartman K.J., T. Bassista, B. Nagy, and R. C. Tipton. 1998. Shooting Fish in a Barrel: Hydroacoustic Comparison with Ohio River Lock Rotenone Surveys. American Fisheries Society Southern Division Mid-year Meeting. Lexington, KY.

Nagy B.W. and K.J. Hartman. 1998. Target Strength Analysis of White Perch (Morone americana) and Striped Bass (Morone saxatilis). American Fisheries Society Southern Division Mid-year Meeting. Lexington, KY.

Nagy B.W., K.S. Henry, N.R. Kevern, M.J. Zabik, and J.P. Giesy. 1996. A Survey and Hazard Assessment of Several Organic Contaminates and Mercury in Fish from a Remote Lake in Michigan's Upper Peninsula. Poster abstract presented at the 1996 annual SOT/SETAC conference (May 21 East Lansing, MI) and at the 1996 annual MSU and University of Guelph Toxicology Minisymposium (June 7 Guelph, Canada). 